Pós-processamento de regras de associação via redes e propagação de rótulos

\author{
Renan de Padua
}





\title{
Pós-processamento de regras de associação via redes e propagação de rótulos
}

\author{
Renan de Padua \\ Orientadora: Profa. Dra. Solange Oliveira Rezende
}

Dissertação apresentada ao Instituto de Ciências Matemáticas e de Computação - ICMC-USP, como parte dos requisitos para obtenção do título de Mestre em Ciências - Ciências de Computação e Matemática Computacional. EXEMPLAR DE DEFESA. 
Ficha catalográfica elaborada pela Biblioteca Prof. Achille Bassi e Seção Técnica de Informática, ICMC/USP, com os dados fornecidos pelo(a) autor(a)

Padua, Renan de
Pós-processamento de regras de associação via
redes e propagação de rótulos / Renan de Padua;
orientadora Solange Oliveira Rezende. - São
Carlos, 2015.
78.
Dissertação (Mestrado - Programa de Pós-Graduação
em Ciências de Computação e Matemática
Computacional) -- Instituto de Ciências Matemáticas
e de Computação, Universidade de São Paulo, 2015.
1. Regras de Associação. 2. Pós-processamento. 3.
Poda. 4. Propagação de Rótulos. 5. Redes. I. Rezende,
Solange Oliveira, orient. II. Título.




\section{Agradecimentos}

Mais uma vitória obtida. Essa vitória jamais seria possível sem a ajuda de algumas pessoas, as quais eu gostaria de agradecer aqui.

Aos meus pais, Eva e Carlos, e aos meus irmãos, Kedma e Maikon, por todo o apoio, incentivo e carinho que me deram, me aturando nos momentos mais difíceis e comemorando cada vitória obtida.

À minha namorada, Tatiane, por acreditar no meu potencial quando eu mesmo já tinha desistido, por sempre me levantar quando eu caía e por estar ao meu lado quando eu mais precisei.

Às minhas orientadoras, Solange Rezende e Veronica Carvalho, com as quais aprendi muito, não apenas profissionalmente, como também pessoalmente. Obrigado por me transformarem em uma pessoa melhor, obrigado por toda a paciência e todo o tempo despendido comigo.

Aos meus amigos do LABIC, em especial Rafael Rossi, por todo o debate, todas as ideias e as inúmeras risadas no horário do café.

Aos funcionários do ICMC, pela atenção, respeito e dedicação.

À Universidade de São Paulo, pela oportunidade e pela qualidade no ensino e pesquisa.

A CAPES e a FAPESP, pelo apoio financeiro que possibilitou o desenvolvimento deste trabalho.

A todos aqueles que, direta ou indiretamente, contribuíram para a realização desta dissertação.

A Deus, por me dar forças para continuar lutando. 



\section{Resumo}

Dentre as técnicas de mineração existentes encontra-se a associação, responsável por identificar relações que ocorrem no conjunto de dados. Embora a associação seja uma das técnicas mais utilizadas, a quantidade de padrões extraídos pode vir a sobrecarregar o usuário de tal maneira que encontrar algo interessante dentre a imensidão de padrões obtidos passa a ser um novo desafio. Para solucionar esse problema, uma grande parte dos trabalhos relacionados à associação está voltada a etapa de pós-processamento. Esses trabalhos geralmente propõem abordagens de pós-processamento que visam, segundo determinada estratégia, facilitar a busca pelos padrões interessantes ao domínio. Nos últimos anos, essas abordagens têm incluído no processo o conhecimento e/ou interesse do usuário sobre o domínio. Contudo, nas abordagens atualmente existentes, o usuário deve, por meio de algum formalismo descrever explicitamente seu conhecimento e/ou interesse, requerendo do usuário um tempo considerável, podendo levar, inclusive, a especificações incompletas e/ou incorretas. Além disso, na maioria das vezes, o usuário não tem ideia do que é provavelmente interessante, nem a partir de quais relações iniciar a busca. Nota-se, portanto, que um dos desafios dessas abordagens é considerar o conhecimento e/ou interesse do usuário. Além disso, é necessário considerar também o número de regras que o usuário analisará. A análise de regras feita por um especialista é custosa e, na maioria dos casos, o usuário quer explorar as regras geradas sem limitar a exploração ao conhecimento que ele já possui. Portanto, é importante que o usuário avalie o menor número de regras possível e, com base nessa avaliação, abordagens de pós-processamento consigam o auxiliar na busca pelas regras que ele poderá considerar interessante. Para tanto, é proposto neste trabalho que o pós-processamento seja tratado como um problema de classificação semissupervisionada transdutiva, uma vez que permite que o usuário rotule, considerando classes pré-definidas (por exemplo, "Interessante" ou "Não Interessante"), apenas algumas regras do conjunto a ser explorado para que todas as outras regras sejam automaticamente rotuladas. Além disso, por meio da definição dos rótulos de algumas regras, é possível capturar implicitamente o conhecimento e/ou interesse do usuário sobre o domínio. Para tanto, é necessário que as regras sejam modeladas de maneira a permitir: (a) selecionar as regras a serem rotuladas pelo usuário a fim de capturar implicitamente seu conhecimento e/ou interesse; (b) propagar os rótulos das regras já classificadas pelo usuário a todas as outras regras não rotuladas. Desse modo, neste trabalho, as regras foram modeladas via redes, uma vez que: (i) uma vasta quantidade de medidas de exploração de redes pode ser utilizada, em conjunto com as informações fornecidas pelo usuário, a fim de viabilizar o item (a); (ii) algoritmos de propagação de rótulos podem ser utilizados a fim de viabilizar o item (b). Diante do apresentado, ressalta-se que as contribuições deste trabalho estão na capacidade de se extrair o conhecimento e/ou interesse do usuário de acordo com as características da base de dados e direcionar sua exploração sem a necessidade de se definir previamente o que será explorado. Além disso, os resultados obtidos demonstram a capacidade da $P A R_{L P}$ em direcionar o usuário para o conhecimento considerado interessante, reduzindo, para tanto, a quantidade de regras a serem exploradas. Por fim, este trabalho contribui também para demonstrar que é possível tratar o pós-processamento de regras de associação como um problema de propagação de rótulos. 



\section{Abstract}

One of the existing data mining techniques is association rules, responsible for identifying relationships that occur in the data set. Although the association rule is one of the most widely used techniques, the amount of extracted patterns can overload the user in such a way that finding interesting patterns among the large amount of obtained patterns becomes a challenge. To solve this problem, a large part of the association-related work is focused on the post-processing step. These works generally propose a post-processing approaches that, according to a certain strategy, aims facilitating the search for interesting patterns. Nowadays, approaches have included the user knowledge in the domain and / or interests on the process. However, in the current existing approaches, the user knowledge and/or interest must be explicitly described by some formalism, requiring a considerable time and may even lead to incomplete and / or incorrect specifications. In addition, the user has no idea what probably is interesting or which patterns to begin the searching. Notice that one of the challenges of these approaches is to consider the knowledge and / or user interest. In addition, consider the number of rules the user will examine is necessary. The analysis of the rules by an expert is expensive and, in most cases, the user wants to explore the rules generated without limiting exploration to the knowledge he already has. Therefore, the user evaluate the fewest amount of rules possible is important and, based on this assessment, the post-processing approaches be able to assist in the search for the rules that he may consider interesting. So, in this work is proposed that the post-processing is treated as a transductive semi supervised classification problem, since it allows the user to label some rules based on two predefined classes (e.g. "interesting"or "not interesting"), in a way that just a small amount of the rule set needs to be explored and all other association rules are automatically labeled. Furthermore, you can implicitly capture the knowledge and / or user interest in the domain by labeling some rules. Thus, the rules need to be modeled to allow: (a) select the rules to be labeled by the user to implicitly capture their knowledge and / or interest; (b) propagate the rules' labels classified by the user to all not labeled rules. To do so, the rules were modeled via networks in this work, due to: (i) a large amount of network measures can be used in conjunction with the information provided by the user, to make item (a) possible; (ii) label propagation algorithms can be used in order to make item (b) possible. Therefore, we highlight that the contributions of this work are the ability to extract knowledge and / or user interest according to database characteristics and direct the user exploration without previously defining what will be explored. In addition, the results demonstrate that the proposed approach is able to direct the user to the knowledge considered interesting, reducing the amount of rules to be explored. Finally, this work also contributes to demonstrate that treat the post-processing of association rules as a problem of propagation of labels is possible. 



\section{Sumário}

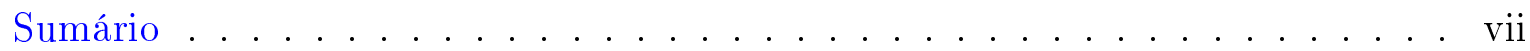

Lista de Figuras . . . . . . . . . . . . . . . . . . ix

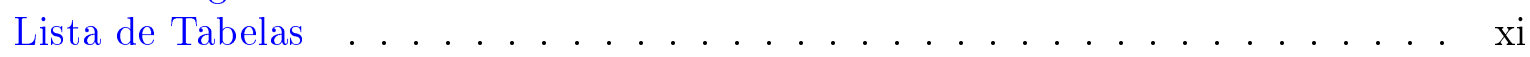

Notações . . . . . . . . . . . . . . . . . . . xiii

1 Introdução 1

1.1 Hipótese e Objetivos . . . . . . . . . . . . . . . . . 4

1.2 Proposta e Contribuições . . . . . . . . . . . . . . . . . 4

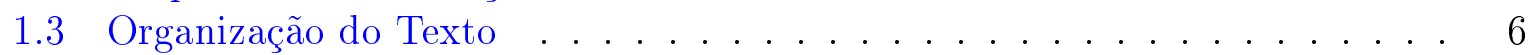

2 Revisão Bibliográfica $\quad 7$

2.1 Regras de Associação . . . . . . . . . . . . . . . . . . . 8

2.1.1 Definições e Conceitos de Regras de Associação . . . . . . . . . . . 8

2.1.2 Abordagens de Pós-Processamento de Regras de Associação . . . . 10

2.1.3 Considerações Finais sobre Regras de Associação . . . . . . . . . . 20

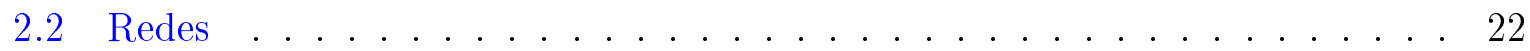

2.2.1 Definições e Conceitos de Redes . . . . . . . . . . . . . . . . 23

2.2.2 Técnicas para Construção de Redes . . . . . . . . . . . . . . 28

2.2 .3 Medidas de Rede . . . . . . . . . . . . . . . . 29

2.2.4 Abordagens de Propagação de Rótulos . . . . . . . . . . . . 32

2.2.5 Considerações Finais sobre Redes . . . . . . . . . . . . . . 36

2.3 Trabalhos Relacionados com Regras de Associação e Redes . . . . . . . . . 36

$3 P A R_{L P}$ : Post-processing Association Rules using Label Propagation 41

3.1 Especificação da Abordagem Proposta . . . . . . . . . . . . . 43

3.2 Ferramenta Desenvolvida para a Abordagem $P A R_{L P}$ e Exemplo de Execução 45

3.3 Avaliação Experimental da $P A R_{L P} \ldots \ldots \ldots \ldots \ldots$

3.3 .1 Avaliação Sem a Participação do Usuário . . . . . . . . . . . . . 50

3.3.2 Avaliação Com a Participação de Usuário Especialista em Segurança

Pública .......................... 64

3.3.3 Discussão sobre as Avaliações Experimentais . . . . . . . . . . . . . 67

3.4 Considerações Finais . . . . . . . . . . . . . . . . . . . 68

4 Conclusões e Trabalhos Futuros $\quad 69$

$\begin{array}{ll}\text { Referências Bibliográficas } & 78\end{array}$ 



\section{Lista de Figuras}

1.1 Abordagem $P A R_{L P} \ldots \ldots \ldots \ldots \ldots \ldots$

2.1 Representação de redes não direcionadas. . . . . . . . . . . . . . . . . . . 23

2.2 Rede direcionada. . . . . . . . . . . . . . . . . . . . 24

2.3 Rede com pesos. . . . . . . . . . . . . . . . . . . 25

2.4 Representação de um hipergrafo. . . . . . . . . . . . . . 27

2.5 Um hipergrafo e suas hiperarestas (esquerda) e sua representação como rede bipartida (direita) . . . . . . . . . . . . . . . 27

2.6 Um exemplo de Association Rule Network retirado de Pandey et al. (2009). 37

3.1 Detalhes da abordagem $P A R_{L P} \ldots \ldots \ldots \ldots \ldots \ldots$

3.2 Execução passo a passo das etapas da abordagem $P A R_{L P} \ldots \ldots$. . . . . 46

3.3 Configuração utilizada para realização do exemplo. . . . . . . . . . . . . . 47

3.4 Regras a serem classificadas pelo usuário na primeira iteração. . . . . . . . 48

3.5 Avaliando o critério de parada na primeira iteração. . . . . . . . . . . . . 48

3.6 Regras a serem classificadas pelo usuário na segunda iteração. . . . . . . . . 49

3.7 Avaliando o critério de parada na segunda iteração. . . . . . . . . . . . 49

3.8 Arquivo de saída obtido após duas iterações. . . . . . . . . . . . . . . . . . . 49

3.9 Exemplo de modelagem utilizando rede homogênea. . . . . . . . . . . . . 52

3.10 Exemplo de modelagem utilizando rede bipartida. . . . . . . . . . . . 53

3.11 Exemplo de cálculo de threshold e simulação da classificação das regras por um usuário. . . . . . . . . . . . . . . . 55

3.12 Teste estatístico realizado nas 20 melhores configurações obtidas. . . . . . . 64 



\section{Lista de Tabelas}

2.1 Medidas objetivas apresentadas em Geng e Hamilton (2007) e MartinezBallesteros et al. (2013). . . . . . . . . . . . . . . 11

2.2 Tabela de validações utilizadas na literatura. . . . . . . . . . . . . . 21

2.3 Matriz de adjacência referente a rede da Figura 2.1(a) . . . . . . . . . . . 24

2.4 Matriz de adjacência referente a rede da Figura 2.1(b). . . . . . . . . . . 24

2.5 Representação da rede da Figura 2.2 como matriz de adjacência. . . . . . . 25

2.6 Matriz de adjacência com pesos, utilizando como base a Figura 2.3. . . . . 25

2.7 Matriz Laplaciana calculada com base na Figura 2.1(a) . . . . . . . . . . 26

2.8 Matriz de incidência calculada como base a rede da Figura 2.5 . . . . . . . 28

3.1 Detalhes das bases de dados utilizadas nos experimentos. . . . . . . . . 50

3.2 Parâmetros associados as redes homogêneas. . . . . . . . . . . . . 56

3.3 Parâmetros associados as redes bipartidas. . . . . . . . . . . . 56

3.4 Particionamento dos resultados para análise estatística. . . . . . . . . . 57

3.5 As 20 melhores configurações obtidas nos experimentos realizados. . . . . . 58

3.6 Resultados obtidos após 30 execuções na base Balance-Scale. . . . . . . . . 60

3.7 Resultados obtidos após 30 execuções na base Breast-Cancer. . . . . . . . . 60

3.8 Resultados obtidos após 30 execuções na base Car. . . . . . . . . . . . 61

3.9 Resultados obtidos após 30 execuções na base Ecoli. . . . . . . . . . . . 61

3.10 Resultados obtidos após 30 execuções na base Habermann. . . . . . . . . . 62

3.11 Resultados obtidos após 30 execuções na base Iris. . . . . . . . . . . . . . 62

3.12 Resultados obtidos após 30 execuções na base Tic-Tac-Toe. . . . . . . . . . 63

3.13 Resultados obtidos após 30 execuções na base Zoo. . . . . . . . . . . . . 63

3.14 Descrição da base de dados incluindo o pré-processamento. . . . . . . . . 65

3.15 Tabela contendo os resultados obtidos na base gold. . . . . . . . . . . . . 66

3.16 Tabela contendo a média de similaridade por medida. . . . . . . . . . 67 



\section{Notações}

A Conjunto de itens contidos em uma transação

B Matriz de incidência de uma rede bipartida

conf-min Confiança mínima utilizada para gerar regras de associação

E Conjunto de arestas de uma rede

G Conjunto de vértices agrupadores de uma rede bipartida

H Conjunto de vértices não agrupadores de uma rede bipartida

L Conjunto de vértices rotulados de uma rede

LHS Left Hand Side, antecedente de uma regra de associação

$\mathbf{P}$ Conjunto de pesos das arestas de uma rede

$\mathbf{R}$ Representação de uma rede

RL Representação de uma regra de associação

RHS Right Hand Side, consequente de uma regra de associação sup-min Suporte mínimo utilizado para gerar regras de associação

T Conjunto de transações de uma base de dados

U Conjunto de vértices não rotulados de uma rede

V Conjunto de vértices de uma rede

W Matriz de adjacência de uma rede 

CAPÍTULO

\section{Introdução}

A quantidade de informação acumulada nas organizações e, principalmente, no mundo digital, vem crescendo incessantemente. Essas informações em geral "escondem" conhecimentos interessantes, os quais poderiam ser utilizados para que tomadores de decisão adquirissem vantagem competitiva e/ou entendessem melhor o domínio da aplicação. Contudo, explorar essa quantidade excessiva de informação disponível nos dias de hoje de modo manual se torna inviável. Para solucionar esse problema diversas áreas de pesquisa surgiram nos últimos anos, dentre elas a mineração de dados e textos.

A tarefa de mineração de dados é composta de três grandes etapas, a saber (Rezende et al., 2003): pré-processamento, extração de padrões e pós-processamento. No pré-processamento os dados a serem minerados são coletados e passam por processos de limpeza, transformação, redução de dimensionalidade, dentre outros, de modo a obter um repositório em formato pré-definido. A etapa de extração de padrões é responsável por extrair os padrões embutidos nos dados a partir do repositório anteriormente obtido. Por fim, no pós-processamento, os padrões minerados são validados de modo a verificar se os conhecimentos extraídos são realmente interessantes ao domínio da aplicação. Todo esse processo é iterativo e interativo, i.e., pode ser necessário reiniciar todo o processo caso nenhum conhecimento interessante seja encontrado, sendo que várias das etapas dependem da interação com o usuário, principalmente a de pós-processamento, uma vez que é ele quem valida os padrões obtidos.

Dependendo do objetivo que se pretende alcançar, determinadas técnicas de mineração podem ser utilizadas. Dentre as existentes, uma que vem se destacando é a associação, devido a sua facilidade de compreensão até mesmo por não especialistas da área. O algoritmo Apriori, amplamente utilizado para obtenção de regras de associação, foi eleito como um dos 10 algoritmos de mineração de dados mais influentes utilizados pela comunidade (Wu e Kumar, 2009). Por esses motivos, a associação vem sendo aplicada em 
diversos domínios, como nota-se nos trabalhos de Alpar e Winkelstrater (2014); Choi e Kim (2014); Munkova et al. (2013); Dadaser-Celik et al. (2012); Xiao (2011); Nuwangi et al. (2010); Rajasekar e Weng (2009); Changguo et al. (2009). Entretanto, a técnica pode extrair uma grande quantidade de padrões, dificultando sua utilização. Em geral, a quantidade de regras extraídas sobrecarrega de tal maneira o usuário que encontrar algo interessante dentre a imensidão de padrões obtidos passa a ser um novo desafio, podendo ser visto, por si só, como um novo processo de mineração. Para solucionar esse problema, uma grande parte dos trabalhos relacionados à associação está voltada a etapa de pósprocessamento. Esses trabalhos geralmente propõem abordagens de pós-processamento de regras de associação que visam, segundo determinada estratégia, facilitar a busca pelos padrões interessantes ao domínio ${ }^{1}$.

Nos últimos anos, as abordagens de pós-processamento de regras de associação têm incluído no processo o conhecimento e/ou interesse do usuário sobre o domínio. Nas abordagens atualmente existentes (Seção 2.1.2), o usuário deve, por meio de algum formalismo (ontologias/taxonomias, schemas, etc.), descrever explicitamente seu conhecimento e/ou interesse sobre o domínio. No entanto, realizar tais descrições requer um tempo considerável do usuário, podendo inclusive levar a especificações incompletas e/ou incorretas às vezes relações conhecidas são esquecidas e o que um usuário tem como conhecimento prévio o outro não tem. Além disso, na maioria das vezes, o usuário não tem ideia do que é provavelmente interessante, nem a partir de quais relações iniciar a busca, uma vez que a motivação da mineração é justamente auxiliar o usuário a descobrir o que ele não sabe. Por fim, diversas abordagens utilizam estratégias automáticas para direcionar a exploração; porém, conforme discutido em Bie (2013), essas estratégias dificilmente capturam a variação de conhecimento existente de usuário para usuário.

Nota-se, portanto, que um dos desafios das abordagens de pós-processamento de regras de associação é considerar o conhecimento e/ou interesse do usuário. Como mencionado, diversas abordagens disponíveis na literatura consideram o conhecimento e/ou interesse do usuário para que a exploração seja realizada. Porém, isso é feito de modo que essas informações sejam definidas apriori, i.e., antes do processamento iniciar. Essa definição prévia exige que o usuário já possua um grande conhecimento no domínio que está sendo explorado. Além do desafio referente a modelagem do conhecimento e/ou interesse, é necessário considerar também o número de regras que o usuário analisará. A análise de regras feita por um especialista é custosa e, na maioria dos casos, o usuário quer explorar as regras geradas sem limitar a exploração ao conhecimento que ele já possui. Portanto, é importante que o usuário avalie o menor número de regras possível e, com base nessa avaliação, abordagens consigam o auxiliar na busca pelas regras que ele poderá considerar interessante. Para tanto, propõe-se neste mestrado que o problema de pós-processamento de regras de associação seja tratado como um problema de classificação, diferenciando as regras em duas classes, "Interessantes" e "Não Interessantes".

\footnotetext{
${ }^{1}$ Neste trabalho, entende-se como interessante um padrão que seja relevante e/ou útil ao usuário.
} 
Algoritmos de classificação são amplamente utilizados na literatura quando se necessita classificar (rotular) um conjunto de dados não rotulado tendo como base um conjunto de dados previamente rotulados. As abordagens de aprendizado de máquina podem ser divididas, basicamente, em 3 sub-áreas (Zhu, 2005): supervisionado, não supervisionado e por reforço. No aprendizado supervisionado utiliza-se um conjunto de elementos já rotulados e busca-se obter um classificador capaz de predizer os rótulos de elementos ainda não vistos (desconhecidos). No aprendizado não supervisionado observa-se um conjunto de elementos não rotulados visando um ou mais dos seguintes objetivos: (i) separar os elementos em grupos, de acordo com a similaridade existente entre os mesmos, de tal modo que elementos pertencentes a um mesmo grupo sejam os mais similares entre si e os mais distintos entre os elementos dos outros grupos; (ii) detectar outliers, i.e., identificar elementos que sejam muito diferentes dos outros elementos contidos no conjunto de dados; (iii) reduzir a dimensionalidade do conjunto de dados, i.e., identificar atributos que possam ser removidos preservando as características dos dados; etc. Por fim, no aprendizado por reforço, observa-se constantemente um ambiente e realizam-se ações. A qualidade dessas ações é medida com uma recompensa numérica. O objetivo é então maximizar essa recompensa.

Este trabalho de mestrado é voltado à classificação, que tradicionalmente é uma tarefa supervisionada. Contudo, para se obter um classificador com boa acurácia é necessário que exista um conjunto significativo de elementos rotulados, o que, na maioria das vezes, é muito custoso e difícil de se adquirir (por exemplo, em um sistema de classificação de e-mails em spam e não spam deve-se rotular inicialmente uma grande quantidade de emails). Por outro lado, elementos não rotulados são, em geral, encontrados em abundância (por exemplo, os e-mails do exemplo anterior). Desse modo, em conjuntos de dados que apresentam uma pequena quantidade de elementos rotulados fica difícil a utilização de algoritmos de classificação supervisionados. Nesse contexto surgiu o aprendizado semissupervisionado, em que se utiliza de um conjunto contendo poucos elementos rotulados e uma grande quantidade de elementos não rotulados para se gerar um bom classificador a fim de predizer os rótulos dos elementos ainda não vistos. O aprendizado semissupervisionado pode ser dividido em indutivo e transdutivo: na indução gera-se um algoritmo de classificação com o objetivo de predizer o rótulo de elementos ainda não conhecidos; na transdução nenhum classificador é gerado, uma vez que o objetivo é classificar apenas os elementos não rotulados contidos no conjunto de dados, i.e., predizer o rótulo apenas dos elementos não rotulados do conjunto. Por fim, é importante mencionar que é possível realizar também agrupamento, regressão, etc., via aprendizado semissupervisionado; porém, os mesmos não serão aqui tratados por não fazerem parte do escopo deste mestrado.

Considerando o exposto, é interessante tratar o pós-processamento de regras de associação como um problema de classificação semissupervisionada transdutiva, uma vez que permite que o usuário rotule, considerando classes pré-definidas (por exemplo, "Interessante" ou "Não Interessante"), apenas algumas regras do conjunto a ser explorado 
para que todas as outras regras sejam automaticamente rotuladas - no problema aqui exposto não é necessário gerar um modelo para classificar novos exemplos, dado que o conjunto de regras está totalmente definido ao se iniciar a etapa de pós-processamento. Além disso, por meio da definição dos rótulos de algumas regras, é possível capturar implicitamente o conhecimento e/ou interesse do usuário sobre o domínio. Contudo, é importante que as regras a serem rotuladas sejam representativas ao domínio para que a propagação ocorra de maneira satisfatória. Desse modo, é necessário que as regras sejam modeladas de maneira a permitir: (a) selecionar as regras a serem rotuladas pelo usuário a fim de capturar implicitamente seu conhecimento e/ou interesse; (b) propagar os rótulos das regras já classificadas pelo usuário a todas as outras regras não rotuladas. Para tanto, neste trabalho de mestrado, as regras foram modeladas via redes, uma vez que: (i) uma vasta quantidade de medidas de exploração de redes podem ser utilizadas, em conjunto com as informações fornecidas pelo usuário, a fim de viabilizar o item (a); (ii) algoritmos de propagação de rótulos podem ser utilizados a fim de viabilizar o item (b).

\subsection{Hipótese e Objetivos}

Diante do cenário apresentado, a hipótese é que a incorporação de conhecimento por parte do usuário durante o pós-processamento, via redes e propagação de rótulos, permite que o usuário seja direcionado ao conhecimento considerado interessante. Para validar a hipótese, foram definidos os seguintes objetivos:

- Modelagem - Avaliar meios de representar as regras de associação via redes que obtenham bons resultados ao modelar as regras e suas ligações.

- Exploração - Pesquisar métodos de processamento de redes capazes de direcionar a exploração para pontos considerados mais importantes.

- Interação - Analisar formas de interação com o usuário com o objetivo de incluir o conhecimento do mesmo no processo de exploração, visando direcionar a exploração para o conhecimento considerado útil.

- Desenvolvimento - Desenvolver uma ferramenta computacional que viabilize a exploração do domínio de regras. Nessa etapa são implementadas todas as possibilidades previamente analisadas, possibilitando ao usuário encontrar as regras interessantes.

\subsection{Proposta e Contribuições}

Considerando os desafios discutidos na literatura, visando auxiliar o usuário na busca por regras de associação interessantes, neste mestrado é proposto uma abordagem interativa e iterativa de pós-processamento de regras de associação denominada Post-processing 


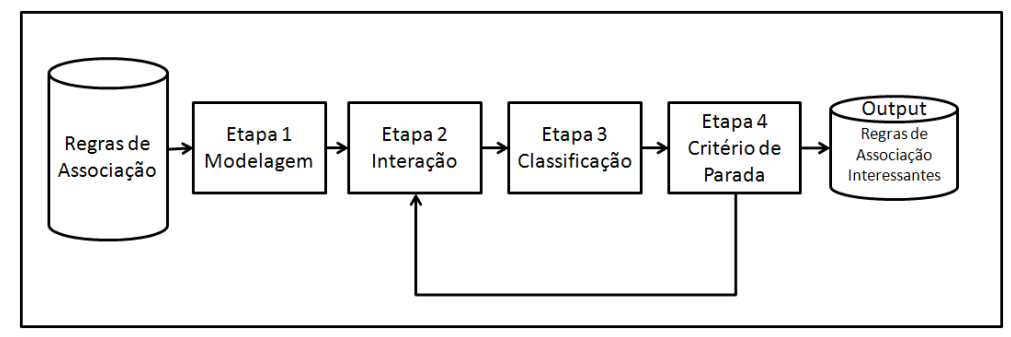

Figura 1.1: Abordagem $P A R_{L P}$.

Association Rules using Label Propagation $\left(P A R_{L P}\right)$. Nessa abordagem o usuário descreve implicitamente seu conhecimento e/ou interesse durante pós-processamento das regras. Para que seja possível realizar a interação durante a exploração, técnicas de processamento de redes são utilizadas visando encontrar as regras mais relevantes para o domínio. Desse modo, a abordagem proposta utiliza redes para modelar o conjunto de regras, medidas de exploração de redes para direcionar o usuário ao conhecimento interessante e algoritmos de propagação de rótulos para propagar as informações fornecidas pelo usuário para todas as outras regras não classificadas.

Na Figura 1.1 é possível visualizar a especificação da abordagem proposta. A abordagem foi dividida em 4 etapas: modelagem, interação, classificação e critério de parada. $\mathrm{Na}$ [Etapa 1] é realizada a modelagem das regras de associação via redes, tendo como base a similaridade existente entre as regras. Na [Etapa 2] é realizada a interação com o usuário, a fim de capturar o conhecimento e/ou interesse do usuário de maneira implícita. Essa interação é realizada utilizando medidas de exploração de redes a fim de sugerir as regras a serem classificadas pelo usuário. Para tanto, duas classes foram utilizadas: "Interessante" [I] e "Não Interessante" [NI]. Essa interação com o usuário evolui conforme as iterações são realizadas, considerando as regras que foram classificadas como [I] nas iterações anteriores. Na [Etapa 3] é realizada a classificação das regras de acordo com as informações fornecidas pelo usuário. Essa classificação é realizada utilizando algoritmos de propagação de rótulos. Dessa maneira, os rótulos [I] e [NI] são propagados para todas as regras ainda não rotuladas. Na [Etapa 4] checa-se um critério de parada, verificando se a quantidade de regras obtidas como similares e, portanto interessantes, é satisfatória para o usuário ou se é necessário realizar mais iterações. Caso o processo seja reiniciado, as regras classificadas com [I] pelo algoritmo de classificação no passo anterior são processadas na [Etapa 2], visando criar a interação com o usuário e direcionar a busca considerando o conhecimento já obtido. Após a realização da interação, todos os rótulos que foram dados pelo algoritmo de classificação na iteração passsada podem ser substituídos por um novo rótulo no processo de classificação que se inicia, continuando o processo até que o usuário opte por finalizar a exploração. Todas as etapas são descritas em detalhes no Capítulo 3.

As contribuições deste trabalho estão, principalmente, na capacidade de extrair o conhecimento do usuário de acordo com as características da base de dados e direcionar a sua exploração sem a necessidade de definir previamente o que deverá ser explorado. Os resultados obtidos demonstram a capacidade da abordagem proposta em direcionar a 
exploração do usuário para o conteúdo que o mesmo deseja explorar, reduzindo significativamente a quantidade de regras que o usuário deverá explorar para obter o conhecimento que deseja. Além disso, esse mestrado contribui também para demonstrar que é possível tratar o problema de pós-processamento de regras de associação como um problema de propagação de rótulos. Portanto, usuários que desejam explorar conjuntos de regras com o objetivo de descobrir regras interessantes de acordo com a importância dessas regras dentro do conjunto total podem ser beneficiados pelo uso da abordagem desenvolvida. Alguns dos resultados obtidos nos experimentos realizados foram publicados em Padua et al. (2014) e Carvalho et al. (2014).

\subsection{Organização do Texto}

Para atender os objetivos deste projeto, o texto encontra-se organizado da seguinte maneira: no Capítulo 2 é apresentada uma revisão bibliográfica das áreas utilizadas no desenvolvimento deste mestrado, iniciando pela Seção 2.1, na qual é realizada uma revisão na área de regras de associação com ênfase no pós-processamento. Na Seção 2.2 é apresentada uma revisão na área de redes com ênfase em propagação de rótulos, começando com a definição dos conceitos básicos, tipos de rede e medidas existentes, passando por técnicas de construção e terminando com a apresentação de diversas abordagens de propagação de rótulos. Na Seção 2.3 são apresentados trabalhos relacionados, que utilizam redes para auxiliar no processo de mineração de regras de associação. No Capítulo 3 é apresentada a abordagem proposta $\left(P A R_{L P}\right)$ iniciando com a descrição da abordagem na Seção 3.1. Na Seção 3.2 é apresentado um exemplo passo a passo do funcionamento da abordagem $P A R_{L P}$, seguida pela descrição dos experimentos realizados e discussão dos resultados obtidos na Seção 3.3. O texto é finalizado com as conclusões e trabalhos futuros, que são apresentados no Capítulo 4. 
CAPÍTULO

\section{Revisão Bibliográfica}

Neste mestrado é proposta uma abordagem de pós-processamento de regras de associação interativa e iterativa, capaz de extrair o conhecimento do usuário durante o pósprocessamento. Essa extração de conhecimento durante o pós-processamento elimina a necessidade do usuário conhecer, apriori, todo o domínio que está sendo explorado e também exclui a necessidade de conhecer um formalismo de representação de conhecimento. Visando facilitar a exploração e a extração do conhecimento, a abordagem proposta utiliza redes e propagação de rótulos como meio de processamento.

Neste capítulo é realizada uma revisão bibliográfica na literatura, analisando os métodos existentes e discutindo seus resultados. Na Seção 2.1 é realizada uma revisão na área de regras de associação, começando com algumas definições e explicando os conceitos da área na Seção 2.1.1. Na Seção 2.1.2 é introduzido o conceito de pós-processamento de regras de associação e discutido a necessidade de sua utilização, explicando na Seção 2.1.2 algumas abordagens existentes na literatura que pós-processam as regras de associação sem a interação do usuário, também são explicadas algumas abordagens interativas na Seção 2.1.2. Na Seção 2.1.2 são exploradas algumas medidas de similaridade entre regras de associação, essa exploração faz-se necessária para a construção da rede, explicada mais adiante na Seção 2.2. A revisão na área de regras de associação termina na Seção 2.1.2, exibindo e discutindo algumas medidas de validação disponíveis na literatura.

Na Seção 2.2 é realizado uma revisão na área de redes, começando com algumas definições sobre estruturas das redes e alguns conceitos na Seção 2.2.1. Na Seção 2.2.2 são explicados alguns métodos utilizados para construir redes, visando melhorar a capacidade de representação e prepara-la para a exploração. Algumas medidas de exploração de redes são explicadas na Seção 2.2.3, essas medidas são de extrema importância para a busca de elementos importantes e direcionamento do pós-processamento pela abordagem proposta. As abordagens de propagação de rótulo são explicadas na Seção 2.2.4, 
diferenciando as abordagens disponíveis para cada tipo de rede. Por fim, na Seção 2.3 são listados alguns trabalhos da literatura que utilizam redes em conjunto com regras de associação. Os trabalhos selecionados para essa seção não se resumem apenas ao pósprocessamento das regras, são também listados trabalhos que utilizam redes para gerar regras ou pré-processar o conjunto de dados.

\subsection{Regras de Associação}

A ideia de minerar regras de associação surgiu da análise de dados de cestas de compras em que regras do tipo "um cliente que compra os produtos $a_{1}, a_{2}, \ldots, a_{n}$ também irá comprar o produto $a_{m}$ com probabilidade c\%" são geradas (Agrawal et al., 1993). Entretanto, as regras de associação não estão restritas a análises de dependência no contexto de aplicações de varejo, uma vez que elas são aplicadas com sucesso a uma ampla gama de problemas (Choi e Kim, 2014; Oellrich et al., 2014; Yu et al., 2014; Dadaser-Celik et al., 2012; Xiao, 2011; Nuwangi et al., 2010; Changguo et al., 2009). Essas regras visam encontrar relacionamentos entre os itens de uma determinada base de dados, com o objetivo de explorar as relações de maneira que seja possível descobrir conhecimentos implícitos na base, que normalmente não seriam descobertos por meios manuais de exploração. Contudo, a quantidade de regras de associação geradas normalmente excede a capacidade de compreensão humana, tornando a etapa de pós-processamento necessária. As abordagens de pós-processamento de regras de associação são responsáveis por direcionar o usuário ao conhecimento potencialmente útil, ou seja, ao conhecimento que trará benefício ao usuário. Para realizar essa tarefa, algumas abordagens utilizam-se de medidas objetivas para explorar as regras de diversas formas, buscando estruturar o domínio ou remover as regras que não são interessantes, enquanto outros utilizam o conhecimento do usuário para ajudar na descoberta dessas regras. Dianto do exposto, nesta seção as regras de associação são definidas e discutidas, em conjunto com alguns trabalhos da área, e algumas abordagens de pós-processamento são discutidas. Após a discussão das abordagens de pós-processamento, é realizada uma discussão sobre os métodos de avaliação existentes para regras de associação.

\subsubsection{Definições e Conceitos de Regras de Associação}

Segundo Agrawal et al. (1993), uma regra de associação é definida da seguinte maneira: seja $D$ uma base de dados composta por um conjunto de itens $A=\left\{a_{1}, \ldots a_{m}\right\}$ e por um conjunto de transações $T=\left\{t_{1}, \ldots t_{n}\right\}$, em que cada transação $t_{i} \in T$ é tal que $t_{i} \subseteq A$. É dito que uma transação $t_{i}$ suporta um itemset $I$, conjunto de itens tal que $I \subseteq A$, se $I \subseteq t_{i}$. Portanto, uma regra de associação $r l$ é uma implicação na forma $L H S \Rightarrow R H S$, em que $L H S$ e RHS são itemsets $(L H S \subset A, R H S \subset A, L H S \cap R H S=\emptyset)$, LHS representa o antecedente (Left Hand Side) e RHS o consequente (Right Hand Side). A regra $r l$ só é gerada caso possua os valores mínimos de confiança e suporte. O suporte do itemset 
$I$ representa a frequência de $I$ em $T$, i.e., $\sup (I)=\frac{n(I)}{|T|}$, em que $n(I)$ indica o número de transações que suportam $I$ e $|T|$ o número de transações. A regra $r: L H S \Rightarrow R H S$ ocorre no conjunto de transações $T$ com confiança conf e suporte sup, em que sup $(r)=$ $\frac{n(L H S \cup R H S)}{|T|}$ representa o suporte da regra e conf $(r)=\frac{n(L H S \cup R H S)}{n(L H S)}$ a confiança da regra.

O processo de geração de regras trabalha de forma iterativa, ou seja, primeiro são gerados os itemsets com 2 itens, então são gerados os itemsets com 3 itens e assim consecutivamente até que não seja mais possível gerar os itemsets de tamanho $k$ pela restrição do sup ou por uma outra limitação dada por parte do usuário. Portanto, segundo Agrawal et al. (1993), o processo de obtenção de regras de associação pode ser decomposto em dois passos:

- Encontrar todos os k-itemsets (conjunto de k itens) que possuam suporte maior ou igual ao suporte mínimo especificado pelo usuário (sup-min). Os itemsets com suporte igual ou superior a sup-min são definidos como itemsets frequentes $(l)$, os demais conjuntos são denominados itemsets não-frequentes;

- Utilizar todos os $\mathrm{k}$-itemsets frequentes, com $\mathrm{k} \geq 2$, para gerar as regras de associação. Para cada itemset frequente $l \subseteq A$, encontrar todos os subconjuntos $a^{\prime}$ de itens não vazios e diferentes de $l$. Para cada subconjunto $a^{\prime} \subseteq l$, gerar uma regra na forma $a^{\prime} \Rightarrow\left(l-a^{\prime}\right)$ se a razão de $\sup (l)$ por $\sup \left(a^{\prime}\right)$ é maior ou igual à confiança mínima especificada pelo usuário (conf-min).

As regras de associação são amplamente aplicadas em vários problemas. A seguir são descritos alguns trabalhos recentes que aplicam regras de associação na solução de um dado problema.

Tsai e Huang (2014) aplicaram regras de associação em uma base de um supermercado utilizando os dados de vendas e os dados de deslocamento dos clientes entre as prateleiras para otimizar a distribuição dos produtos nas prateleiras. O trabalho iniciou com o preparo dos dados de consumo dos clientes no supermercado e com a coleta do deslocamento utilizando um dispositivo de rádio. Essas informações foram preparadas para a aplicação do algoritmo Apriori, para geração das regras em conjunto com um algoritmo para mineração UMSP (high utility mobile sequential patterns). Essa mineração em conjunto é realizada utilizando as regras de associação como entrada do algoritmo UMSP, que irá buscar por padrões com alto valor de utilidade para serem considerados como ótimos pelo usuário. Baseado no resultado obtido pelo UMSP, todos os itens foram classificados como "Mais importante", "Menos importante" ou "Trivial", no qual os itens "Mais importante" são itens com alta quantidade de venda, itens "Menos importante" são itens que não vendem tanto, porém, estão associados aos itens "Mais importante" e os itens "Trivial" são itens que não são nem "Mais importante" nem "Menos importante". Após a aplicação do algoritmo, os produtos foram realocados de acordo com o resultado obtido. Os resultados experimentais demonstraram que o método proposto pelos autores conseguiu realocar os 
produtos de forma otimizada e que o resultado final aumentou drasticamente a venda dos produtos.

Yu et al. (2014) utilizaram regras de associação para analisar casos de pacientes com doenças respiratórias, os quais foram tratados por médicos chineses com medicina chinesa ou via medicina tradicional. Com o uso de regras de associação, os autores descobriram que a maioria dos pacientes que possuem problemas respiratórios procuram a medicina tradicional, com excessão dos casos de gripe, em que a maioria resolve optar pela medicina chinesa. A conclusão obtida pelos autores foi que a maioria das pessoas que utilizam-se de medicina chinesa o fazem quando os sintomas são mais leves e, na maioria das vezes, a escolha é feita por mulheres. Baseado nessas informações e no conhecimento de área, os autores sugeriram métodos de divulgação direcionada da medicina chinesa visando aumentar o número de pacientes que optem pelo tratamento.

Em geral, independente do domínio, o processo de geração de regras de associação acaba resultando em uma quantidade muito grande de padrões, o que dificulta a exploração por parte do usuário. Com o objetivo de contornar esse problema, vários pesquisadores desenvolveram ao longo dos anos algumas abordagens para pós-processar o conjunto de regras gerado. Essas abordagen são discutidas na próxima seção.

\subsubsection{Abordagens de Pós-Processamento de Regras de Associação}

Como a quantidade de regras de associação geradas geralmente excede a capacidade de compreensão humana, foram desenvolvidas abordagens para processar o conhecimento obtido. Em geral, essas abordagens visam facilitar a busca por um subconjunto de regras que seja interessante ao usuário. A seguir, são descritas diversas abordagens encontradas na literatura voltadas ao pós-processamento de regras de associação. As abordagens foram divididas em "Interativas" e "Não Interativas" de acordo com a possibilidade do usuário interagir ou não com a técnica. A classificação das abordagens foi realizada, nesse trabalho, da seguinte maneira: caso uma determinada abordagem possua, no mínimo, uma etapa de interação com o usuário, então sua classificação é "Interativa", mesmo que a maior parte do processo seja realizada sem a intervenção do usuário.

\section{Abordagens Não Interativas para Pós-Processsamento de Regras}

Abordadagens não interativas de pós-processamento de regras de associação utilizamse de mecanismos automáticos que não necessitam da interferência do usuário para selecionar as regras que são interessantes. Algumas dessas abordagens utilizam ranqueamento de acordo com medidas objetivas, que visam calcular a importância das regras de associação perante todo o conjunto gerado de acordo com alguma semântica. Na Tabela 2.1 são exibidas algumas medidas objetivas apresentadas em Geng e Hamilton (2007) e MartinezBallesteros et al. (2013). Nessa tabela, as regras encontram-se no formato $L H S \Rightarrow R H S$. Além das medidas aqui explicadas, é possível encontrar muitas outras nas referências citadas por esses autores. 
Tabela 2.1: Medidas objetivas apresentadas em Geng e Hamilton (2007) e Martinez-Ballesteros et al. (2013).

\begin{tabular}{|c|c|c|}
\hline Medida & Equação & Descrição \\
\hline Support & $\frac{n(L H S \cup R H S)}{|T|}$ & $\begin{array}{l}\text { Probabilidade dos itens contidos na regra } \\
\text { aparecerem nas transações da base de dados. } \\
\text { Medida que leva em consideração o itemset. }\end{array}$ \\
\hline Jaccard & $\frac{\operatorname{Sup}(L H S \cup R H S)}{\operatorname{Sup}(L H S)+\operatorname{Sup}(R H S)-S u p(L H S \cup R H S)}$ & $\begin{array}{l}\text { Calcula o quanto os itemsets LHS e RHS } \\
\text { aparecem juntos na base de dados. Não leva } \\
\text { em consideração a implicação da regra. Valo- } \\
\text { res próximos a } 1 \text { resultam em uma alta taxa } \\
\text { de coocorrência enquanto valores próximo a } \\
0 \text { mostram que os conjuntos não ocorrem si- } \\
\text { multaneamente. }\end{array}$ \\
\hline Confidence & $\frac{\operatorname{Sup}(L H S \cup R H S)}{\operatorname{Sup}(L H S)}$ & $\begin{array}{l}\text { Probabilidade de RHS ocorrer dado que } \\
L H S \text { ocorreu. Leva em consideração a im- } \\
\text { plicação da regra e visa quantificar o quanto } \\
\text { o itemset LHS influencia na ocorrência do } \\
\text { conjunto } R H S \text {. }\end{array}$ \\
\hline Recall & $\frac{\operatorname{Sup}(L H S \cup R H S)}{\operatorname{Sup}(R H S)}$ & $\begin{array}{l}\text { Probabilidade de LHS ocorrer dado que } \\
R H S \text { ocorreu. Leva em consideração a im- } \\
\text { plicação da regra e visa quantificar o quão } \\
\text { dependente a aparição de } L H S \text { é em relação } \\
\text { a } R H S \text {. }\end{array}$ \\
\hline Lift & $\frac{\operatorname{Sup}(L H S \cup R H S)}{\operatorname{Sup}(L H S) \operatorname{Sup}(R H S)}$ & $\begin{array}{l}\text { Calcula a correlação entre } L H S \text { e } R H S \text {. Va- } \\
\text { lores acima de } 1 \text { indicam correlação positiva } \\
\text { entre os itemsets; valores menores que } 1 \text { in- } \\
\text { dicam que a correlação é negativa; valores } \\
\text { iguais a } 1 \text { indicam que os itens são indepen- } \\
\text { dentes. }\end{array}$ \\
\hline Added_Value & $\left|\frac{\operatorname{Sup}(L H S \cup R H S)}{\operatorname{Sup}(L H S)}-\operatorname{Sup}(R H S)\right|$ & $\begin{array}{l}\text { Calcula o quanto } L H S \text { e } R H S \text { são depen- } \\
\text { dentes. Valores próximos a } 1 \text { indicam maior } \\
\text { dependência. }\end{array}$ \\
\hline
\end{tabular}

Outras abordagens visam estruturar o domínio de exploração, aplicando técnicas de agrupamento (clustering) para separar o conhecimento em diferentes grupos. Para realizar o agrupamento, é necessário calcular medidas de similaridade entre regras. Muitos trabalhos adaptam medidas objetivas para realizar esse cálculo. A mais comum de ser adaptada é a medida Jaccard, que utiliza teoria dos conjuntos para encontrar a similaridade entre as regras. As regras são agrupadas e então exibidas para exploração do usuário. Além do agrupamento, também existem as abordagens que visam adquirir regras generalizadas, exibindo assim uma quantidade menor de regras para o usuário a fim de direcionar a exploração para determinados itens ou implicações. Alguns trabalhos que utilizam essas abordagens são apresentados a seguir.

Liu et al. (1999) propuseram uma abordagem que poda as regras de associação utilizando uma medida de correlação e regras generalizadas, para direcionar a exploração do usuário de acordo com regras mais gerais. Essa poda é realizada selecionando as regras que possuem o mesmo consequente e medindo a correlação entre elas: caso exista uma regra que esteja contida em outra, ou seja, que represente o mesmo conhecimento, porém 
de maneira não significativa, então essa regra é descartada. Após a realização da poda, inicia-se a busca pelas regras mais gerais que serão exibidas no fim para o usuário. Para verificar as regras mais gerais é também aplicada a medida de correlação, verificando se a regra nova é diferente ou não das regras já exploradas, montando assim um conjunto de regras gerais para serem exibidas para o usuário. O resultado final dessa abordagem é um conjunto de regras gerais que exibem o conhecimento do domínio para o usuário explorar. Caso alguma dessas regras gerais sejam interessantes, o usuário seleciona-a e a abordagem exibe todas as regras não gerais que estão contidas nela. Foram realizados experimentos em 30 conjuntos de dados diferentes e, apesar do número de regras geradas sempre ser muito alto, o número de regras gerais foi bem pequeno, possibilitando assim a exploração do usuário de maneira mais fácil.

Blanchard et al. (2005) propuseram uma medida para filtragem de regras baseado nos exemplos e contra-exemplos das regras. Nesse trabalho, é considerado contra-exemplo os casos em que, dado uma regra $L H S \Rightarrow R H S$, LHS ocorre e $R H S$ não, ou seja, o inverso da confiança. A medida proposta, nomeada Directed Information Ratio é apresentada na Equação 2.1, em que $\hat{\mathcal{H}}(L H S)$ é chamado de entropia reduzida de $L H S$ e $\hat{\mathcal{H}}(L H S \rightarrow$ $R H S)$ é a entropia reduzida condicional de RHS dado que $L H S$ ocorreu.

$$
D I R(L H S \Rightarrow R H S)=\frac{\hat{\mathcal{H}}(R H S)-\hat{\mathcal{H}}(L H S \rightarrow R H S)}{\hat{\mathcal{H}}(R H S)}
$$

caso $\operatorname{Sup}(R H S) \leq 0.5$ então $\hat{\mathcal{H}}(R H S)=1$, caso contrário, $\mathcal{H}(R H S)=\operatorname{Entropia}(R H S)$. Essa medida é indefinida no caso de $\operatorname{Sup}(R H S)=1$, pois $\hat{\mathcal{H}}(R H S)=0$. Nesse caso, a regra é descartada por ser considerada "óbvia" demais. Para que uma regra seja considerada informativa, o resultado da DIR precisa ser positivo. Os casos negativos são excluídos da base de regras.

Berrado e Runger (2007) propuseram uma abordagem para agrupamento e poda de regras de associação que possuem o mesmo consequente. Nesse trabalho os autores primeiro encontram meta-regras que representam o conhecimento de um conjunto de regras. Para realizar essa representação, os autores consideram cada regra gerada como um item e geram as meta-regras na forma $r l_{i} \Rightarrow r l_{j}$ en que $r l_{i}$ e $r l_{j}$ fazem parte do conjunto de regras a ser explorado. Dessa forma, os autores exploram a correlação entre as regras geradas de acordo com suporte e confiança mínimos. Após a geração, essas meta-regras são exploradas em busca de conjuntos disjuntos, visando separar as regras em diferentes grupos. Essa busca é realizada utilizando uma análise de ligação entre as regras para dividí-las em grupos. Além do uso para o agrupamento, os autores também sugerem o uso dessas meta-regras para realização da poda. Considerando as regras $r l_{i}$ e $r l_{j}$, em que o antecedente de $r l_{i}$ está contido no antecedente de $r l_{j}$, a regra $r l_{i}$ poderia ser excluída, pois a regra $r l_{j}$ é considerada mais complexa e possuidora de mais informação. Os experimentos executados demonstraram que a abordagem proposta foi capaz de reduzir o número de regras exploradas e dividir as regras de associação em diferentes grupos satisfatoriamente, 
reduzindo o espaço de exploração em até, aproximadamente, $83 \%$.

Liu et al. (2009) propuseram uma abordagem para poda de regras de associação redundantes. Primeiro os autores aplicam um algoritmo de mineração de closed-ruleset $^{1}$ no conjunto de regras de associação. Tendo esse conjunto definido, é calculado o suporte de todas as regras geradas e realizada uma ordenação de forma crescente de acordo com os valores de suporte. A última regra que, teoricamente, é a regra mais interessante é então utilizada como base para checar as outras regras geradas: se $\frac{\operatorname{Sup}(\text { Ultima } \operatorname{Regra})}{\operatorname{Sup}\left(R L_{i}\right)}$, com $i$ variando de 0 até o total de regras no closed-ruleset -1, for maior que um $k$ especificado, então a regra é mantida na base; caso contrário, ela é descartada. É importante ressaltar que quanto maior o valor de $k$, menor a quantidade de regras que irão passar pelo filtro e menos confiável será o resultado final.

Carvalho et al. (2011) propuseram uma abordagem de pós-processamento de regras de associação utilizando medidas objetivas e clustering. Inicialmente é calculado o valor de $n$ medidas objetivas em todas as regras de associação geradas. Com esse valor calculado, a abordagem seleciona as $h$ melhores regras. Então, é aplicado um algoritmo de clusterização e as regras são agrupadas de acordo com uma medida de similaridade selecionada. Após o agrupamento, é calculado o número de regras do conjunto $h$ melhores que estão em cada grupo. Se um grupo possui regras que estão entre as $h$ melhores então o grupo tende a possuir conhecimento interessante. Partindo desse princípio, é então realizado um ranqueamento dos grupos finalizado e são exibidos apenas os $m$ melhores grupos para os usuários. Esse ranqueamento é realizado de acordo com o número de regras que estão contidas no conjunto das $h$ melhores regras. Os resultados obtidos demonstram que a abordagem proposta consegue direcionar o usuário para o conhecimento potencialmente útil, utilizando como base medidas objetivas e os $m$ melhores grupos de acordo com uma dada configuração feita pelo usuário. Os resultados também mostraram que o número de regras a ser explorada caiu praticamente pela metade quando comparada com outras abordagens da literatura.

Martinez-Ballesteros et al. (2013) propuseram o uso de PCA (Principal Component Analysis) para a definição de uma função de fitness a ser otimizada por um algoritmo genético. Essa medida visa otimizar o ranqueament das regras de associação de acordo com a base de dados a ser explorada. Foi utilizado como base o trabalho de MartinezBallesteros et al. $(2011)^{2}$ e foram realizadas alterações na função de fitness, com a aplicação de PCA, para verificar quais medidas objetivas obteriam um melhor resultado. Após a verificação, foi desenvolvida uma função de fitness que visa encontrar as melhores regras, dentro de um conjunto de regras já gerado. Os resultados mostraram que a alteração na função a ser otimizada melhorou a qualidade das regras de acordo com as medidas objetivas utilizadas para validação.

Singh e Mustafi (2014) propuseram uma medida de fitness a ser otimizada por um algoritmo genético para ranqueamento de regras de associação para exibição para o usuá-

\footnotetext{
${ }^{1}$ Conjunto de regras formadas por closed itemsets

${ }^{2}$ Por ser um método de geração de regras, o trabalho não será abordado nesta dissertação.
} 
rio. A função de fitness proposta consiste em 3 medidas objetivas multiplicadas por três parâmetros a serem otimizados $(\alpha, \beta e \gamma)$. O algoritmo genético otimiza os valores dos parâmetros visando maximizar a função de fitness. Após a otimização, as regras são ranqueadas de acordo com a função de fitness e seus pesos para serem exibidas para o usuário.

As abordagens não interativas processam a base de regras de associação por meios automáticos, sem a intervenção do usuário, com o objetivo de reduzir o total de regras a serem exploradas. Essas abordagens são capazes de direcionar a exploração, porém, não são capazes de capturar o interesse do usuário. Muitas vezes o conjunto de regras que o usuário deseja explorar é um conjunto que contém apenas regras cujos itens possuem uma baixa ocorrência, dificultando assim a localização pelos meios automáticos. Visando auxiliar na exploração dessas regras, várias abordagens de pós-processamento interativas foram propostas. Essas abordagens diferem às abordagens não interativas por possibilitar que o conhecimento do usuário seja considerado. Na próxima seção algumas das abordagens interativas são apresentadas.

\section{Abordagens Interativas para Pós-Processsamento de Regras}

As abordagens interativas permitem, em pelo menos uma etapa do processamento, a intervenção do usuário adicionando o conhecimento que ele possui. Nesse tipo de abordagem, o usuário pode interagir com a abordagem de pós-processamento, fornecendo seu conhecimento, por meio de ontologias ou taxonomias, podendo também criar schemas que exigem um formalismo pré-definido para as regras e também participar ativamente das escolhas das regras interessantes ou não interessantes. Um schema de regra é uma definição que utiliza o formalismo da própria regra para definir as expectativas do usuário. Um exemplo seria um usuário que comprou algo do grupo de laticínios estar interessado agora em comprar algum item do grupo de carnes, representando o interesse da seguinte forma: (Laticínios $\Rightarrow$ Carne). Abordagens desse tipo visam direcionar a exploração para o que o usuário considera interessante, levando em consideração a subjetividade de cada um dos usuários e seus diferentes interesses. Muitas dessas abordagens também utilizam medidas objetivas ou macanismos utilizados nas abordagens não interativas; porém, nessas abordagens existe a intervenção do usuário em alguma etapa que direciona a exploração. Alguns trabalhos são descritos a seguir.

Carvalho et al. (2007) propuseram uma abordagem de exploração de regras de associação (GARPA - Generalized Association Rule Post-processing Approach) que utiliza taxonomias geradas por um especialista do domínio e generalização de regras de associação para reduzir a quantidade de regras a ser explorada pelo usuário. Antes da exploração iniciar, é necessário que o usuário defina a taxonomia do domínio. A GARPA então considera essa taxonomia para gerar as regras de associação gerais. É importante ressaltar que nessa abordagem não é necessário que todos os itens contidos na taxonomia estejam presentes na regra para que ela seja generalizada, ou seja, se o usuário define que há 5 
marcas de leite em uma base de dados e existe um conjunto de regras possui apenas 3 marcas diferentes, sendo que cada regra possui pelo menos 1 marca de leite no antecedente e compartilham o mesmo consequente, essas regras serão generalizadas mesmo sem a existência das outras 2 marcas. Para avaliar os resultados, os conjuntos finais gerados foram avaliados utilizando medidas objetivas. Os resultados mostram que, na grande maioria dos casos, a generalização conseguiu melhores resultados em comparação com o conjunto completo. Também mostrou que o lado da regra em que é realizada a generalização (apenas no LHS, apenas no RHS, tano LHS como no RHS) exerce uma grande influência no resultado final.

Rezende et al. (2009) propuseram um ambiente de exploração de regras de associação no qual o usuário ajuda na realização da filtragem das regras. Inicialmente, o ambiente funciona com a construção de um schema para selecionar as configurações de regras que podem ser consideradas interessantes pelo usuário. Após a geração, o ambiente filtra as regras de acordo com os schemas e seleciona apenas as regras que são consideradas potencialmente interessantes. Nesse ambiente, essa etapa pode não ser realizada caso o usuário não tenha uma ideia bem formada do tipo de regra que ele deseja analisar. Caso o usuário opte por não inserir informações, o ambiente mantém todo o conjunto de regras como potencialmente interessantes. Tendo o conjunto das regras potencialmente interessantes, o ambiente aplica várias medidas objetivas para realizar um ranqueamento e possibilitar uma análise. Com os resultados, é possível realizar uma análise de resultados, a partir de gráficos, para definir um ponto de corte e remover as regras que não possuem um valor mínimo para uma dada medida objetiva. Após a filtragem, o usuário analiza todas as regras resultantes, classificando-as de acordo com valores: conhecimento inesperado ou esperado; conhecimento óbvio ou não óbvio; novidade ou já conhecido e relevante ou não relevante. Caso o usuário classifique uma regra como irrelevante o usuário tem a opção de marcar o item que tornou a regra irrelevante. Caso o usuário selecione o item como irrelevante, então todas as regras que possuem aquele item serão excluídas e o usuário não precisará avaliá-las. Um estudo de caso foi realizado com o auxílio de um especialista em um conjunto com 4.122 regras resultando em um conjunto final com apenas 20 regras. Além dessa grande diminuição, durante a exploração do usuário, com a detecção de apenas 4 regras irrelevantes, foi possível remover mais 276 regras utilizando apenas a definição de itens irrelevantes pelo usuário.

Mansingh et al. (2011) propuseram uma abordagem de pós-processamento de regras de associação que utiliza ontologia para modelar o domínio e a interação com o usuário como auxílio para exploração. A abordagem inicia com a definição da ontologia do domínio. Essa definição é realizada com o auxílio do usuário, informando seu conhecimento. Com a ontologia modelada, os autores então propõem um mecanismo para dividir as regras em diferentes grupos, utilizando a medida Added_Value (av $)^{3}$. Os grupos definidos são: Novidade Alta, Conhecidas Alta, Conhecidas Baixa, Faltantes e Contraditórias. As regras

\footnotetext{
${ }^{3}$ No artigo os autores chamam a medida de reliability, porém, nesse texto é utilizada a nomenclatura adotada na Tabela 2.1
} 
do grupo Novidade Alta são regras que não estão descritas na ontologia e possuem um alto valor na medida av. Regras do grupo Conhecidas Alta ou Baixa são regras que já foram modeladas na ontologia pelo especialista e possuem valor av alto ou baixo. Regras do grupo Faltantes são regras que foram modeladas pelo especialista e não foram encontradas pelo método de geração de regras. Por fim, regras do grupo Contraditórias são regras com valores de $a v$ altos que contradizem a especificação do especialista. A divisão de valores altos ou baixos de av foi feito de acordo com um threshold informado pelo usuário. Após a geração dos grupos, o usuário analisa os grupos Contraditórias e Conhecidas Baixas, visando encontrar alguma falha na definição do threshold, de acordo com o número de regras que foram alocadas em grupos errados. Caso não seja necessário a realização de ajustes, o conhecimento adquirido é adicionado a ontologia e todo o processo pode ser executado novamente até que não haja mais novidades ou que o usuário julgue suficiente.

Sulthana e Murugeswari (2011) propuseram um framework para pós-processar as regras de associação chamado ARIPSO, o qual utiliza ontologia e schemas. O framework inicia com a definição da ontologia, em conjunto com schemas, para criar conceitos em $N$ níveis, ou seja, um conceito folha (na ponta da árvore) pode estar a 2, 3 ou N níveis de profundidade de acordo com a definição utilizada. Utilizando a definição em conjunto, é possível criar definições semânticas em que um conceito folha possui elementos da própria base enquanto os elementos em níveis superiores possuem conceitos agrupadores. Nesse trabalho, os autores propuseram 3 tipos de schemas: Impressão Geral (IG), Conhecimento Razoavelmente Preciso (CRP) e Conhecimento Preciso (CP). Os schemas do tipo IG não levam em consideração a implicação da regra nem as medidas informadas, uma vez que quaisquer regras que possuam itens com essa classificação serão consideradas interessantes. Já o tipo CRP leva em conta a implicação, ou seja, a regra deve possuir os itens definidos no antecedente e no consequente respectivamente de acordo com o schema definido. Por último os CPs, que precisam ser exatamente iguais, inclusive nas medidas informadas. Após todo o processamento, as regra são ranqueadas com o objetivo de criar um ranking final com as regras consideradas interessantes. Esse ranking auxilia o usuário na exploração do conjunto resultante, colocando as regras que podem ser mais interessantes no topo para que sejam exploradas primeiro.

Sweetlin e Kalaivani (2012) propuseram um framework para pós-processamento de regras de associação que pode ser considerado uma extensão do trabalho anterior (Sulthana e Murugeswari, 2011). O framework começa com a definição da ontologia em três tipos de conceitos: conceitos folhas, conceitos gerais e conceitos restritivos. Utilizando a análise de cesta de compras de um supermercado como exemplo, os conceitos folhas representam os itens do carrinho (leite, pão, bolacha). Os conceitos gerais são responsáveis por uma representação de grupos dos itens do carrinho (laticínios, carnes, bebidas). Os conceitos restritivos são responsáveis por representar os conceitos mais individuais de cada usuário de acordo com os outros conceitos (Saudável, Ruim, Gostoso). Após modelar todos os itens da base de dados nos conceitos definidos, o usuário então deve definir os schemas. 
Com essas definições, os filtros são aplicados nas regras de associação, excluindo as regras que não satisfazem as restrições dos schemas e mantendo apenas as que satisfazem, as quais são denominadas regras interessantes. É realizado um filtro nas regras de associação consideradas interessantes, excluindo todas as regras que possuem um valor de lift (Tabela 2.1) menor que 1, ou seja, as regras que não possuem correlação forte. Após a filtragem pelo lift, o framework, denominado UPACBR, começa uma busca por regras que possuem o mesmo conhecimento. Mantendo o exemplo do carrinho de supermercado, se o processo mantivesse as regras $\{$ pão $\Rightarrow$ leite; carne $\Rightarrow$ leite; pão, carne $\Rightarrow$ leite $\}$ então a regra pão, carne $\Rightarrow$ leite seria removida pois é possível chegar nela a partir das duas regras anteriores. Sweetlin e Kalaivani (2012) realizaram experimentos em uma base de dados que possuía 4.627 transações e 39 itens distintos, gerando um total de 2.755 regras de associação. Após modelar a ontologia e definir os schemas, as regras foram processadas e o total de regras foi reduzida para 399, sendo esse conjunto não redundante. O resultado foi comparado com o framework proposto por Sulthana e Murugeswari (2011) e conseguiu um número de regras ainda menor como resultado final.

As abordagens interativas permitem que o usuário adicione seu conhecimento visando melhorar a exploração, permitem também que seu interesse seja considerado direcionando assim a exploração das regras. Essa interação é realizada previamente, por meio de algum formalismo, sendo necessário que o usuário possua conhecimento prévio do domínio que será explorado e também do objetivo de sua exploração. As abordagens disponíveis na literatura demonstraram-se capazes de direcionar a exploração do domínio de acordo com o interesse previamente informado pelo usuário, porém, em alguns casos o usuário não sabe exatamente o que quer encontrar na base de dados ou apenas quer realizar uma análise exploratória de acordo com as características da base. Visando auxiliar nessa exploração, foi proposto neste mestrado uma abordagem interativa e iterativa de pós-processamento que sugere regras para serem exploradas de acordo com a sua importância na base de regras e realiza uma exploração de acordo com a similaridade das regras consideradas interessante. Para que essa exploração seja possível, é necessário que sejam definidas medidas de similaridade entre regras de associação, algumas medidas são apresentadas na próxima seção.

\section{Medidas de Similaridade de Regras de Associação}

Em alguns tipos de abordagem de pós-processamento, como nas abordagens de agrupamento por exemplo, é necessário que medidas de similaridades sejam definidas. Essas medidas são responsáveis por criar um valor de similaridade (que pode ser transformado em distância) entre as regras, para que as abordagens consigam dividir o domínio em diferentes grupos. Além do uso em agrupamento, medidas de similaridade podem ser utilizadas para construir redes, conforme discutido na próxima seção. Existem várias medidas de similaridade na literatura, as quais podem ser divididas em dois grandes grupos: as similaridades voltadas aos itens e as simularidades voltadas à cobertura. Medidas de 
similaridade de itens analisam a similaridade entre duas regras de acordo com os itens que as compõem, desconsiderando a cobertura de cada uma das regras. Já as medidas de similaridade de cobertura calculam a similaridade de acordo com as transações que as regras compartilham, verificando a similaridade na base de dados. Existem também algumas medidas que encontram-se na intersecção desses grupos, ou seja, realizam o cálculo considerando a similaridade entre os itens e a cobertura das regras. É necessário mencionar que alguns trabalhos calculam a distância entre as regras e não a similaridade. Dessa forma, as regras com menor distância são consideradas as mais similares. Algumas dessas medidas são explicadas a seguir.

Toivonen et al. (1995) utilizam uma medida baseado na distância dos suportes em regras que possuem o mesmo consequente. A medida é exibida na Equação 2.2, em que $\operatorname{Sup}\left(R L_{i}\right)$ retorna o suporte de $R L_{i}$. Essa medida calcula a distância das regras de acordo com a cobertura nas transações, medindo a diferença entre a quantidade de transações que geraram as regras em comparação. Essa medida resulta em valores entre 0 e 1, sendo que resultados iguais a 0 significam que todas as transações cobertas por $R L_{i}$ também são cobertas por $R L_{j}$ e todas as transações cobertas por $R L_{j}$ também são cobertas por $R L_{i}$, ou seja, as duas regras foram geradas pelo mesmo conjunto de transações. Valores iguais a 1 significam que as regras não compartilham transações.

$$
\operatorname{Dist}\left(R L_{i}, R L_{j}\right)=\operatorname{Sup}\left(R L_{i}\right)+\operatorname{Sup}\left(R L_{j}\right)-2 \operatorname{Sup}\left(R L_{i} \cap R L_{j}\right)
$$

Gupta et al. (1999) utilizam uma medida de distância baseada na cobertura das regras, conforme exibido na Equação 2.3, em que $\# \mathrm{~T}\left(R L_{i}\right)$ retorna o número de transações cobertas por $R L_{i}$. Dessa forma, a equação calcula a similaridade variando entre $0 \mathrm{e}$ 1 na fração e subtrai o valor obtido de 1, convertendo o valor em distância entre as regras. Regras totalmente similares (com similaridade igual a 1) receberão distância 0 , significando que essas regras foram geradas pelo mesmo conjunto de transações.

$$
\operatorname{Dist}\left(R L_{i}, R L_{j}\right)=1-\frac{\# T\left(R L_{i} \cup R L_{j}\right)}{\# T\left(R L_{i}\right)+\# T\left(R L_{j}\right)-\# T\left(R L_{i} \cup R L_{j}\right)}
$$

Reynolds et al. (2006) utilizam como cálculo de distância as transações que são cobertas apenas por uma regra, utilizando o operador lógico xor. É possível visualizar a medida na Equação 2.4, em que $\oplus$ é o operador ou exclusivo (xor). Nessa medida proposta, a distância entre as regras é igual ao total de transações que cobrem apenas uma das regras.

$$
\operatorname{Dist}\left(R L_{i}, R L_{j}\right)=\#\left(T\left(R L_{i}\right) \oplus T\left(R L_{j}\right)\right)
$$

Nesse mesmo trabalho é exibida uma variação dessa medida para ser utilizada como medida de similaridade, exibida na Equação 2.5.

$$
\operatorname{Jaccard}\left(R L_{i}, R L_{j}\right)=\frac{\#\left(T\left(R L_{i}\right) \cap T\left(R L_{j}\right)\right)}{\#\left(T\left(R L_{i}\right) \cup T\left(R L_{j}\right)\right)}
$$


Essa medida considera o número de transações cobertas por ambas as regras e divide pelo total de transações cobertas pelas regras separadamente. A medida possui valores entre 0 e 1 , sendo que valores iguais a 1 são para regras que compartilham todas as transações e valores igual a 0 para regras que não compartilham nenhuma transação.

Jorge (2004) utiliza uma medida de similaridade considerando os itens que fazem parte da regra. A medida é exibida na Equação 2.6. Nessa medida, calcula-se o número de itens em comum nas regras e divide-se pelo total de itens distintos. Dessa forma, regras que possuem exatamente os mesmos itens, independentemente da ordem em que aparecem, sempre receberão valor de similaridade 1, enquanto regras que não compartilham itens recebem valor 0 .

$$
\operatorname{Jaccard}\left(R L_{i}, R L_{j}\right)=\frac{\#\left(R L_{i} \cap R L_{j}\right)}{\#\left(R L_{i} \cup R L_{j}\right)}
$$

Sahar (2002) propôs uma medida de distância entre regras que considera tanto a cobertura da regra quanto a diferença entre os itens. A distância é exibida na Equação 2.7, em que $\operatorname{diff} \sup \left(R L_{i}, R L_{j}\right)=\operatorname{Sup}\left(R L_{i}\right)+\operatorname{Sup}\left(R L_{j}\right)-2 \operatorname{Sup}\left(R L_{i} \cup R L_{j}\right)$. Nesses casos, o valor 1 é adicionado na primeira parte de cada termo para atender os casos em que diffsup $=0$ e $R L_{i} \oplus R L_{j} \neq 0$. Na segunda parte da equação, o gamma de cada termo é definido de acordo com o resultado da equação. Por exemplo, caso esteja sendo calculado $\operatorname{Dist}\left(R L_{i}, R L_{j}\right)$, exibindo apenas um termo, fração ficaria $\frac{\#\left(R L_{i} \oplus R L_{j}\right)}{\#\left(R L_{i} \cup R L_{j}\right)} \gamma_{x}$. Nesse caso, $\gamma_{x}$ receberá $\frac{1}{2}$ se $R L_{i} \subset R L_{j}$ ou $R L_{j} \subset R L_{i}$, ou $\gamma_{x}$ receberá 1 caso contrário. Esse valor de gama vale para todos os termos da equação, cada qual considerando a fração que multiplica o respectivo gamma. A principal diferença dessa medida é que ela considera não somente a diferença de cobertura das regras como também a diferença entre os itens contidos em cada uma das regras.

$$
\begin{gathered}
\operatorname{Dist}\left(R_{i}, R_{j}\right)=\left[1+\operatorname{diffsup}\left(\operatorname{LHS}\left(R_{i}\right), \operatorname{LHS}\left(R_{j}\right)\right) \frac{\#\left(\operatorname{LHS}\left(R_{i}\right) \oplus \operatorname{LHS}\left(R_{j}\right)\right)}{\#\left(\operatorname{LH}\left(R_{i}\right) \cup \operatorname{LHS}\left(R_{j}\right)\right)} \gamma_{1}\right]+ \\
{\left[1+\operatorname{diffsup}\left(\operatorname{RHS}\left(R_{i}\right), \operatorname{RHS}\left(R_{j}\right)\right) \frac{\#\left(R H S\left(R_{i}\right) \oplus R H S\left(R_{j}\right)\right)}{\#\left(R H S\left(R_{i}\right) \cup R H S\left(R_{j}\right)\right)} \gamma_{2}\right]+} \\
{\left[1+\operatorname{diffsup}\left(R_{i}, R_{j}\right) \frac{\#\left(R_{i} \oplus R_{j}\right)}{\#\left(R_{i} \cup R_{j}\right)} \gamma_{3}\right]}
\end{gathered}
$$

Observando as medidas descritas, é possível verificar que a maioria delas não considera a implicação da regra ao calcular a similaridade ou a distância, calculando os valores sob o itemset que gerou a regra. Uma exceção deve ser feita a medida proposta por Sahar (2002), que aplica a medida no antecedente, consequente e depois na regra como um todo, considerando como parte do valor final as partes separadas das regras. 
Validações Utilizadas na Literatura

Nos trabalhos descritos anteriormente, tanto nas abordagens interativas quanto nas abordagens não interativas, nota-se que a validação dos resultados varia de autor para autor. Alguns autores consideram a redução no número de regras como meio de validação; outros comparam o valor das medidas objetivas antes e depois da aplicação da abordagem; alguns outros validam sua abordagem com ajuda do especialista. Na Tabela 2.2 é possível visualizar algumas de formas de validações com seus respectivos trabalhos. Todos os trabalhos da tabela foram descritos anteriormente com excessão de alguns que possuem validação similar. Essa omissão ocorre pois o objetivo da tabela é exibir diversas validações utilizadas e não reforçar algumas.

Observa-se que não há uma medida de avaliação amplamente aceita na literatura, ficando a validação da abordagem a cargo de cada autor. Dessa forma, alguns autores utilizam medidas objetivas para validar o resultado final de suas abordagens, comparando a média de uma ou mais medidas antes e depois da aplicação da abordagem, analisando dessa forma o ganho final. Nesses casos, os autores discutem os ganhos de acordo com o objetivo das medidas escolhidas. Alguns outros autores consideram a diminuição do número de regras e o tempo de execução, discutindo somente a quantidade de regras que serão analisadas pelo usuário e o tempo que o usuário necessita esperar até obter o resultado final. Por fim, alguns autores testam suas abordagens com especialistas, aplicando a abordagem em bases de dados de interesse do usuário e obtendo uma análise de novidade, facilidade e usabilidade. Essa é a validação mais cara e mais complexa de se obter.

\subsubsection{Considerações Finais sobre Regras de Associação}

Nesta seção foi realizada uma revisão bibliográfica dos principais conceitos que motivaram o desenvolvimento deste mestrado. Iniciou-se com a definição de regras de associação e seus conceitos, apontando alguns trabalhos na área e a importância dessa área de pesquisa. Após essa explicação, foi então tratado o problema do alto número de regras geradas, que dificulta o processo de exploração do conhecimento obtido. Foram discutidos trabalhos que pós-processam os resultados, visando encontrar o conjunto de regras considerado mais interessantes, para que não seja necessário explorar todo o conjunto resultante de regras. Na discussão dos trabalhos de pós-processamento foi levantado o problema de não ter sido encontrado abordagens que utilizem o conhecimento durante o pós-processamento, sendo as abordagens que consideram o conhecimento do usuário o fazendo de forma prévia, antes do processo iniciar. As abordagens interativas foram descritas na Seção 2.1.2, é possível observar que essas abordagens exigem um conhecimento prévio do usuário no domínio a ser explorado e também exigem que o usuário já saiba, previamente, qual o conhecimento que ele deseja obter. Nem sempre o usuário possui o interesse da exploração bem definido ou as vezes o usuário deseja explorar as regras mais 
Tabela 2.2: Tabela de validações utilizadas na literatura.

\begin{tabular}{|c|c|}
\hline Referência & Validação \\
\hline Liu et al. (1999) & $\begin{array}{l}\text { O método foi aplicado em } 30 \text { bases. Foi analisado a quantidade } \\
\text { de regras restantes, que serão exibidas para o usuário explorar, } \\
\text { avaliando a redução do espaço de busca. }\end{array}$ \\
\hline $\begin{array}{l}\text { Berrado e Run- } \\
\text { ger }(2007)\end{array}$ & $\begin{array}{l}\text { O método foi aplicado em } 7 \text { bases. Foi realizada uma análise no } \\
\text { impacto do agrupamento das regras na sumarização. O objetivo } \\
\text { principal de análise foi a redução total de regras a serem exploradas. }\end{array}$ \\
\hline $\begin{array}{l}\text { Carvalho et al. } \\
(2007)\end{array}$ & $\begin{array}{l}\text { O método foi aplicado em } 2 \text { bases. Foram utilizadas } 20 \text { medidas } \\
\text { para análise da abordagem, realizando o cálculo antes e depois da } \\
\text { aplicação da abordagem proposta e analisando a melhora nos valo- } \\
\text { res. }\end{array}$ \\
\hline Liu et al. (2009) & $\begin{array}{l}\text { O método foi aplicado em } 11 \text { bases e comparado com } 3 \text { outras abor- } \\
\text { dagens da literatura. Os autores então realizam uma discussão na } \\
\text { quantidade de regras que serão exibidas para o usuário com Zaki } \\
\text { (2004) e Berrado e Runger (2007) e o tempo de execução do método } \\
\text { com Berrado e Runger (2007). A abordagem de Zaki (2004) não } \\
\text { será explicada neste trabalho pois atua na geração de regras e não } \\
\text { no pós-processamento. }\end{array}$ \\
\hline $\begin{array}{l}\text { Rezende et al. } \\
(2009)\end{array}$ & $\begin{array}{l}\text { Foi realizado um estudo de caso em uma base de qualidade de vida } \\
\text { urbana, avaliando o resultado com a ajuda de um especialista. O } \\
\text { especialista realizou todo o processo e foram discutido o impacto } \\
\text { a interação do usuário no resultado final e o total de regras que o } \\
\text { usuário necessitou validar. }\end{array}$ \\
\hline $\begin{array}{l}\text { Mansingh et al. } \\
(2011)\end{array}$ & $\begin{array}{l}\text { Foi realizado um estudo de caso em uma base de dados na área mé- } \\
\text { dica com especialista da área. Foram realizadas análises utilizando } \\
\text { o conhecimento que o usuário já possuia e o conhecimento que a } \\
\text { abordagem classificou como interessante, assim como uma análise } \\
\text { do conhecimento novo. }\end{array}$ \\
\hline $\begin{array}{l}\text { Sulthana e Mu- } \\
\text { rugeswari (2011) }\end{array}$ & $\begin{array}{l}\text { Há uma discussão teórica sobre a abordagem justificando as etapas } \\
\text { e os possíveis ganhos. }\end{array}$ \\
\hline $\begin{array}{l}\text { Sweetlin e Kalai- } \\
\text { vani }(2012)\end{array}$ & $\begin{array}{l}\text { Foi realizado um experimento em uma base de dados e comparado } \\
\text { com Sulthana e Murugeswari (2011). Na análise dos autores, o } \\
\text { método proposto exibiu um menor número de regras a ser explorada } \\
\text { pelo usuário. }\end{array}$ \\
\hline $\begin{array}{l}\text { Martinez- } \\
\text { Ballesteros } \\
\text { et al. }(2013)\end{array}$ & $\begin{array}{l}\text { Foi realizado um experimento em } 15 \text { bases. São aplicadas } 4 \text { me- } \\
\text { didas objetivas no conjunto final de regras e é realizado um teste } \\
\text { estatístico para verificar se o método proposto é estatisticamente } \\
\text { superior aos métodos utilizados como base. }\end{array}$ \\
\hline $\begin{array}{l}\text { Singh e Mustafi } \\
(2014)\end{array}$ & $\begin{array}{l}\text { O experimento foi realizado em } 1 \text { base. É realizada uma compa- } \\
\text { ração com um ranqueamento realizado utilizando apenas suporte e } \\
\text { confiança e também são analisadas as diferenças entre os ranquea- } \\
\text { mentos gerados pelas diferentes medidas. }\end{array}$ \\
\hline
\end{tabular}

livremente, de acordo com a importância das regras no conjunto total. Esse problema de obter o conhecimento do usuário durante o pós-processamento das regras foi abordado neste mestrado e a solução proposta será explicada no Capítulo 3. Para o desenvolvimento 
da solução, foi necessário utilizar redes e algoritmos de propagação de rótulos, que são explicados na próxima seção.

\subsection{Redes}

Uma rede pode ser caracterizada como um conjunto de objetos e as relações entre eles. Formalmente uma rede pode ser representada por $\mathrm{R}=(\mathrm{V}, \mathrm{E}, \mathrm{P})$ no qual $\mathrm{V}$ são os nós ${ }^{4}$ da rede, E são as conexões entre os vértices e $\mathrm{P}$ o peso das conexões.

Em geral, qualquer conjunto de dados pode ser representado como uma coleção de objetos conectados via redes, podendo as conexões serem explícitas, como a Web, ou implícitas, sendo necessário, nesses casos, o uso de medidas para se extrair essas relações. Essas conexões ${ }^{5}$ geralmente exibem padrões que podem indicar propriedades da base de dados como a importância, o ranking ou a categoria dos objetos. Os objetos das redes podem ser do mesmo tipo ou de tipos diferentes, gerando dois tipos de redes, a saber: redes homogêneas e redes heterogêneas. Redes homogêneas são redes em que os objetos que a compõe são de apenas um tipo e as ligações entre eles também. Exemplos de redes homogêneas incluem redes sociais simples, em que há conexão apenas entre pessoas com vínculo de amizade, ou a WWW, que possui ligação entre várias páginas. Redes heterogêneas são redes que possuem objetos de tipos diferentes e/ou diferentes tipos de conexões. Exemplos de redes heterogêneas incluem mecanismos contendo sites e consultas, redes sociais mais complexas, com conexões entre pessoas, eventos e gostos pessoais.

Para que uma rede (ou um grafo) ${ }^{6}$ seja descrita de forma geral, três itens são necessários:

- uma lista de nós;

- uma lista de conexões;

- pesos das conexões.

Os nós podem ter rótulos e propriedades associadas, dependendo do objetivo da rede. Porém, para que uma rede básica seja descrita, essas propriedades extras não são necessárias. Já as arestas podem também possuir propriedades extras, tal como utilizar mais de um peso por conexão entre os nós, fazendo com que a mesma conexão possua diferentes importâncias de acordo com cada peso. No caso mais simples o peso possui o valor fixo 1 quando há conexão entre dois nós e 0 quando a conexão é inexistente.

Nesta seção é realizada uma revisão bibliográfica na área de redes e propagação de rótulos. Na Seção 2.2.1 são definidos os conceitos básicos de redes e apresentados os divertos tipos de redes existentes na literatura. Na Seção 2.2.2 são apresentadas técnicas para otimizar a construção das redes, com o objetivo de melhorar o desempenho das

\footnotetext{
${ }^{4}$ Nesse texto, nós e vértices são utilizados como semelhantes

${ }^{5}$ Neste texto, conexões, links e arestas são utilizados como sinônimos

${ }^{6}$ Neste texto, redes e grafos são utilizados como sinônimos.
} 
técnicas de processamento. Na Seção 2.2.3 são apresentadas e discutidas algumas medidas de processamento de rede disponíveis na literatura. Na Seção 2.2.4 são apresentados alguns algoritmos de propagação de rótulos, visando dois tipos de redes especifícas, são apenas analisadas esses dois tipos de redes por serem utilizadas neste mestrado.

\subsubsection{Definições e Conceitos de Redes}

Segundo Newman (2010) o modo mais trivial de se representar uma rede é por meio de uma matriz de adjacência. Nesse caso, numera-se os nós, de 1 até $n$, para tratá-los como índices da matriz $n \times n$. Essa matriz controla os vínculos entre os nós da rede: caso haja uma conexão entre um nó $V_{x}$ e um nó $V_{y}$, a posição $\mathbf{W}_{x y}$ na matriz de adjacência $\mathbf{W}$ possuirá o valor 1; caso não haja conexão entre esses dois nós essa posição possuirá o valor 0. Na Figura 2.1(a) é ilustrada uma rede com suas ligações. Nessa rede é considerado que cada ligação possui peso único, ou seja, 1 . Na Tabela 2.3 é exibida como a matriz de adjacência é representada. É importante ressaltar que em casos de redes que não possuem auto arestas (nós que possuem ligação com ele mesmo), a diagonal é zero. Já na Figura 2.1(b) é apresentada uma rede com multiplas ligações e auto arestas. A matriz de adjacência é representada na Tabela 2.4. As matrizes de adjacência, tanto da rede 1 quanto da rede 2, são simétricas, o que significa que essa rede é não direcionada, ou seja, se existe uma conexão do vértice $j$ para o vértice $i$ então existe, obrigatoriamente, uma conexão de $i$ para $j$. É importante ressaltar o valor 2 para a diagonal da matriz em casos de auto aresta, conforme é possível visualizar na Tabela 2.4 com o vértice $f$. Nesse caso, de existir uma única conexão o peso atribuído é 2, pois a rede é uma rede não direcionada, ou seja, não existe ponto de saída de conexão nem de entrada definidos, fazendo com que cada ponta dessa conexão seja considerada como saída e como entrada.

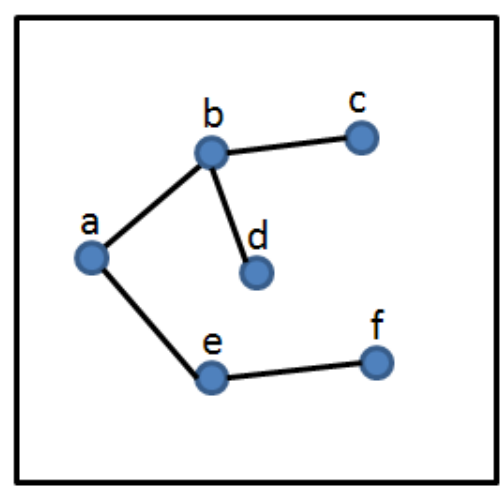

(a) Rede simples.

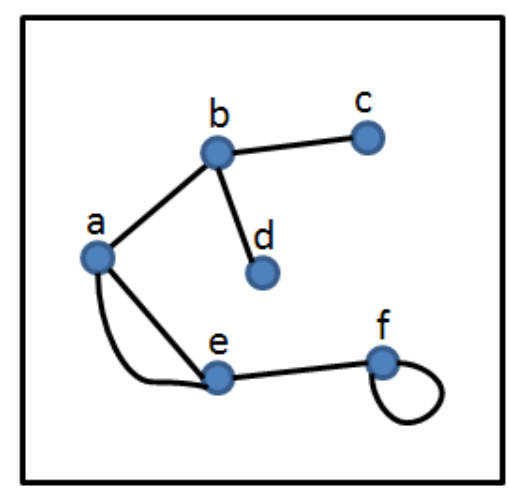

(b) Rede com auto arestas.

Figura 2.1: Representação de redes não direcionadas.

Uma variação desse tipo de conexão é a rede direcionada. Uma rede direcionada é uma rede em que cada ligação possui uma direção, apontando de um vértice para outro. Essas ligações são chamadas de arestas direcionadas, e podem ser representadas por linhas com setas, conforme ilustrado na Figura 2.2. Da mesma forma que redes não direcionadas 
Tabela 2.3: Matriz de adjacência referente a rede da Figura 2.1(a).

\begin{tabular}{|c|c|c|c|c|c|c|}
\hline & $\mathrm{a}$ & $\mathrm{b}$ & $\mathrm{c}$ & $\mathrm{d}$ & $\mathrm{e}$ & $\mathrm{f}$ \\
\hline $\mathrm{a}$ & 0 & 1 & 0 & 0 & 1 & 0 \\
\hline $\mathrm{b}$ & 1 & 0 & 1 & 1 & 0 & 0 \\
\hline $\mathrm{c}$ & 0 & 1 & 0 & 0 & 0 & 0 \\
\hline $\mathrm{d}$ & 0 & 1 & 0 & 0 & 0 & 0 \\
\hline $\mathrm{e}$ & 1 & 0 & 0 & 0 & 0 & 1 \\
\hline $\mathrm{f}$ & 0 & 0 & 0 & 0 & 1 & 0 \\
\hline
\end{tabular}

Tabela 2.4: Matriz de adjacência referente a rede da Figura 2.1(b).

\begin{tabular}{|c|c|c|c|c|c|c|}
\hline & $\mathrm{a}$ & $\mathrm{b}$ & $\mathrm{c}$ & $\mathrm{d}$ & $\mathrm{e}$ & $\mathrm{f}$ \\
\hline $\mathrm{a}$ & 0 & 1 & 0 & 0 & 2 & 0 \\
\hline $\mathrm{b}$ & 1 & 0 & 1 & 1 & 0 & 0 \\
\hline $\mathrm{c}$ & 0 & 1 & 0 & 0 & 0 & 0 \\
\hline $\mathrm{d}$ & 0 & 1 & 0 & 0 & 0 & 0 \\
\hline $\mathrm{e}$ & 2 & 0 & 0 & 0 & 0 & 1 \\
\hline $\mathrm{f}$ & 0 & 0 & 0 & 0 & 1 & 2 \\
\hline
\end{tabular}

podem ser representadas por uma matriz de adjacência, as redes direcionadas também podem. Os elementos da matriz de adjacência de uma rede direcionada são definidos na Equação 2.8.

$$
W_{i j}= \begin{cases}1 & \text { se existe uma conexão saindo de } i \text { levando a } j \\ 0 & \text { caso contrário. }\end{cases}
$$

Uma rede direcionada é ilustrada na Figura 2.2 e a sua representação como matriz de adjacência na Tabela 2.5. A matriz de adjacência para redes direcionadas é assimétrica. Essas redes também podem possuir várias conexões entre dois pontos e auto arestas. A diferença entre elas é que nas redes direcionadas, quando um nó possui uma auto aresta, é adicionado o valor 1 e não 2, como anteriormente, pois no caso de redes direcionadas são definidos os pesos de entrada e saída das conexões; já as redes não direcionadas não possuem essa definição, contando então 1 conexão para cada uma das pontas da auto aresta.

Além de redes que possuem peso binário para cada ligação, existem também um tipo

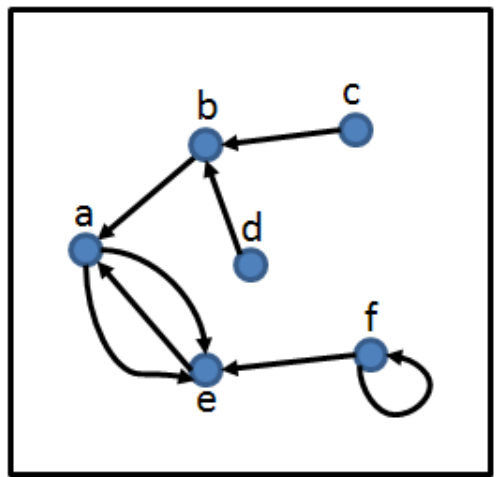

Figura 2.2: Rede direcionada. 
Tabela 2.5: Representação da rede da Figura 2.2 como matriz de adjacência.

\begin{tabular}{|c|c|c|c|c|c|c|}
\hline & $\mathrm{a}$ & $\mathrm{b}$ & $\mathrm{c}$ & $\mathrm{d}$ & $\mathrm{e}$ & $\mathrm{f}$ \\
\hline $\mathrm{a}$ & 0 & 0 & 0 & 0 & 2 & 0 \\
\hline $\mathrm{b}$ & 1 & 0 & 0 & 0 & 0 & 0 \\
\hline $\mathrm{c}$ & 0 & 1 & 0 & 0 & 0 & 0 \\
\hline $\mathrm{d}$ & 0 & 1 & 0 & 0 & 0 & 0 \\
\hline $\mathrm{e}$ & 1 & 0 & 0 & 0 & 0 & 0 \\
\hline $\mathrm{f}$ & 0 & 0 & 0 & 0 & 1 & 1 \\
\hline
\end{tabular}

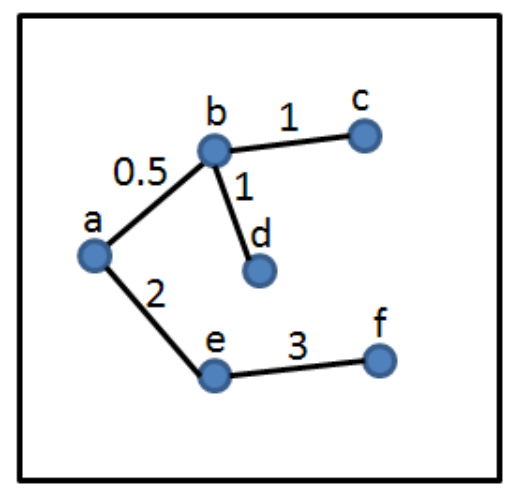

Figura 2.3: Rede com pesos.

de rede na qual as ligações possuem pesos reais, ou seja, caso haja uma ligação entre $i$ e $j$ a matriz não terá o valor 1 e sim um valor real denotando a força da ligação. Essa força de ligação pode representar, por exemplo, o fluxo de dados entre sites, o fluxo de energia entre predador e presa, a frequência de contato em uma rede social, etc. Um exemplo de matriz de adjacência pode ser vista na Tabela 2.6, que representa a Figura 2.3. Essa matriz possui alguns indicadores, por exemplo, a conexão entre $a$ e $e$ (valor de ligação é 2) é quatro vezes mais forte do que a conexão entre $a$ e $b$; já a conexão entre $e$ e $f$ pode ser considerada a mais importante da rede toda.

Tabela 2.6: Matriz de adjacência com pesos, utilizando como base a Figura 2.3.

\begin{tabular}{|c|c|c|c|c|c|c|}
\hline & $\mathrm{a}$ & $\mathrm{b}$ & $\mathrm{c}$ & $\mathrm{d}$ & $\mathrm{e}$ & $\mathrm{f}$ \\
\hline $\mathrm{a}$ & 0 & 0.5 & 0 & 0 & 2 & 0 \\
\hline $\mathrm{b}$ & 0.5 & 0 & 1 & 1 & 0 & 0 \\
\hline $\mathrm{c}$ & 0 & 1 & 0 & 0 & 0 & 0 \\
\hline $\mathrm{d}$ & 0 & 1 & 0 & 0 & 0 & 0 \\
\hline $\mathrm{e}$ & 2 & 0 & 0 & 0 & 0 & 3 \\
\hline $\mathrm{f}$ & 0 & 0 & 0 & 0 & 3 & 0 \\
\hline
\end{tabular}

Essa configuração de conexões com peso pode ser utilizada com qualquer configuração de rede, ou seja, redes direcionadas, não direcionadas e até mesmo em redes com várias conexões entre os mesmos vértices. $\mathrm{O}$ fato de adicionar peso a uma determinada conexão não impede que haja outra conexão entre os mesmos pontos. No final, esses pesos podem ser somados e considerados como peso final ou podem ser tratados como duas conexões distintas. Vale ressaltar que os pesos não precisam ser, obrigatoriamente, positivos. Em casos como rede sociais, pesos negativos podem representar animosidade, antipatia, etc. 
Em outras configurações de rede, pesos negativos podem denotar diferença entre os vértices, ou seja, vértices conectados por uma aresta com peso negativo possuem menos chance de acontecer do que elementos que não possuem ligação (peso 0).

Além dessas modelagens, existe também uma matriz com cálculo diferenciado, utilizada principalmente no particionamento de redes. Essa matriz é chamada de Matriz Laplaciana (Fritscher et al., 2011), que é outra forma de representar uma rede por meio de uma matriz. Essa matriz é calculada de forma que todos os seus autovalores sejam positivos. A matriz laplaciana de uma rede pode ser calculada conforme Equação 2.9, em que D é uma matriz no qual a diagonal é o número de conexões de saída de cada vértice e W é a matriz de adjacência. Utilizando como exemplo a Figura 2.1(a) a Tabela 2.7 é a representação da rede em uma matriz laplaciana.

$$
L=D-W
$$

Tabela 2.7: Matriz Laplaciana calculada com base na Figura 2.1(a).

\begin{tabular}{|c|c|c|c|c|c|c|}
\hline & $\mathrm{a}$ & $\mathrm{b}$ & $\mathrm{c}$ & $\mathrm{d}$ & $\mathrm{e}$ & $\mathrm{f}$ \\
\hline $\mathrm{a}$ & 2 & -1 & 0 & 0 & -1 & 0 \\
\hline $\mathrm{b}$ & -1 & 3 & -1 & -1 & 0 & 0 \\
\hline $\mathrm{c}$ & 0 & -1 & 1 & 0 & 0 & 0 \\
\hline $\mathrm{d}$ & 0 & -1 & 0 & 1 & 0 & 0 \\
\hline $\mathrm{e}$ & -1 & 0 & 0 & 0 & 2 & -1 \\
\hline $\mathrm{f}$ & 0 & 0 & 0 & 0 & -1 & 1 \\
\hline
\end{tabular}

Alguns tipos de redes possuem ligações que englobam mais de 2 elementos, ou seja, uma única ligação que une 3 ou mais vértices. Um exemplo seria a representação de uma família em uma rede social. As famílias normalmente são constituídas por mais de uma pessoa, fazendo-se necessário um outro tipo de aresta para conectar as pessoas. Essas arestas são chamadas de hiperarestas. Uma rede que possui hiperarestas é chamada de hipergrafo (Newman e Girvan, 2004). Um exemplo de um hipergrafo pode ser visualizado na Figura 2.4. Nessa figura é possível visualizar 3 hiperarestas e 1 aresta convencional: a aresta convencional que une os vértices 1 e 4 é identificada por uma linha pontilhada; já as 3 hiperarestas unem mais que 2 vértices. Uma das hiperarestas une os vértices 3 , 4 e 5. Essa hiperaresta é identificada por uma linha tracejada com traços longos. Outra hiperaresta une os pontos 1, 2, 3 e 4 e é identificada por uma linha contínua; a última une os pontos 2, 3 e 5 e é identificada por uma linha com um tracejado menor.

Outra forma de representar várias conexões simultaneas é por meio de redes bipartidas. Redes bipartidas são redes que possuem dois tipos de vértices: um deles representa os vértices originais da rede e o outro tipo representa os grupos que cada vértice pertence. Nesse tipo de rede as conexões somente existem entre vértices de tipos diferentes, ou seja, não existem conexões entre os vértices originais da rede nem entre os grupos definidos, fazendo com que os vértices originais apenas pertençam aos grupos e os grupos não sejam conectados entre si. A vantagem de se utilizar uma rede bipartida é que a diferença 


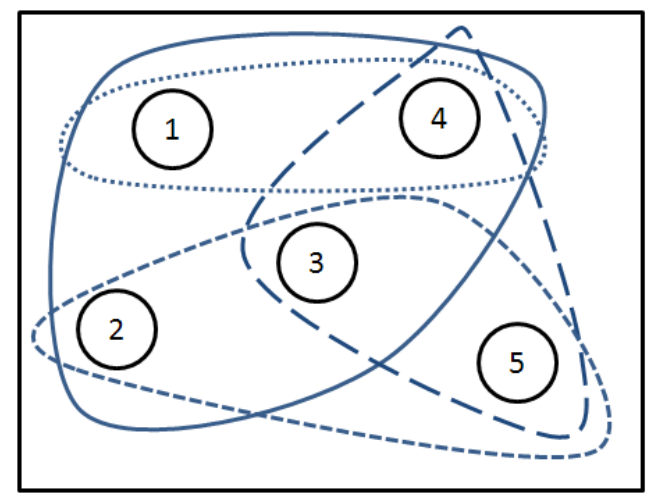

Figura 2.4: Representação de um hipergrafo

Fonte: (Newman e Girvan, 2004).

existente entre os vértices (agrupadores e elementos) está na estrutura da rede, ou seja, existem vértices do tipo elemento e vértices agrupadores, diferente de redes convencionais, que podem também possuir vértices variados, porém, os mesmos não apresentam uma diferenciação na estrutura da rede. Esse tipo de diferenciação visa reunir a rede em uma configuração de membros, ou seja, reúne em pequenos grupos membros de um determinado elemento agrupador. Esse tipo de rede é bastante utilizada como outra forma de representar um hipergrafo, conectando todos os vértices de uma hiperaresta em um mesmo grupo, conforme pode ser visto na Figura 2.5.

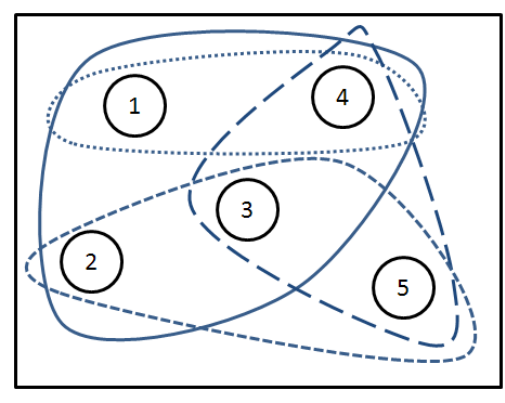

(a) Hipergrafo (Newman e Girvan, 2004).

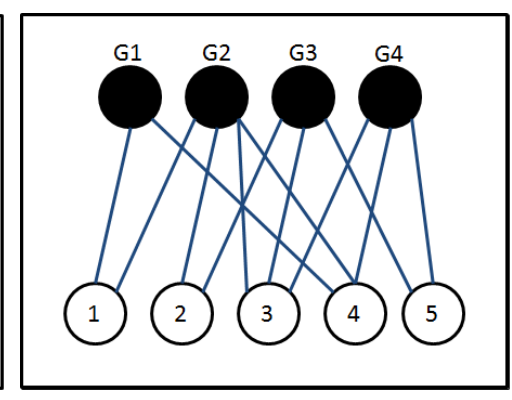

(b) Representação do hipergrafo utilizando rede bipartida (Newman e Girvan, 2004).

Figura 2.5: Um hipergrafo e suas hiperarestas (esquerda) e sua representação como rede bipartida (direita)

Para representar uma rede bipartida é utilizada uma matriz equivalente a uma matriz de adjacência, porém retangular, chamada de matriz de incidência, sendo $n$ o número de objetos dessa rede e $g$ o número de grupos. Desse modo, $\mathrm{B}$ é uma matriz $n \mathrm{x} g$ tendo elementos $B_{i j}$ preenchidos de acordo com a Equação 2.10.

$$
B_{i j}= \begin{cases}1 & \text { se o vértice } j \text { pertence ao grupo } i \\ 0 & \text { caso contrário. }\end{cases}
$$

Portanto, a matriz de incidência referente a rede exibida na Figura 2.5 é representada conforme exibido na Tabela 2.8.

Nessa seção foram explicados os conceitos básicos de redes, bem como algumas de 
Tabela 2.8: Matriz de incidência calculada como base a rede da Figura 2.5.

\begin{tabular}{|c|c|c|c|c|}
\hline & $G_{1}$ & $G_{2}$ & $G_{3}$ & $G_{4}$ \\
\hline 1 & 1 & 1 & 0 & 0 \\
\hline 2 & 0 & 1 & 1 & 0 \\
\hline 3 & 0 & 1 & 1 & 1 \\
\hline 4 & 1 & 1 & 0 & 1 \\
\hline 5 & 0 & 0 & 1 & 1 \\
\hline
\end{tabular}

suas construções. Na literatura existem técnicas que são capazes de otimizar a construção dessas redes, criando conexões mais relacionadas e ponderando os pesos. Essas técnicas serão explicadas na próxima seção.

\subsubsection{Técnicas para Construção de Redes}

A etapa de modelagem das redes visa gerar as conexões entre os vértices de acordo com a similaridade existente entre eles. Para realizar essa modelagem, algumas técnicas são utilizadas, visando obter uma melhor representação. Inicialmente, duas técnicas para geração da matriz de adjacência são apresentadas, seguidas de algumas abordagens que influenciam no peso das conexões.

Para a geração da matriz de adjacência, duas abordagens são mais utilizadas (de Sousa et al., 2013), são elas: $\epsilon$-vizinhança e $k$-vizinhos mais próximos $(k \mathbf{N N})$.

As redes $\epsilon$-vizinhança são construídas de acordo com um threshold $\epsilon$, ou seja, somente haverá uma ligação entre os vértices $x_{i}$ e $x_{j}$ caso a distância entre eles seja menor que $\epsilon$. Esse tipo de construção não é muito utilizada em casos reais pois, na maioria das vezes, gera-se uma rede desconexa, ou seja, uma rede em que alguns vértices não possuam ligação com elementos rotulados, sendo necessário aplicar técnicas para sanar esse problema. Por esse motivo, esse tipo de construção não será explorada neste mestrado.

Já na rede $k \mathbf{N N}$, existe uma ligação entre os vértices $x_{i}$ e $x_{j}$ se $x_{j}$ está entre os $k$ vizinhos mais próximos de $x_{i}$. Nessa abordagem de geração de rede, a matriz de adjacência pode não ser simétrica, pois $x_{j}$ estar entre os $k$ vértices mais próximos de $x_{i}$ não implica que $x_{i}$ esteja entre os $k$ vértices mais próximos de $x_{j}$. É necessário então uma etapa de pós-processamento da matriz de adjacência, para garantir a simetria da rede. Para tanto, três técnicas foram criadas (Liu e Chang, 2009): $k \mathbf{N N}$ Mútuo ( $m u t K \mathbf{N N}$ ), $k \mathbf{N N}$ Simétrico $(\operatorname{sym} K \mathbf{N N})$ e $k \mathbf{N N}$ favorável a simetria $(\operatorname{sym} F K \mathbf{N N})$. As variações simétrica e mútua foram amplamente estudadas na área de agrupamento de grafos (Maier et al., 2007, 2009a) e apresentaram um impacto elevado em medidas de avaliação de modelos de agrupamentos baseados em grafos (Maier et al., 2009b).

No caso do método mutKNN verifica-se os casos em que existe uma conexão entre $x_{i}$ e $x_{j}$ e não existe uma conexão entre $x_{j}$ e $x_{i}$. Nesses casos, o método adiciona uma conexão entre $x_{j}$ e $x_{i}$. O método symKNN verifica os mesmos casos que o método anterior, porém, em vez de adicionar a conexão entre os vértices não conectados remove-se a conexão entre os vértices que apresentam a conexão, ou seja, a conexão existente entre $x_{i}$ e $x_{j}$ seria 
desfeita. Por fim, o método symFKNN verifica as conexões e soma seus pesos, em um caso que exista conexão entre $x_{i}$ e $x_{j}$ e $x_{j}$ e $x_{i}$ com peso 1 em cada uma delas, são somadas as conexões e o peso final de ambas as conexões é 2. Nos casos de existir apenas a conexão entre $x_{i}$ e $x_{j}$ e não entre $x_{j}$ e $x_{i}$ o método possui o mesmo comportamento que o $m u t K \mathbf{N N}$.

Além dos métodos para tornar a rede não direcionada, existem também os métodos que alteram o peso das conexões. Esses métodos são responsáveis por ponderar os valores das conexões entre dois vértices. Existem dois métodos principais (de Sousa et al., 2013): Kernel RBF (Gaussiana) e Similaride de Hein e Maier (HM).

O Kernel RBF (Gaussiana) consiste na aplicação de uma função gaussiana no peso da conexão entre os vértices, ponderando seu valor de acordo com a abertura $\sigma$ da gaussiana especificada por parâmetro, conforme exibido na Equação 2.11, em que $w_{i j}$ é o peso da conexão entre os vértices $i$ e $j$.

$$
\text { NovoPeso }_{i j}=\exp \left(-\frac{w_{i j}}{2 \sigma^{2}}\right)
$$

Já a similaridade HM (Hein e Maier, 2007) consiste também na aplicação de uma função gaussiana no peso da conexão entre os vértices, porém, nesse caso não é necessário um parâmetro, conforme exibido na Equação 2.12, em que $k$ é o conjunto de vizinhos do elemento $i$ e $l$ é o conjunto de vizinhos do elementos $j$. Nessa similaridade, a abertura da gaussiana é adaptada de acordo com o peso dos vizinhos dos elementos.

$$
\text { NovoPeso } i j=\exp \left(-\frac{w_{i j}}{\max \left(w_{i k}, w_{j l}\right)^{2}}\right)
$$

Com as redes construídas e os pesos entre os vértices ponderados, é então possível realizar a exploração da mesma com o objetivo de extrair conhecimento da rede. Para tanto, diversas medidas e algoritmos foram propostos na literatura. Algumas dessas medidas e alguns desses algoritmos serão explicados nas próximas seções.

\subsubsection{Medidas de Rede}

O conceito de centralidade é altamente explorado nas pesquisas em redes ((Benzi e Klymko, 2013), (Yan et al., 2013), (Hines e Blumsack, 2008), (Estrada e RodriguezVelazquez, 2005)). O conceito visa abordar a questão "Quais são os vértices mais importantes ou mais centrais em uma rede?". Há várias definições de importância e, consequentemente, várias medidas de centralidades propostas que exploram as redes de maneiras diferentes. A seguir, algumas dessas medidas são explicadas de acordo com as definições encontradas em Newman (2010).

1. Centralidade de Grau - Provavelmente a medida de centralidade mais simples. Essa medida calcula a somatória de todas as conexões de um vértice. Nos casos de redes direcionadas, os vértices possuem tanto grau de entrada como grau de saída. É uma 
medida que visa analisar a importância de um determinado vértice em uma rede, levando em consideração apenas as ligações com os seus vizinhos. Na Equação 2.13 é possível visualizar o cálculo, em que $w$ é a matriz de pesos, $i$ é o vértice sobre o qual se está calculando e $j$ são os outros vértices da rede.

$$
\text { CentGrau }_{i}=\sum_{j} w_{i j}
$$

Essa medida pode estimar a centralidade desse vértice na rede de acordo com o número de conexões e seus respectivos pesos. É uma abordagem simples, rápida e bastante utilizada na literatura (Newman, 2010).

2. Centralidade de autovetor - Pode-se pensar como uma "extensão" da centralidade de grau. A diferença é que a centralidade usando autovetor leva em consideração a importância do vizinho para calcular a importância de um vértice. É uma medida de centralidade calculada iterativamente. Na Equação 2.14 é exibido o cálculo, em que $k_{1}$ é o maior valor de autovetor existente.

$$
\text { CentVetor }_{i}=\frac{1}{k_{1}} \sum_{j} w_{i j} \text { CentVetor }_{j}
$$

É necessário inicializar os valores antes de iniciar o processamento; portanto, é comum fazer a inicialização com valores 1 e depois iniciar a iteração (Newman, 2010). Essa medida de centralidade é interessante pois considera não só o número de vizinhos, como também a importância desses vizinhos na rede. Porém, essa centralidade possui um problema: em redes que não possuem ligações muito fortes (como redes de citação, por exemplo, que possuem poucas ligações fortes) a rede inteira tende a ter resultado 0 como valor dessa centralidade.

3. Centralidade de Katz - Visando resolver o problema da centralidade de autovetor, essa centralidade propõe basicamente a mesma equação, porém, somando um valor fixo $\beta$ para cada vértice, impedindo assim que os valores sejam zerados. Outra diferença é que essa centralidade possui um parâmetro livre $\alpha$, para variar o peso da equação. A medida é exibida na Equação 2.15. Se comparada com a Equação 2.14, foi adicionada uma constante $\beta$ e o valor $\frac{1}{k_{1}}$ foi alterado para um parâmetro livre $\alpha$. Se esse parâmetro $\alpha$ for um valor muito próximo a 0 , então todos os vértices terão o valor fixo $\beta$; se o valor for muito alto então a equação não irá convergir. Na literatura, o valor de $\alpha$ é utilizado próximo ao valor de $\frac{1}{k_{1}}$, pois dessa forma os valores de centralidade são semelhantes aos obtidos pela centralidade autovetor e o parâmetro $\beta$ se certifica que nenhum vértice possua valor 0 . O principal problema com a centralidade de Katz é que se existir um elemento com um valor de centralidade muito alto conectado a vários outros elementos, esse valor é então propagado e no final a rede terá valores de centralidade muito altos. 


$$
\text { CentKatz }_{i}=\alpha \sum_{j}\left(w_{i j} \text { CentKatz }_{j}\right)+\beta
$$

4. PageRank - Visando contornar o problema da propagação de valores demasiadamente altos, o PageRank cria uma ponderação de acordo com os pesos dos vizinhos. Com a ponderação, os vértices que apontam para muitos outros tem o seu valor diminuído, enquanto os vértices que apontam para um único outro elemento passam o seu valor total. O pagerank é calculado iterativamente e cria um ranking de importância dos vértices, conforme Equação 2.16, em que $p$ expressa $\frac{1}{N}$ a probabilidade de escolher aleatoriamente qualquer outro vértice na rede, sendo $N$ o total de elementos na rede e $d$ um fator definido pelo usuário.

$$
\text { PageRank }_{i}=d p(1-d) \sum_{j} \frac{\text { PageRank }_{j}}{\text { CentGrau }_{j}}
$$

No PageRank, o valor que é enviado por um elemento é ponderado pela sua centralidade de grau, fazendo com que os seus valores de centralidade sejam dividos igualmente entre os vértices que os receberão. Dessa forma, vértices que possuem muitas ligações e valores muito altos são balanceados, previnindo o desequilíbro da rede.

5. Centralidade de proximidade - Uma noção de centralidade diferente das anteriores. Essa medida calcula a distância média entre todos os vértices da rede usando a distância geodésica, ou seja, o menor caminho possível entre dois vértices. A medida é exibida na Equação 2.17, em que $n V i z$ é o número de vizinhos que o elemento $i$ possui, $d_{i j}$ é o valor da distância geodésica entre os vértices $i$ e $j$ e $j$ está contido nos vizinhos de $i$.

$$
\text { Proximidade }_{i}=\frac{1}{n V i z} \sum_{j} d_{i j}
$$

Nessa medida de centralidade, a importância do vértice na rede é calculada de acordo com a rede toda, não somente em relação aos seus vizinhos. Dessa forma, é possível obter uma visão um pouco mais geral da importância do vértice na rede, já que vértices mais afastados tendem a ter distâncias maiores enquanto vértices que estejam inseridos em pontos mais concentrados da rede tendem a ter distâncias menores. O principal problema dessa medida é a aplicação em redes que não são totalmente conectadas ou que possuem vértices desconectados. Esse problema normalmente é solucionado fixando uma distância muito alta, fazendo com que o valor atribuído para um determinado vértice seja ruim.

6. Centralidade de betweenness - Medida de centralidade que calcula o fluxo de informações nos vértices. Essa medida é interessante para verificar se a posição de 
um vértice é uma posição de alta conectividade da rede, calculada pelo número de caminhos mínimos. A Equação 2.18 exibe o cálculo da medida.

$$
\text { Betweenness }_{i}=\sum_{s, t} \frac{c_{s t}^{i}}{g_{s t}}
$$

A medida percorre todos os elementos $s$ e $t$ diferentes de $i, c_{s t}^{i}$ retorna o número de caminhos mínimos entre $s$ e $t$ que $i$ faz parte e $g_{s t}$ retorna o número de caminhos entre $s$ e $t$. Essa medida visa calcular a importância de determinado vértice no fluxo de informação da rede, de acordo com o número de caminhos mínimos que passam por ele. A medida resulta em maiores valores para vértices que estão mais bem posicionados e valores baixos para vértices que não possuem posição privilegiada na rede.

Essas medidas de centralidade visam analisar a importância dos vértices na rede. Com essas medidas é possível explorar a rede buscando por vértices mais relevantes e analisálos. Essas análises são amplamente utilizadas, principalmente quando um ranqueamento de informação é necessário. Um grande exemplo de utilização é do PageRank, em conjunto com outros métodos, pelo Google ${ }^{7}$ para exibição dos resultados de busca. Além de medidas de análise individual dos vértices, existem as abordagens que exploram a rede com uma visão mais geral, visando classificá-la e não apenas encontrar os vértices mais relevantes. Uma dessas abordagens é conhecida como propagação de rótulos, que será explicada na próxima seção.

\subsubsection{Abordagens de Propagação de Rótulos}

Segundo Zhu (2005), o campo de aprendizado de máquina pode ser dividido tradicionalmente em 3 grandes áreas: (i) aprendizado não supervisionado, (ii) aprendizado supervisionado e (iii) aprendizado por reforço. O aprendizado não supervisionado observa um conjunto de elementos não rotulados com o objetivo de organizá-los. Nessa área existem algoritmos de agrupamento que visam organizar o conhecimento de acordo com a similaridade; algoritmos de detecção de novidade que visam encontrar conhecimento diferente do existente e algoritmos de redução de dimensionalidade que visam reduzir o tamanho de uma base de dados preservando determinadas propriedades da base. O aprendizado supervisionado observa um conjunto de elementos rotulados, a ser utilizado como conjunto de treinamento. O objetivo principal é descobrir o rótulo de um novo elemento que apareça para ser rotulado. Em casos que o rótulo é discreto, o processo é chamado de classificação, em casos que o rótulo é contínuo o processo é chamado de regressão. O aprendizado por reforço repetidamente analisa o conjunto de elementos, realiza ações de acordo com esse conjunto e recebe uma recompensa. O objetivo dessa área é realizar ações que maximizem futuras recompensas.

\footnotetext{
${ }^{7}$ http://www.google.com.br
} 
A obtenção de elementos rotulados é um processo bastante custoso, dado que muitas das vezes é necessário que a rotulação seja realizada por um especialista e a quantidade de dados disponíveis é extremamente grande. Dessa forma, é interessante que os elementos não rotulados auxiliem o processo de classificação, facilitando assim a obtenção de elementos rotulados. Com o objetivo de utilizar esses elementos não rotulados na classificação, surgiu a área de aprendizado semissupervisionado. Essa área observa um conjunto de elementos em que uma pequena quantia dos elementos possui rótulos definidos e a grande maioria dos elementos não, dessa forma o aprendizado é realizado sobre os dados rotulados e não rotulados (Zhu, 2005).

Abordagens de aprendizado semissupervisionado utilizam os objetos classificados e os não classificados para aprender, propagando o conhecimento na base de dados e utilizando os objetos recém classificados para continuar a classificação. Dessa forma, bases que possuem poucos elementos rotulados conseguem ser classificadas. Recentemente, abordagens de aprendizado transdutivo utilizando redes vêm atraindo bastante a atenção de pesquisadores. Métodos baseados em redes iniciam com uma rede com alguns vértices rotulados e maior parte não rotulada. Os pesos das arestas dessas redes refletem a similaridade entre os elementos. É assumido que vértices que possuem uma conexão com peso alto (alta similaridade) devem ter a mesma classe. Dessa forma, o conhecimento é propagado pela rede (Zhu, 2005). Esse método é conhecido como propagação de rótulos.

Seja $\left\{\left(x_{1}, y_{1}\right), \ldots\left(x_{l}, y_{l}\right)\right\}$ o conjunto de vértices rotulados, $y \in\{1, \ldots, C\}$ o conjunto de classes e $\left\{x_{l+1}, \ldots x_{l+u}\right\}$ o conjunto de vértices não rotulados, no qual normalmente $l \ll u$. Será utilizado como notação $L$ para os vértices rotulados e $U$ para os vértices não rotulados, portanto, $V=L+U$ é a base de dados inteira, contendo os elementos rotulados e não rotulados. Define-se também $\Gamma\left(x_{i}\right)$ como o conjunto de vértices que são vizinhos de $x_{i}$. Também é assumido que o número de classe $C$ é conhecido e todas as classes estão presentes no conjunto rotulado. O problema de propagação de rótulos visa encontrar a classe correta para os vértices em $U$. A abordagem indutiva, que visa encontrar a classe para elementos fora de $V$ não será tratado nesse trabalho, pois todos os elementos são conhecidos no momento da classificação, conforme será explicado posteriormente.

Os métodos de propagação de rótulos descritos neste capítulo propagam a classe de maneira iterativa, ou seja, a cada iteração as classes são propagadas para os vizinhos até que seu critério de parada seja atingido. A grande variação entre os algoritmos que serão descritos é a função utilizada para realizar a propagação, já que todos são iterativos e propagam a classe vizinho a vizinho. Os classificadores foram divididos em 2 grupos: os que são aplicados em redes homogêneas e os que são aplicados em redes heterogêneas.

\section{Redes Homogêneas}

Métodos desenvolvidos para redes homogêneas consideram todos os vértices presentes na rede sem distinção. As abordagens de propagação de rótulos para redes homogêneas, geralmente, possuem um framework de regularização (Zhu, 2005). Esse framework é 
dividido em 2 partes com diferentes objetivos: vértices previamente rotulados e vértices a serem rotulados. A parte da equação responsável pelos vértices préviamente rotulados garante que esses rótulos não sejam alterados, fazendo com que a rotulação prévia seja tratada como verdade absoluta e imutável. Já a parte que considera os vértices a serem rotulados é responsável por classifica-los de acordo com a similaridade/distância, fazendo com que os vértices mais próximos estejam na mesma classe e reduzindo a distância total entre vértices de diferentes classes.

Blum e Chawla (2001) propuseram o classificador Mincut para bases que possuam apenas 2 classes disponíveis. O objetivo desse classificador é encontrar o menor conjunto de ligações possíveis cuja remoção isole totalmente as duas classes. É possível visualizar a função de perda a ser minimizada na Equação 2.19, em que $f$ em cada ponto é a classe que o vértice recebeu pelo algoritmo de propagação de rótulos. Como o classificador trata apenas o problema de classificação binária, as classes são divididas em 0 e 1.

$$
F=\infty \sum_{x_{i} \in L}\left(f_{i}-y_{i}\right)^{2}+\frac{1}{2} \sum_{x_{i}, x_{j}} w_{i j} *\left(f_{i}-f_{j}\right)^{2}
$$

Zhu et al. (2003) propôs o método GFHF (Gaussian Fields and Harmonic Functions) que otimiza a Equação 2.20 .

$$
F=\infty \sum_{x_{i} \in L}\left(f_{i}-y_{i}\right)^{2}+\frac{1}{2} \sum_{x_{i} ; x_{j} \in D} w_{i j}\left(f_{i}-f_{j}\right)^{2}
$$

A principal diferença dessa equação com a equação proposta no Mincut por Blum e Chawla (2001) é o valor de $f$, que em cada ponto não rotulado é a média harmônica de $f$ nos pontos vizinhos 2.21. Dessa forma, o método funciona calculando iterativamente todos os valores de f, até a equação convergir, e então esses valores são aplicados à Equação 2.20 para propagar as classes.

$$
f_{i}=\frac{\sum_{v_{j} \in \Gamma\left(v_{i}\right)} w_{i j} f_{j}}{\sum_{v_{j} \in \Gamma\left(v_{i}\right)} w_{i j}}
$$

Zhou et al. (2004) propôs o método LLGC (Learning with Local and Global Consistency), que otimiza uma função diferente, exibida na Equação 2.22, em que $d_{i i}$ é o grau do vértice $i$. Essa equação é diferente da anterior em dois pontos principais: primeiro que a função de perda dos elementos rotulados não é mais multiplicada por infinito e sim por um parâmetro. A principal diferença é na ponderação dos pesos dos vértices pelo grau de saída. Dessa forma, os vértices que possuem um alto grau não sejam extremamente dominantes na rede, diminuindo assim sua influência na propagação das classes.

$$
F=\mu \sum_{x_{i} \in L}\left(f_{i}-y_{i}\right)^{2}+\frac{1}{2} \sum_{x_{i} ; x_{j} \in D} w_{i j}\left\|\frac{f_{i}}{\sqrt{d_{i i}}}-\frac{f_{j}}{\sqrt{d_{j j}}}\right\|^{2}
$$

Abordagens de propagação de rótulos em redes homogêneas consideram todos os vér- 
tices como sendo do mesmo tipo, porém, algumas redes necessitam da diferenciação entre seus vértices. Em alguns casos, é necessário considerar que o conhecimento modelado na rede não é de um único tipo e sim de tipos variados. Para classificar essas redes foram sugeridos alguns algoritmos especificos, que são explicados a seguir.

\section{Redes Heterogêneas}

A classificação de uma rede heterogênea segue o mesmo princípio da classificação de redes homogêneas, porém, nessas redes é necessário considerar que objetos com valores semânticos diferentes estão interrelacionados e podem pertencer a mesma classe. Portanto, o objetivo da classificação de redes heterogêneas é classificar os elementos nela presentes utilizando a informação de classe dos diferentes tipos de objetos ligados ao elemento.

Ji et al. (2010) propuseram um framework de classificação de redes heterogêneas que leva em consideração as diferentes semânticas de cada tipo de relação. Para que a classificação seja realizada, duas premissas são consideradas: (i) Dois objetos similares tendem a ter a mesma classe e (ii) Objetos rotulados tendem a manter suas classes pré-definidas. Dessa forma, para satisfazer essas duas premissas, é então otimizada a Equação 2.23, em que $G$ é o conjunto de vértices agrupadores e $H$ o conjunto de vértices não agrupadores da rede, $\alpha_{G, H}\left(0 \leq \alpha_{G, H} \leq 1\right)$ é a importância dada à relação entre os objetos $G$ e $H$, $\beta_{G_{l}}\left(O \leq \beta_{G_{l}} \leq 1\right)$ é a importância dada as classes pré-definidas em $G_{l}$ e $d_{i, i}$ é o valor da posição $i, i$ da matriz de graus $D$ obtida da matriz de adjacência $w$ que armazena as ligações entre $G$ e $H$. A primeira parte da equação satisfaz a primeira premissa, que vértices similares tentem a ter a mesma classe. É realizada a normalização por $d$ para que vértices que possuam uma quantidade muito grande de conexões não sejam muito dominantes na rede, considerando assim os vértices que possuem menos ligações. A segunda parte da equação satisfaz a segunda premissa, que os vértices rotulados tendem a manter a classe pré-definida, minimizando a diferença entre as classes atribuídas em comparação com as classes reais. A propagação é realizada iterativamente, vizinho a vizinho, até que a função convirja e não haja alterações nas classes.

$$
\begin{aligned}
& F=\sum_{G, H \in D} \alpha_{G, H} \sum_{g_{i} \in G ; h_{j} \in H} w_{i j}\left\|\frac{f_{i}(G)}{\sqrt{d_{i, i}(G, H)}}-\frac{f_{j}(H)}{\sqrt{d_{j, j}(G, H)}}\right\|^{2}+ \\
& \sum_{x_{i} \in G_{l}, G_{l} \in \mathcal{L}} \beta_{G_{l}}\left(\mathbf{f}_{i}\left(G_{l}\right)-\mathbf{y}_{i}\left(G_{l}\right)\right)
\end{aligned}
$$

Rossi et al. (2014) propuseram o LPBHN (Label Propagation using Bipartite Heterogeneous Network) para propagação de rótulos para classificação de textos em uma rede documento-termo que pode ser extendida para redes heterogêneas bipartidas no geral. Esse classificador trabalha otimizando a equação $F=P F$ no qual $F$ é o vetor que armazena todos os graus dos vértices e $P$ é descrito conforme Equação 2.24 para calcular a probabilidade da conexão dos vértices em $G \operatorname{com} H$ e Equação 2.25 para calcular a probabilidade da conexão dos vértices em $H$ com $G$. Em ambas as equações, $g_{i} \in G$ e 
$h_{j} \in H$

$$
\begin{aligned}
P_{g_{i}, h_{j}} & =\frac{w_{g_{i}, h_{j}}}{\sum_{g_{k} \in G ; w_{k j} \in W} w_{k j}} \\
P_{h_{j}, g_{i}} & =\frac{w_{g_{i}, h_{j}}}{\sum_{h_{l} \in H ; w_{i k} \in W} w_{i l}}
\end{aligned}
$$

Nesse algoritmo, alguns dos vértices pertencentes a $G$ estão rotulados e a propagação é realizada utilizando os vértices contidos em $H$ para a propagação. No trabalho proposto, Rossi et al. (2014) considerou os vértices de $G$ como documentos, alguns deles classificados, e os vértices em $H$ como termos que estão presentes nos documentos.

\subsubsection{Considerações Finais sobre Redes}

Nesta seção foi apresentada a definição e os conceitos de redes, suas medidas e algumas de suas aplicações, focando especificamente em abordagens de propagação de rótulos. Essas abordagens visam classificar todos os vértices de uma rede baseando-se em poucos elementos rotulados de acordo com a similaridade entre os vértices. Neste mestrado foram contemplados algoritmos de propagação de rótulos para redes homogêneas e para redes heterogêneas bipartidas, de acordo com os problemas que estão sendo tratados, os quais são detalhados no Capítulo 3 e, portanto, outros tipos de redes não foram consideradas. Os algoritmos de propagação de rótulos foram introduzidos e discutidos visando determinar o funcionamento de cada um deles para que possam ser utilizados no problema que se deseja explorar neste mestrado.

Por fim, existem trabalhos na literatura que unem o uso de redes e regras de associação em diferentes etapas da exploração das regras. Alguns trabalhos pré processam a base de dados, com o objetivo de gerar os itemsets frequentes para geração das regras. Outros trabalhos geram regras de associação de acordo com técnicas de exploração de redes e outros modelagem as regras com o objetivo de facilitar a exploração. Alguns desses trabalhos são apresentados e discutidos na próxima seção.

\subsection{Trabalhos Relacionados com Regras de Associação e Redes}

Nesta seção são discutidos alguns dos trabalhos que utilizam regras de associação e redes. Os trabalhos aqui descritos contemplam desde a etapa de geração das regras de associação até o pós-processamento e visualização das regras.

Cavique (2007) propôs um método para extrair itemsets frequentes utilizando redes. Nesse trabalho, primeiro o autor desenvolveu uma rede de produtos, no qual cada vértice representa um produto e a ligação entre os vértices o número de transações que esses produtos aparecem em conjunto. Após a modelagem, a rede é processada em busca de cliques, subredes no qual todos os vértices encontram-se conectados entre si. A exploração é feita definindo o tamanho da subrede, iniciando em 2 e terminando em $k$, definido pelo 


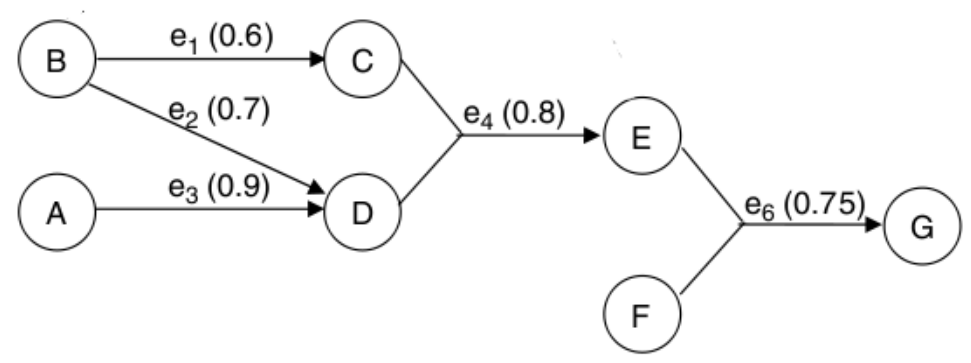

Figura 2.6: Um exemplo de Association Rule Network retirado de Pandey et al. (2009).

usuário. Inicialmente, são encontradas todas as subredes com 2 vértices, depois com 3 vértices e assim por diante. Tendo os cliques definidos, é aplicado o algoritmo proposto, Similis, que transforma os cliques em itemsets para geração de regras de associação. O trabalho explora os resultados obtidos apenas com os itemsets, sem a geração das regras de associação.

Pandey et al. (2009) utiliza um grafo direcionado, com multi-arestas, para explorar as regras de associação geradas, com o objetivo de ajudar na construção de hipóteses. Para realizar a exploração, os autores constroem o grafo de acordo com um item objetivo, ou seja, o usuário define qual item da base de dados ele deseja explorar e a abordagem constrói um hipergrafo a partir desse item. A construção do grafo leva em consideração a implicação da regra. O item escolhido pelo usuário será utilizado como filtro para escolher todas as regras que possuem aquele item como consequente. As regras escolhidas são modeladas no formato de grafo. Para que a modelagem seja viabilizada em regras que possuem mais de um item no antecedente, cada vértice representa um item e é adicionada uma hiperaresta direcionada, ligando todos os itens do antecedente com o item objetivo no consequente.

Após a construção ser feita com o item selecionado pelo usuário, a abordagem funciona recursivamente, escolhendo os itens modelados como antecedente e as colocando como objetivo. Dessa forma, a abordagem modela as regras de acordo com níveis de distância em relação ao item objetivo selecionado pelo usuário. Para cada conjunto de vértices adicionado, o autor diz que desceu um "nível", ou seja, o item objetivo que o usuário definiu está no nível 1, os antecedentes de suas regras estão no nível 2 e assim por diante. É possível visualizar um exemplo de resultado obtido pela abordagem na Figura 2.6. Para que não sejam criados loopings dentro da rede, os autores adicionaram restrições nas ligações: (i) para que seja adicionado um novo vértice na rede, ele não pode ter aparecido em nenhum nível superior e (ii) a ligação é sempre feita saindo de um nível inferior para um nível exatamente superior, ou seja, vértices no nível 3 podem apenas se ligar com o nível 2. Os resultados obtidos pelos autores destacam 3 características das ARNs (Association Rule Network): (i) a capacidade de podar as regras de acordo com um objetivo bem definido; (ii) a transformação dos métodos de poda em simples operações de grafo e (iii) a possibilidade de utilizar as ARN como base para explorar as regras geradas.

Já Raeder e Chawla (2011) propuseram um framework para processamento de dados 
de cesta de compras para facilitar a exploração do usuário, o qual aplica técnicas de processamento de redes. Inicialmente, o framework gera uma rede de produtos, em que cada vértice representa um produto, e a ligação entre os produtos representam as transações de venda em que eles ocorreram juntos, ou seja, se o produto A e o produto B foram comprados juntos, em uma mesma compra, por 4 pessoas, então esses produtos possuirão uma aresta com peso 4. Após a construção da rede, os autores verificaram que a maioria dos vértices possuem ligações com grau baixo, significando que a compra em conjunto não possui realmente um vínculo, e poucos vértices possuem ligações com grau muito alto, significando que realmente há um vínculo entre esses produtos. Baseado nisso, é aplicado um threshold para remover os vértices que possuem ligação muito baixa e diminuir a densidade da rede e facilitar a exploração do domínio. Com as poucas ligações restantes, é então utilizado a medida de confiança e são geradas regras de associação. No trabalho, também é sugerido utilizar a abordagem de ARN proposta por Pandey et al. (2009) para direcionar a exploração da regra baseado em um produto objetivo.

Videla-Cavieress e Rios (2014) propuseram uma abordagem para geração de regras de associação utilizando técnicas de mineração de grafos. A abordagem tem como principal objetivo minerar grandes quantidades de dados, já que as técnicas convencionais de geração de regras de associação tendem a gerar uma quantidade de regras extremamente grandes e levar muito tempo para processar bases de dados extremamente grandes. Para realizar o processamento, os autores criaram uma rede de produtos, em que cada vértice representa um produto e a ligação entre eles tem como valor o número de transações que ambos ocorrem, ou seja, o número de clientes que compraram os dois produtos em uma mesma compra. Inicialmente, os dados são divididos em períodos de tempo (diário, semanal, mensal, quadrimestral, semestral e anual). Para que depois a rede produtos seja construída. Após análise da distribuição de grau da rede, os autores constataram que uma rede de produtos possui várias conexões com grau muito baixo e poucas conexões com grau muito altos. Portanto, foram aplicados filtros utilizando um threshold mínimo para manter apenas os produtos que possuem alta correlação. Com as ligações das redes filtradas, são aplicados algoritmos de detecção de comunidade, visando encontrar diferentes sub-redes de produtos. Então, são aplicados algoritmos de deteç̧ão de sobreposição de comunidades. Esses algoritmos visam encontrar conjuntos de vértices que participam de mais de uma comunidade, os quais serão utilizados como itemsets frequentes. Os autores compararam o trabalho com técnicas que preparam os dados utilizando clustering e, com a análise de um especialista do domínio, chegaram a conclusão que a abordagem proposta supera e muito os resultados obtidos com técnicas convencionais de clustering.

Os trabalhos voltados ao pós-processamento utilizando rede visam realizar o processo utilizando o conhecimento do usuário. Na abordagem de Pandey et al. (2009) o usuário é responsável por definir, a priori, qual o item de interesse dentro da base de dados. Nesse caso, o usuário precisa ter o conhecimento prévio bem definido na área que quer descobrir, especificamente em um determinado item que se deseja explorar. Essa abordagem modela 
todas as regras geradas de acordo com o item selecionado e, dessa forma, direciona o conhecimento do usuário. Já outra abordagem de processamento analisa uma rede de produtos, mantendo apenas os produtos que possuem um vínculo maior exibindo assim para o usuário. Nessa segunda abordagem o conhecimento do usuário não é considerado, apenas as características da base de dados. É importante ressaltar que o conhecimento varia de usuário para usuário, ou seja, o que um usuário considera interessante pode não ser interessante para outro. Assim como criar a necessidade do usuário informar o objetivo da exploração antes do processamento da base iniciar faz com que a exploração tenha uma tendência a exibir um conhecimento já adquirido pelo usuário. Baseado nessas afirmações é possível visualizar uma lacuna que esse mestrado visou preencher.

Com base no cenário apresentado, neste mestrado é proposto o desenvolvimento de uma abordagem de pós-processamento interativa e iterativa, especificada no Capítulo 3. Interativa, permitindo ao usuário agir diretamente no resultado final da exploração, alimentando a abordagem com seu conhecimento de acordo com uma exploração prévia já realizada pela abordagem. Iterativa, uma vez que a abordagem pode ser executada mais de uma vez com o objetivo de refinar os resultados. 



\section{$P A R_{L P}$ : Post-processing Association Rules using Label Propagation}

O número de regras de associação geradas normalmente excede a capacidade humana de interpretação. Para auxiliar no processo de exploração, diversas abordagens de pósprocessamento foram propostas para reduzir o número de regras a serem analisadas pelo especialista. Muitos autores utilizam-se de abordagens automáticas para encontrar as regras consideradas mais interessantes, analisando as regras de acordo com sua importância na base de dados, tendo como referência alguma medida de avaliação. Porém, o grande problema dessas abordagens é que o conceito de interesse varia de usuário para usuário, i.e., o que é interessante para um usuário pode não ser considerado interessante por outro usuário. Além da diferença entre os usuários, o conhecimento e/ou interesse de um mesmo usuário pode variar conforme o tempo passa, fazendo com que o que era considerado interessante por um determinado usuário possa não ser mais interessante depois de algum tempo (Bie, 2013).

Visando considerar esse conhecimento e/ou interesse subjetivo, vários autores propuseram abordagens de pós-processamento interativas de regras de associação, que consideram o conhecimento e/ou interesse do usuário. A principal dificuldade dessas abordagens consiste na necessidade de inserir o conhecimento e/ou interesse antes do processamento iniciar, exigindo assim que o usuário defina previamente o que ele deseja analisar no conjunto de regras. No entanto, realizar tais definições requer um tempo considerável do usuário, podendo inclusive levar a especificações incompletas e/ou incorretas. Além da dificuldade da obtenção do conhecimento e/ou interesse do usuário, várias abordagens da literatura tratam o problema de pós-processamento como um problema de aprendizado não supervisionado. Nessas abordagens, mesmo que o usuário modele seu conhecimento e/ou interesse, esse conhecimento e/ou interesse será apenas utilizado para estruturar o 
domínio e exibir as regras, muitas vezes não utilizando o conhecimento modelado como meio de aprendizado.

Nota-se, portanto, que um dos desafios das abordagens de pós-processamento de regras de associação é considerar o conhecimento e/ou interesse do usuário. Como mencionado, diversas abordagens disponíveis na literatura consideram o conhecimento e/ou interesse do usuário para que a exploração seja realizada. Porém, isso é feito de modo que essas informações sejam definidas a priori, i.e., antes do processamento iniciar. Essa definição prévia exige que o usuário já possua um grande conhecimento no domínio que está sendo explorado. Além do desafio referente a modelagem do conhecimento e/ou interesse, é necessário considerar também o número de regras que o usuário analisará. A análise de regras feita por um especialista é custosa e, na maioria dos casos, o usuário quer explorar as regras geradas sem limitar a exploração ao conhecimento que ele já possui. Portanto, é importante que o usuário avalie o menor número de regras possível e, com base nessa avaliação, abordagens de pós-processamento consigam o auxiliar na busca pelas regras que ele poderá considerar interessante. Para tanto, é proposto neste trabalho que o pós-processamento seja tratado como um problema de classificação semi-supervisionada transdutiva, uma vez que permite que o usuário rotule, considerando classes pré-definidas (por exemplo, "Interessante"ou "Não Interessante"), apenas algumas regras do conjunto a ser explorado para que todas as outras regras sejam automaticamente rotuladas. Além disso, por meio da definição dos rótulos de algumas regras, é possível capturar implicitamente o conhecimento e/ou interesse do usuário sobre o domínio. Contudo, é importante que as regras a serem rotuladas sejam representativas ao domínio para que a propagação ocorra de maneira satisfatória. Desse modo, é necessário que as regras sejam modeladas de maneira a permitir: (a) selecionar as regras a serem rotuladas pelo usuário a fim de capturar implicitamente seu conhecimento e/ou interesse, que pode ser de acordo com algum "tema"; (b) propagar os rótulos das regras já classificadas pelo usuário a todas as outras regras não rotuladas. Para tanto, neste trabalho de mestrado, as regras foram modeladas via redes, uma vez que: (i) uma vasta quantidade de medidas de exploração de redes podem ser utilizadas, em conjunto com as informações fornecidas pelo usuário, a fim de viabilizar o item (a); (ii) algoritmos de propagação de rótulos podem ser utilizados a fim de viabilizar o item (b).

Diante do apresentado, a hipótese considerada foi a de que a incorporação de conhecimento por parte do usuário durante o pós-processamento, via redes e propagação de rótulos, permite que o usuário seja direcionado ao conhecimento considerado interessante. Como resultado, foi proposta uma abordagem de pós-processamento, denominada Postprocessing Association Rules using Label Propagation $\left(P A R_{L P}\right)$, interativa e iterativa, em que o usuário é direcionado para o conhecimento que considerará como interessante. Neste capítulo, a abordagem proposta é explicada em detalhes (Seção 3.1), seguido da descrição da ferramente desenvolvida e de um exemplo de execução (Seção 3.2), assim como as configurações experimentais e os resultados obtidos (Seção 3.3). 
Diante do apresentado, ressalta-se que as contribuições deste trabalho estão na capacidade de se extrair o conhecimento e/ou interesse do usuário de acordo com as características da base de dados e direcionar sua exploração sem a necessidade de se definir previamente o que será explorado. Além disso, os resultados obtidos demonstram a capacidade da $P A R_{L P}$ em direcionar o usuário para o conhecimento considerado interessante, reduzindo, para tanto, a quantidade de regras a serem exploradas. Por fim, este trabalho contribui também para demonstrar que é possível tratar o pós-processamento de regras de associação como um problema de propagação de rótulos.

\subsection{Especificação da Abordagem Proposta}

Conforme discutido anteriormente, a abordagem proposta trata o problema de pósprocessamento de regras de associação como um problema de propagação de rótulo. As abordagens de propagação de rótulos utilizam uma pequena quantidade de elementos rotulados em conjunto com uma grande quantia de elementos não rotulados para classificar toda a base de dados. Essa classificação é realizada de acordo com a similaridade dos elementos da base de dados, classificando elementos similares em uma mesma classe e colocando elementos distantes em classes diferentes. Para utilizar o mecanismo de propagação de rótulos, as regras são modeladas em redes. Redes são capazes de modelar conjuntos de dados sem perder informação, criando ligações entre os elementos presentes de acordo com medidas de similaridade. Após a seleção das técnicas a serem utilizadas, foi então necessário realizar a especificação da $P A R_{L P}$. É possível visualizar a sequência de passos a serem realizados na Figura 3.1. A $P A R_{L P}$ pode ser divida em quatro grandes etapas: Modelagem, Interação com o Usuário, Classificação e Critério de Parada.

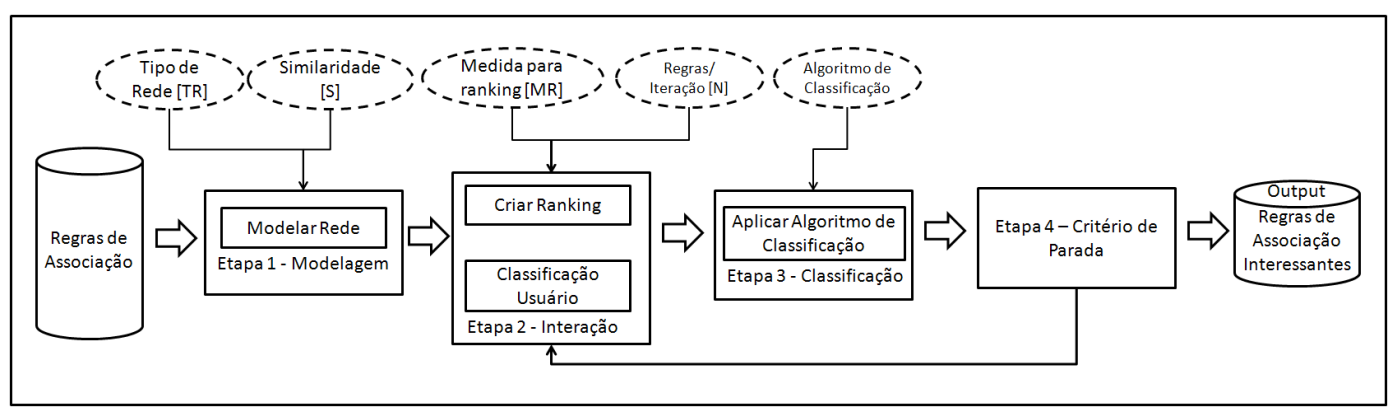

Figura 3.1: Detalhes da abordagem $P A R_{L P}$.

\section{Etapa 1 - Modelagem}

Nessa etapa as regras são modeladas em redes para que seja possível realizar a exploração. A modelagem via redes possibilita a exploração das regras por meio de medidas de similaridade, assim como a indicação de regras para serem classificadas pelo usuário de acordo com sua importância na rede e o uso de algoritmos de propagação de rótulos. Para realizar a modelagem é necessário a configuração de dois parâmetros: Tipo de Rede [TR] e Medida de Similaridade [S]. A escolha do 
tipo de rede definirá a representação das regras na rede; por exemplo, se o tipo de rede escolhido for rede homogênea, cada elemento da rede será uma regra que se conectará as outras de acordo com uma medida de similaridade selecionada. Já a medida de similaridade, que depende do tipo de rede, é utilizada para calcular a força das conexões entre as regras, de acordo com a similaridade existente entre elas. Essa especificação inicial é muito importante para todo o processo, dado que os algoritmos aplicados para processamento de rede possuem uma alta dependência ao formato da rede e ao peso das conexões entre os vértices.

\section{Etapa 2 - Interação}

Essa etapa é responsável por capturar o conhecimento e/ou interesse do usuário implicitamente e adicioná-lo a exploração. A captura do conhecimento do usuário ocorre com o auxílio da abordagem, direcionando o usuário a analisar as regras que são consideradas potencialmente mais interessante de acordo com uma medida de ranqueamento. Essa captura de conhecimento é realizada selecionando algumas regras, de acordo com medidas de rede, e as exibindo para o usuário classificar. Entende-se, então, que a interação com o usuário é facilitada e o número de regras que deverão ser analisadas é reduzido. A interação é realizada utilizando medidas de redes com o objetivo de encontrar as regras que melhor representam os centros de cada classe. A interação com o usuário pode ocorrer mais de uma vez, dependendo somente da escolha realizada pelo usuário na última etapa. Nessa etapa é necessário a definição de alguns parâmetros: medida de rede utilizada para ranqueamento $[\mathrm{MR}]$ e número de regras a serem classificadas $[\mathrm{N}]$. A medida de rede utilizada para o ranqueamento [MR] é responsável por processar a rede, levando em consideração suas ligações, e selecionar as regras que serão classificadas pelo usuário. A quantidade de regras que serão selecionadas $[\mathrm{N}]$ é definido pelo parâmetro número de regras a serem classificadas. Todas as regras consideradas interessantes pelo algoritmo de classificação na última iteração (detalhes adiante) são ranqueadas utilizando a medida selecionada, visando encontrar as $\frac{N}{2}$ regras com maior valor e as $\frac{N}{2}$ regras com pior valor, de acordo com a medida de rede definida. São selecionadas as $\frac{N}{2}$ melhores e as $\frac{N}{2}$ piores com o objetivo de prevenir que as regras selecionadas estejam em um ponto denso da rede.

Na primeira iteração, todas as regras do domínio são consideradas para exploração; a partir da segunda iteração são exploradas apenas as regras que foram consideradas interessantes pelo algoritmo de classificação. É importante ressaltar que, caso o número de regras classificadas como "Interessantes" [I] seja menor que [N], o valor é completado com regras selecionadas aleatoriamente do domínio até que o número de regras seja igual a [N]. Com o ranqueamento realizado, o usuário analisa as regras exibidas e as classifica entre "Interessantes" [I] e "Não Interessantes" [NI]. As regras classificadas nessa etapa são utilizadas na próxima, para classificação das regras ainda não rotuladas. 


\section{Etapa 3 - Classificação}

Nessa etapa as classificações do usuário são propagadas por toda a rede, rotulando todas as regras do domínio. É necessário que seja definido qual o algoritmo de classificação a ser utilizado e, caso haja, os parâmetros para classificação. Após a execução do algoritmo de classificação todas as regras da base estarão, obrigatoriamente, classificadas entre "Interessantes" e "Não Interessantes". As regras "Interessantes" podem ser divididas entre as selecionadas e classificadas pelo usuário e as classificadas pelo algoritmo. As regras classificadas pelo usuário não serão analisadas novamente nas possíveis próximas iterações, pois a classificação do usuário é considerada como verdade imutável. As regras "Interessantes" classificadas pelo algoritmo serão analisadas a cada nova iteração, podendo ter seus rótulos alterados. Essas regras são as regras que serão apresentadas ao usuário, em conjunto com as regras já classificadas pelo próprio usuário, como resultado final da abordagem.

Vale ressaltar que após a classificação do usuário, todas as regras que não foram rotuladas pelo usuário são classificadas novamente, podendo realizar alterações nas classes previamente estabelecidas pelo algoritmo de classificação. A repetição da classificação nas regras não rotuladas pelo usuário é necessária para considerar o novo conhecimento inserido no sistema, realizando alterações na classificação com o objetivo de melhorar o conjunto de regras interessantes.

\section{Etapa 4 - Critério de Parada}

Etapa responsável por decidir se a abordagem continuará a explorar o conjunto de regras ou se o resultado obtido é suficiente. Nessa etapa é necessário que o usuário decida se deve realizar mais uma iteração na abordagem ou se a quantia de regras obtidas já é o suficiente para que o processo seja finalizado. Assim, após a execução do algoritmo de classificação, é questionado ao usuário se ele deseja executar novamente o processo visando obter melhores resultados ou se ele deseja finalizar a exploração. Caso o usuário escolha executar novamente, a abordagem volta para a etapa de "Interação" considerando apenas as regras "Interessantes" classificadas pelo algoritmo para criação do ranqueamento; caso contrário, as regras classificadas como interessantes pelo usuário e pelo algoritmo de classificação são selecionadas como resultado final e exibidas para o usuário em um arquivo de saída.

Para viabilizar a execução da abordagem $P A R_{L P}$, a seguir é apresentado um esquema do passo a passo e a ferramenta desenvolvida com um exemplo de execução.

\subsection{Ferramenta Desenvolvida para a Abordagem $P A R_{L P}$ e Exem- plo de Execução}

Visando facilitar o entendimento da abordagem proposta, na Figura 3.2 é apresentado um esquema com o passo a passo das etapas da $P A R_{L P}$. A execução inicia-se com um 
conjunto de regras de associação a ser explorado pela abordagem, conforme visualizado em [A]. Em [B] as regras são modeladas em uma rede (Etapa 1 da Figura 3.1), de acordo com um tipo de rede [TR] e medida de similaridade $[\mathrm{S}]$ escolhida. Em [C] inicia-se a etapa de interação (Etapa 2 da Figura 3.2), que consiste em ranquear e selecionar as regras para serem classificadas pelo usuário. No exemplo, 2 regras foram selecionadas (R1 e R4), a melhor e a pior do ranqueamento. A classificação do usuário pode ser visualizada em [D]. Em [E] é realizada a etapa de classificação, em que um algoritmo de classificação é aplicado e as classes [I] e [NI] são propagadas para toda a rede. No exemplo, os vértices destacados com borda mais grossa representam as regras classificadas pelo usuário e os destacados com borda mais fina as classificadas pelo algoritmo de classificação. Em [F] analisa-se o critério de parada. Neste exemplo optou-se por continuar o processo iniciando uma nova interação do processo. Em $[G]$, o ranqueamento é novamente realizado, mas agora considerando apenas as regras classificadas como [I] pelo algoritmo de classificação. Em seguida, o processo ocorre conforme já explicado. Em [H] é executada novamente a classificação pelo algoritmo de classificação, considerando as novas classificações realizadas pelo usuário (R3 e R5). Em [J] são exibidas novamente as regras selecionadas como [I] no critério de parada, seguido pelo output ao fim do processo (nesse ponto optou-se por não continuar o processo).

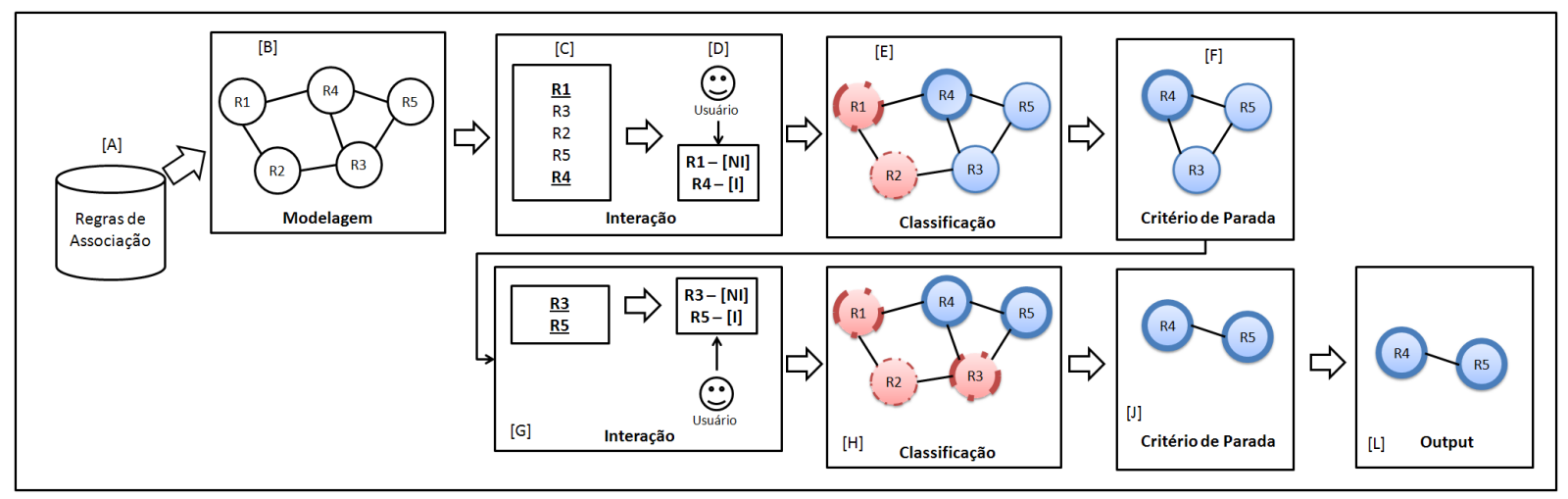

Figura 3.2: Execução passo a passo das etapas da abordagem $P A R_{L P}$.

A fim de vialibilizar a utilização da abordagem proposta, uma ferramenta computacional foi implementada para realizar a exploração das regras e viabilizar a execução dos experimentos. A ferramenta possibilita a seleção e a configuração dos parâmetros necessários a utilização da $P A R_{L P}$. A interface referente as configurações associadas a interação com o usuário, como número de regras a serem classificadas por interação $([\mathrm{N}])$, podem ser visualizadas na Figura 3.3(a), e as configurações associadas aos outros parâmetros da abordagem na Figura 3.3(b).

Visando facilitar o entendimento da ferramenta, é apresentado a seguir um exemplo de execução da $P A R_{L P}$ por meio da ferramenta desenvolvida. Inicialmente, é necessário que se selecione o conjunto de regras a ser processado, o conjunto contendo o suporte das regras sendo calculadas para calcular as medidas transacionais quando necessário e o diretório onde os resultados serão gravados ([A] da Figura 3.3(a)). Em seguida 
é necessário selecionar o tipo de rede, redirecionado o usuário para a interface da Figura 3.3(a) ([B] da Figura 3.3(a)). No exemplo, o tipo de rede [TR] escolhido foi rede homogênea ([B] da Figura 3.3(a)), a medida de similaridade [S] a JaccardHomogenea (Figura 3.3(b)) (Seção 3.3.1, Equação 3.1), usando como estratégia de construção a técnica padrão (Figura 3.3(b), "concetada por similaridade"), a medida de ranqueamento [MR] a Centralidade de Grau (Figura 3.3(b)) e, por fim, como algoritmo de classificação o GFHF (Figura 3.3(b)). Em [D], na Figura 3.3(a), foi indicado como 10 o número de regras a serem analisadas pelo usuário [N]. Por fim, para simular a classificação das regras por um usuário, as regras a serem consideradas interessantes foram selecionadas aleatoriamente, apenas como meio de demonstrar o processo em execução. Maiores detalhes sobre essas configurações paramétricas podem ser vistas na Seção 3.3.1 na avaliação da abordagem.

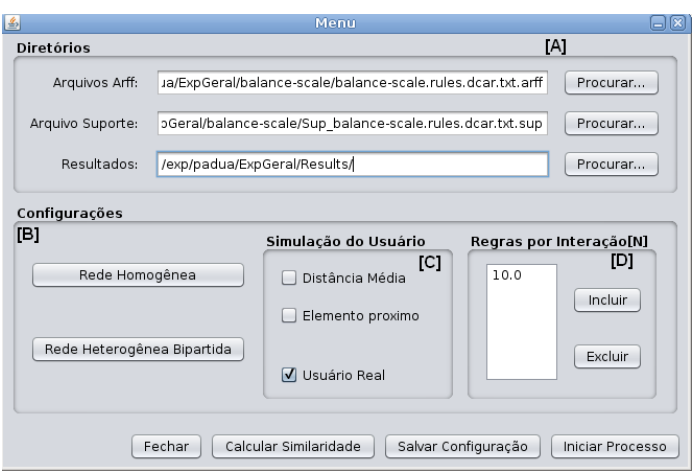

(a) Configuração contendo base de dados e informações sobre o usuário.

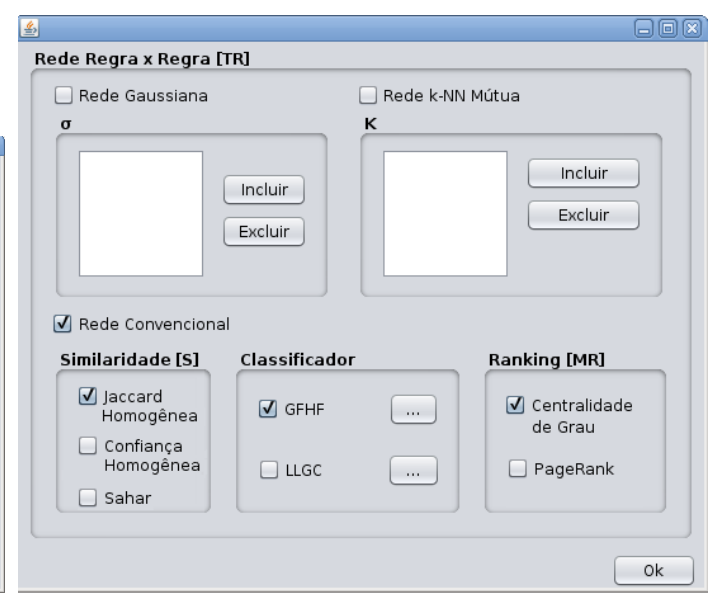

(b) Configuração referente a rede homogênea.

Figura 3.3: Configuração utilizada para realização do exemplo.

Após a realização das configurações, o processamento das regras é iniciado. O processo inicia-se com a [Etapa 1], que consiste em modelar a rede calculando a similaridade entre todas as regras utilizando a medida de similaridade [S] e o tipo de rede [TR] informados. Essa rede de regras de associação é enviada para a [Etapa 2], que é responsável pela interação com o usuário. A [Etapa 2] inicia-se com a aplicação da medida de rede [MR] em toda a rede para realizar o ranqueamento das regras. Calcula-se então a medida [MR] para todas as regras e realiza-se um ranqueamento de acordo com os valores obtidos. Do ranqueamento, são selecionadas as 5 regras melhor posicionadas e as 5 regras pior posicionadas, conforme explicado anteriormente. Essas regras são então exibidas para o usuário para classificação, conforme Figura 3.4. As regras são exibidas no formato de lista, na qual o usuário seleciona as regras que considera interessante e clica em "Ok" para confirmar a classificação. Nessa figura as regras são apresentadas de acordo com o ranqueamento, ou seja, a regra no topo da lista é a regra que obteve a melhor posição no ranqueamento enquanto a última regra é a que obteve a pior posição. A ordem foi mantida apenas para exibir as características das regras que obtiveram melhor e pior resultado de acordo com a medida de rede [MR] selecionada. Após rotular as regras selecionadas é 
iniciada a [Etapa 3]. Nessa etapa o algoritmo de classificação propaga os rótulos dados pelo usuário para todas as regras da rede, classificando-as como "Interessante" ou "Não Interessante". Após a classificação, é executada a [Etapa 4], que consiste em realizar uma contagem das regras interessantes e questionar o usuário referente ao término do processo, conforme Figura 3.5.

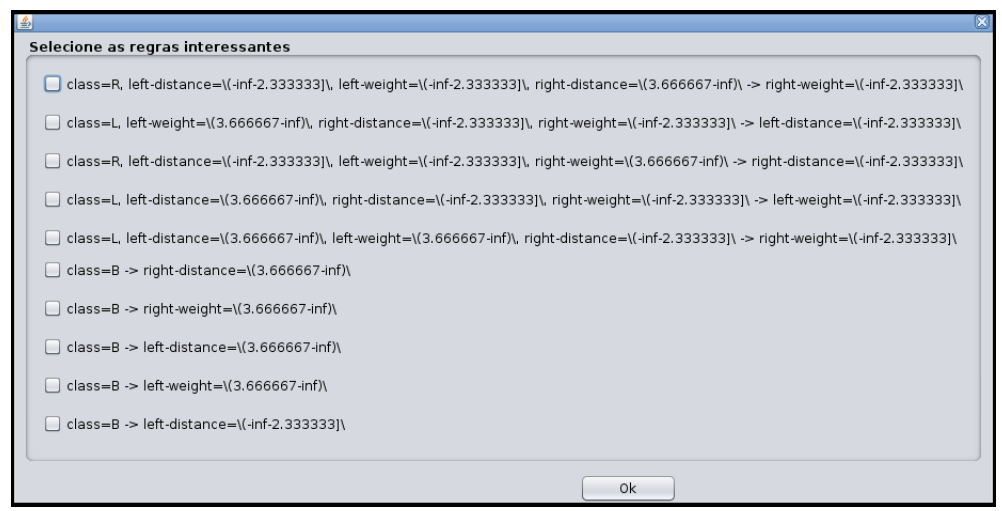

Figura 3.4: Regras a serem classificadas pelo usuário na primeira iteração.

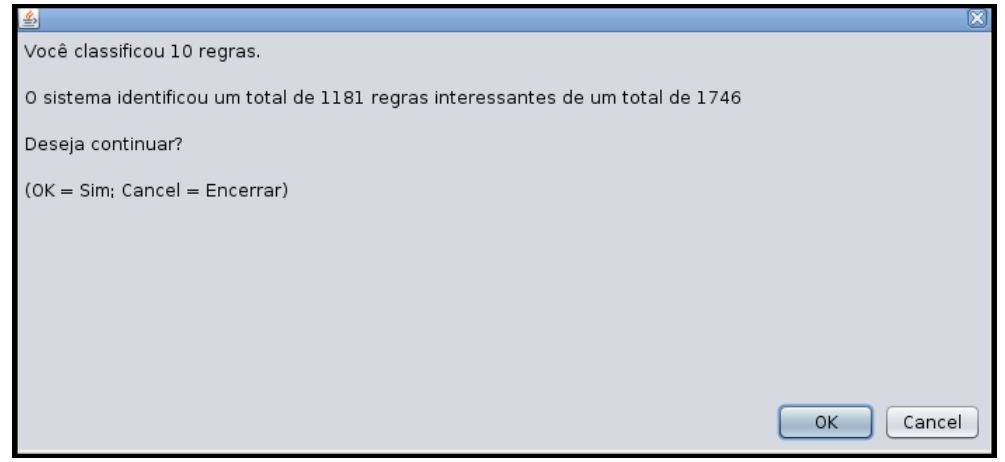

Figura 3.5: Avaliando o critério de parada na primeira iteração.

Visando exemplificar as iterações, foi selecionado que o processo continuasse. O ranqueamento foi realizado mais uma vez, considerando apenas as regras classificadas como interessantes pelo algoritmo de classificação. O segundo ranqueamento pode ser visto na Figura 3.6. Após o ranqueamento, foi novamente realizada a classificação, tanto pelo usuário quanto pelo algoritmo de classificação, e as regras interessantes foram contadas e exibidas para o usuário, conforme Figura 3.7. Foi selecionado que a abordagem finalize e parte do resultado final pode ser visualizado na Figura 3.8 .

\subsection{Avaliação Experimental da $P A R_{L P}$}

Com o objetivo de avaliar a abordagem proposta, experimentos foram realizados. Esses experimentos foram divididos em dois tipos: (i) sem a participação do usuário (Seção 3.3.1) e (ii) com a participação do usuário (Seção 3.3.2). Os experimentos sem a participação do usuário foram realizados visando encontrar as melhores configurações a serem utilizadas pela $P A R_{L P}$, a fim de definir o melhor funcionamento da abordagem, 


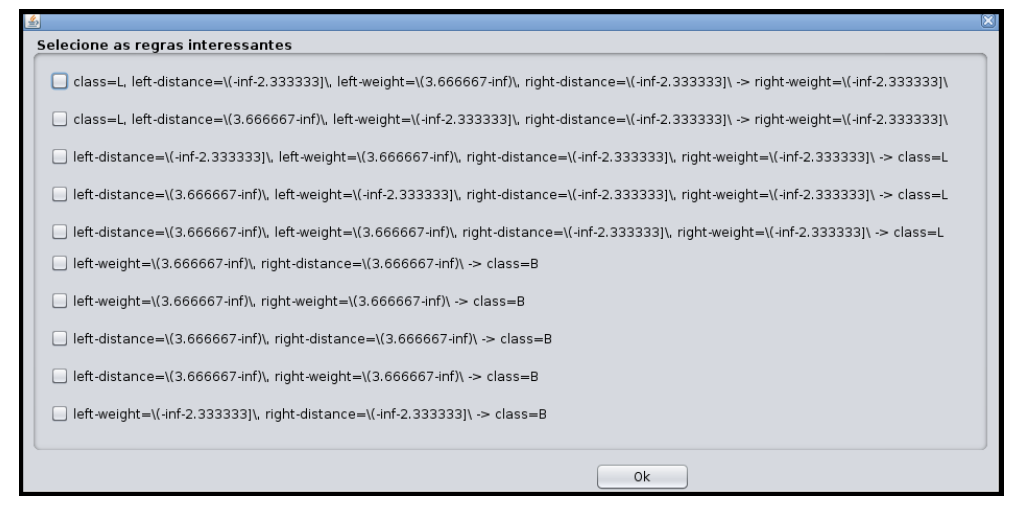

Figura 3.6: Regras a serem classificadas pelo usuário na segunda iteração.

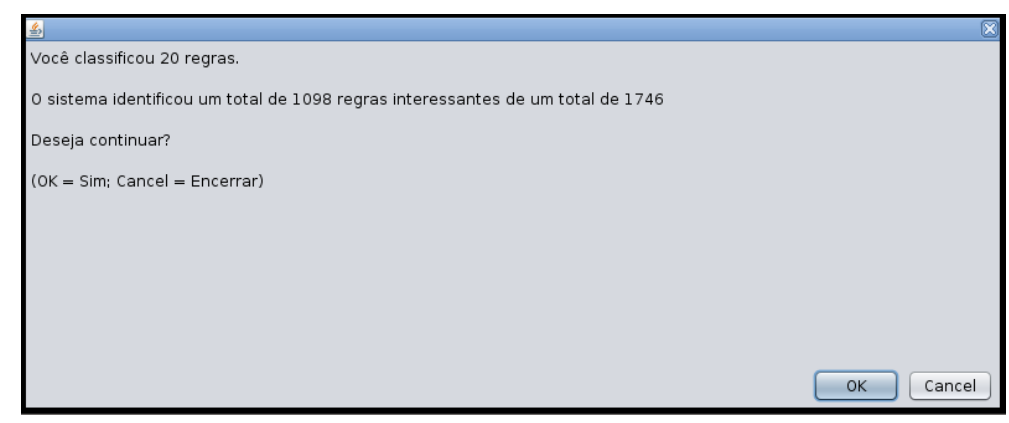

Figura 3.7: Avaliando o critério de parada na segunda iteração.

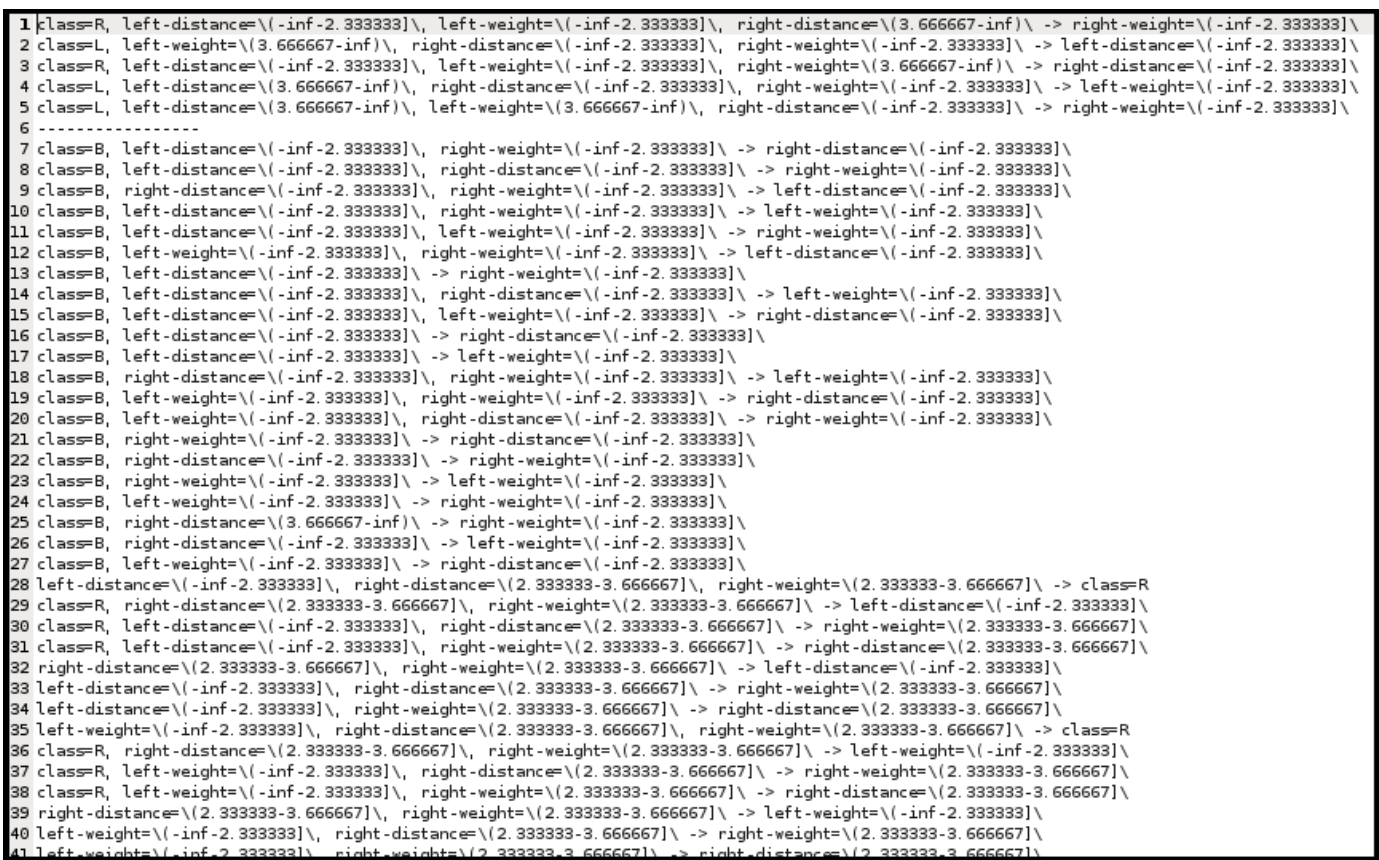

Figura 3.8: Arquivo de saída obtido após duas iterações.

assim como suas limitações. Nesse tipo de experimento, a [Etapa 2] da Figura 3.1, referente a classificação das regras a ser realizada pelo usuário, é simulada utilizando bases de dados de domínio público. Os experimentos com a participação do usuário foram realizados visando encontrar as regras de associação já consideradas interessantes por um especialista de domínio. Nesse tipo de experimento, a [Etapa 2] da Figura 3.1, referente a classificação, foi realizada pelo usuário. 


\subsubsection{Avaliação Sem a Participação do Usuário}

Como se pôde observar, a abordagem proposta possui alguns parâmetros a serem definidos (vide Seção 3.1). Visando analisar essa variação de parâmetros com o objetivo de encontrar as melhores configurações, experimentos foram realizados instanciando cada etapa do processo com diferentes tipos de redes, com diferentes medidas de similaridade, em conjunto com diferentes medidas de ranqueamento para realizar a interação, e algoritmos de classificação em diferentes bases de dados de domínio público. Nesse tipo de experimento, a [Etapa 2] da Figura 3.1, referente a classificação das regras a ser realizada pelo usuário é simulada. As configurações e as bases de dados utilizadas são descritas na próxima seção e, logo em seguida, são apresentados os resultados realizando uma discussão a respeito da abordagem.

\section{Experimentos}

As configurações descritas nesta seção foram executadas em 8 bases de dados. As bases selecionadas foram: balance-scale, breast-cancer, car, ecoli, habermann, iris, tic-tac-toe e zoo. Todas as bases estão disponíveis gratuitamente através do repositório UCI ${ }^{1}$. Na Tabela 3.1 é possível visualizar mais informações referentes as bases de dados. Algumas bases de dados possuem elementos faltantes em seus registros, ou seja, possuem valores desconhecidos em algumas transações. Como o objetivo deste mestrado não contempla a geração de regras de associação em bases de dados com informações faltantes, essas transações específicas foram removidas, restando apenas as transações que não possuem valores faltantes (valores apresentados na Tabela 3.1). O suporte e a confiança de cada base de dados foram definidos empiricamente, com o objetivo de gerar uma quantidade razoável de regras de associação. O objetivo foi gerar entre 1.000 e 2.000 regras, sendo uma quantidade não muito pequena, a ponto do conjunto objetivo (1\% do total) possuir no mínimo 10 regras e também não muito grande forçando um processamento maior e mais demorado.

Tabela 3.1: Detalhes das bases de dados utilizadas nos experimentos.

\begin{tabular}{|c|c|c|c|c|}
\hline Base & Número de Exemplos & Suporte & Confiança & Número de Regras \\
\hline balance-scale & 625 & $1 \%$ & $10 \%$ & 1746 \\
\hline breast-cancer & 277 & $10 \%$ & $50 \%$ & 1602 \\
\hline car & 1728 & $1 \%$ & $50 \%$ & 1326 \\
\hline ecoli & 336 & $10 \%$ & $50 \%$ & 1685 \\
\hline habermann & 306 & $0 \%$ & $1 \%$ & 1006 \\
\hline iris & 150 & $0 \%$ & $0 \%$ & 967 \\
\hline tic-tac-toe & 958 & $5 \%$ & $50 \%$ & 1317 \\
\hline zoo & 101 & $40 \%$ & $50 \%$ & 1658 \\
\hline
\end{tabular}

Para realizar os experimentos foi necessário a definição das configurações em cada uma

\footnotetext{
${ }^{1}$ http://archive.ics.uci.edu/ml/.
} 
das etapas apresentadas na Figura 3.1. Essas configurações são explicadas a seguir.

\section{Etapa 1 - Modelagem}

Para realizar a modelagem das regras de associação é necessário a definição dos seguintes parâmetros: tipo de rede [TR] e medida de similaridade [S]. O tipo de rede é responsável pela definição da configuração da rede e como ela será construída. Já a medida de similaridade irá ditar o valor das conexões entre as regras e quais regras serão conectadas. Para realização dos experimentos foram escolhidas dois tipos de rede: redes homogêneas e redes heterogêneas bipartida. Como a medida de similaridade depende da rede escolhida, elas serão explicadas a seguir, em conjunto com a explicação dos tipos de rede.

$\mathrm{Na}$ rede homogênea cada vértice representa uma regra de associação e a medida de similaridade é calculada de acordo com as regras, permitindo que a exploração seja direcionada de acordo com a similaridade existente tanto entre os itens que compõem cada regra como de acordo com as transações que geraram essas regras. As redes homogêneas também possuem técnicas para construção visando melhorar os resultados da exploração. Nos experimentos foram utilizadas 3 técnicas de construção: rede convencional, kNN mútua e gaussiana. A rede convencional é a rede gerada pela medida de similaridade sem alteração alguma. Na rede kNN mútua utiliza-se da técnica de construção kNN, em que apenas realiza-se a ligação entre os $\mathrm{k}$ vizinhos mais próximos. Na gaussiana aplica-se à rede convencional o kernel RBF, alterando o peso das conexões de acordo com um parâmetro $\sigma$. As técnicas kNN mútua e kernel RBF foram explicadas na Seção 2.2.2. Na Figura 3.9 é possível visualizar um exemplo de cada configuração modelada de acordo com a tabela de similaridade apresentada. A rede convencional realiza as ligações de acordo com os valores da tabela. A rede $\mathrm{kNN}$ mútua realiza as ligações respeitando o $k$ máximo, que no caso do exemplo é igual a 1. E a rede gaussiana aplica o kernel RBF sobre os pesos da tabela de similaridade.

Para cada uma das redes selecionadas foram utilizadas 3 medidas de similaridade: JaccardHomogênea, ConfiançaHomogênea e Sahar. A escolha foi realizada de modo a conter uma medida de similaridade voltada aos itens (JaccardHomogênea), uma voltada à cobertura (ConfiançaHomogênea) e uma que contemplasse a junção das anteriores (Sahar). A medida JaccardHomogênea (Eq. 3.1) foi proposta a partir da Jaccard, apresentada na Equação 2.6, para considerar o LHS e o RHS separadamente, aplicando-se a medida Jaccard em cada um dos lados da regra e calculando-se o valor médio obtido, a fim de considerar implicação da regra no cálculo da similaridade, em vez de utilizar a regra apenas como um itemset. A ConfiançaHomogênea foi proposta a partir da Confiança, apresentada na Seção 2.1.1, para considerar a possibilidade do itemset de uma regra favorecer a ocorrência do itemset da outra regra (Equação 3.2), explorando a similaridade de acordo com as transações que geraram as regras. Na medida convencional calcula-se a implicação entre o LHS e o 


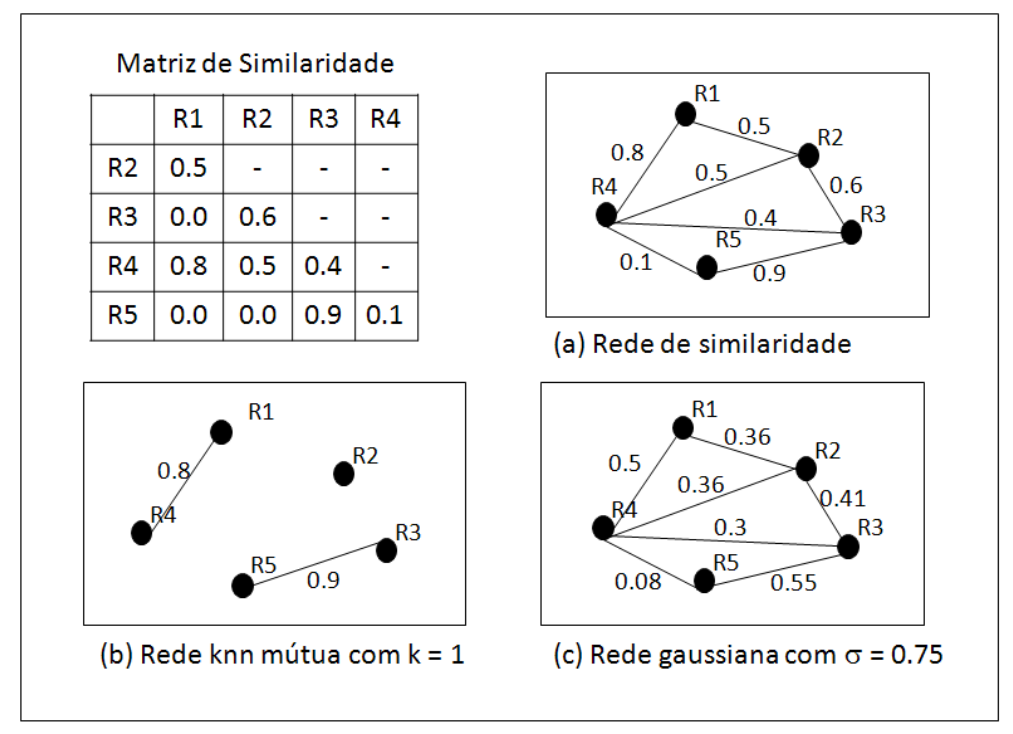

Figura 3.9: Exemplo de modelagem utilizando rede homogênea.

RHS de uma mesma regra. Já a medida Sahar (Equação 2.7) é originalmente uma medida de distância que varia de 3 (totalmente similar) a 6 (totalmente dissimilar) e considera tanto os itens em comum em uma regra quanto as transações que as geraram. Essa medida precisou ser adaptada, uma vez que as redes são construídas sobre medidas de similaridade. A medida modificada é apresentada na Equação 3.3, considerando o valor 0 para regras totalmente dissimilares e 3 para regras totalmente similares.

$$
\operatorname{JaccardHomogenea}\left(R L_{1}, R L_{2}\right)=\frac{\operatorname{Jaccard}\left(L H S\left(R L_{1}\right), L H S\left(R L_{2}\right)\right)+\operatorname{Jaccard}\left(R H S\left(R L_{1}\right), R H S\left(R L_{2}\right)\right)}{2}
$$

$$
\text { ConfiancaHomogenea }\left(R L_{1}, R L_{2}\right)=\frac{\#\left(T\left(R L_{1}\right) \cup T\left(R L_{2}\right)\right)}{\#\left(T\left(R L_{1}\right)\right)}
$$

$$
\operatorname{SaharAdaptada}\left(R L_{1}, R L_{2}\right)=6.0-\operatorname{Sahar}\left(R L_{1}, R L_{2}\right)
$$

Já na rede bipartida os vértices agrupadores são as regras enquanto os vértices não agrupadores são os itens que pertencem àquela regra, calculando-se o peso das conexões de acordo com medidas objetivas aplicadas às regras. Com essa configuração é possível realizar uma exploração voltada ao item como meio de ligação entre as regras. Para a rede bipartida foram utilizadas medidas objetivas para calcular o peso dos itens em cada regra. As medidas objetivas utilizadas foram: JaccardBipartida e Confiança. A medida JaccardBipartida foi proposta a partir da medida Jaccard, apresentada na Equação 2.6, para o numerador considerar o suporte da regra como um todo e o denominador o suporte individual de cada um dos lados, calculando, dessa maneira, o quão similares os lados da regra são em relação as transações que os mesmos cobrem. É possível visualizar a medida JaccardBipartida 
na Equação 3.4. Já a Confiança utilizada na rede bipartida é a medida convencional, explicada na Seção 2.1.1. Na Figura 3.10 é possível visualizar um exemplo de modelagem utilizando rede bipartida. Baseado em uma tabela de similaridade, as regras são modeladas de maneira que cada item receba o valor da medida objetivo da respectiva regra em sua respectiva ligação.

$$
\operatorname{JaccardBipartida}(R L)=\frac{\#(T(R L))}{\#(T(L H S(R L)))+\#(T(R H S(R L)))-\#(T(R L))}
$$

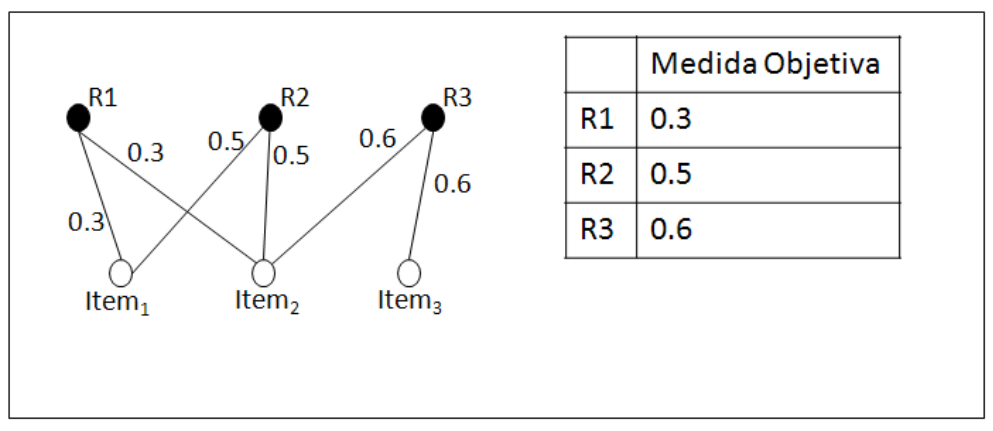

Figura 3.10: Exemplo de modelagem utilizando rede bipartida.

\section{Etapa 2 - Interação com o usuário}

Para sugerir as regras a serem classificadas pelo usuário foram utilizadas duas medidas de rede: Centralidade de Grau e PageRank (ambas explicadas na Seção 2.2.3). A Centralidade de Grau encontra as regras mais importantes de acordo com a proximidade com seus vizinhos, somando a similaridade de todas as conexões. Já o PageRank calcula a importância da regra de acordo com toda a rede, calculando a importância da regra nas conexões existentes. Utilizando as medidas descritas, a abordagem seleciona as $\frac{N}{2}$ melhores regras e as $\frac{N}{2}$ piores regras de acordo com as medidas de ranqueamento selecionadas. O ranqueamento é gerado considerando apenas as regras classificadas como "Interessantes" na etapa de classificação. Como na primeira iteração a classificação ainda não foi executada, todas as regras são consideradas para a geração do ranqueamento. Nos experimentos foram rotuladas 10 regras por interação; sendo assim, a abordagem seleciona as 5 melhores e as 5 piores regras, de acordo com o ranqueamento gerado, para serem rotuladas pelo usuário. O número de regras selecionadas por interação foi definido levando em consideração que a quantidade de regras a ser rotulada pelo usuário deve ser pequena, reduzindo o esforço realizado, mas deve possuir uma quantidade o suficiente para que os algoritmos de classificação consigam propagar os rótulos por toda a rede.

A abordagem necessita, nesta etapa, que um usuário classifique o conjunto de regras de acordo com o conhecimento que ele possui. Um dos desafios encontrados em abordagens que utilizam especialista é o custo associado a validação, sendo interessante a criação de meios para simular os interesses do usuário a fim de reduzir o 
esforço a ser realizado pelo especialista humano (Bie, 2013; Hanhijärvi et al., 2009; Gionis et al., 2007). Além disso, não é fácil obter avaliações com especialistas em diversas bases de dados. Mesmo sendo fácil, vale mencionar que o interesse em uma exploração de um dado domínio varia de usuário para usuário. Diante do exposto, o processo de classificação das regras que serão consideradas como "Interessantes" foi simulado. Para que esse processo de classificação fosse simulado, com a maior precisão possível, definiu-se como mecanismo de simulação a obtenção de conjuntos de regras contendo as regras que seriam identificadas como interessantes pelo usuário se o mesmo tivesse avaliado todas as regras do conjunto. Desse modo, esses conjuntos, denominados aqui de conjuntos de regras objetivo, são considerados para serem encontrados nas explorações, simulando, dessa maneira, as classificações do usuário. A simulação consegue ser bastante abrangente, sendo diversificada o suficiente para validar a abordagem proposta.

Foram utilizadas 2 estratégias diferentes para selecionar esses conjuntos de regras objetivo: totalmente aleatória e semi aleatória. A estratégia totalmente aleatória seleciona aleatoriamente $1 \%$ do total de regras, sem reposição, e as define como pertencentes ao conjunto de regras objetivo. Já a estratégia semi aleatória seleciona 1 regra aleatoriamente e cria um ranqueamento utilizando a medida Jaccard (Equação 2.6) para, então, selecionar as regras mais similares a regra escolhida até que o número atinja $1 \%$ do total das regras de associação. Ressalta-se que essa medida não foi utilizada como medida de similaridade para construção das redes, mas sim uma variação da mesma, a fim de evitar que a exploração fosse enviesada pela medida de similaridade. A diferença entre esses conjuntos objetivo está na similaridade entre as regras que precisam ser encontradas: o conjunto totalmente aleatório possui uma similaridade muito menor que o conjunto semi aleatório, que foi construído baseado em uma medida de similaridade. Desse modo, consegue-se avaliar a abordagem em relação a conjuntos objetivos com características distintas. Como as estratégias de seleção de regras possuem comportamento aleatório, foram gerados 30 conjuntos objetivo com cada estratégia para cada base de dados testada, obtendo assim resultados estatisticamente significativos.

Com as regras definidas nos conjuntos objetivos a simulação da classificação do usuário é realizada com base em um threshold calculado na primeira iteração. $\mathrm{O}$ valor de threshold é o valor médio de similaridade entre todas as regras a serem classificadas pelo usuário com a regra mais próxima de cada uma delas no conjunto objetivo, ou seja, para o cálculo de média é considerado, para cada regra a ser classificada pelo usuário, apenas a sua regra mais similar no conjunto objetivo. Após o cálculo do threshold, é realizada a classificação das regras sugeridas. Para cada regra a ser classificada, considera-se apenas o maior valor de similaridade entre ela e as regras contidas no conjunto objetivo. Esse valor de similaridade é comparado com o threshold obtido: caso o valor de similaridade seja maior que 


\begin{tabular}{|c|c|c|c|c|c|c|}
\hline Conjunto Objetivo & \multirow{2}{*}{$\begin{array}{l}\text { Regras a serem classificadas } \\
\text { pelo usuário na } 1 \text { iteração }\end{array}$} & \multicolumn{5}{|c|}{ Matriz de Similaridade } \\
\hline & & & $\mathrm{Ra}$ & $\mathrm{Rb}$ & Rc & $\mathrm{Rd}$ \\
\hline \multirow{3}{*}{$\begin{array}{l}\mathrm{R} 2 \\
\mathrm{R} 3\end{array}$} & \multirow{3}{*}{$\begin{array}{l}\mathrm{Ra}[+\mathrm{R} 2[0.7]][\mathrm{I}] \\
\mathrm{Rb}[+\mathrm{R} 3[0.8]][\mathrm{I}] \\
\mathrm{Rc}[+\mathrm{R} 3[0.3]][\mathrm{NI}] \\
\mathrm{Rd}[+\mathrm{R} 1[0.7]][\mathrm{I}]\end{array}$} & R1 & 0.3 & 0.4 & 0.2 & 0.7 \\
\hline & & R2 & 0.7 & 0.3 & 0.2 & 0.5 \\
\hline & & R3 & 0.4 & 0.8 & 0.3 & 0.2 \\
\hline & eshold $=(0.7+0.8+0.3+0.7)$ & 0,62 & & & & \\
\hline
\end{tabular}

Figura 3.11: Exemplo de cálculo de threshold e simulação da classificação das regras por um usuário.

o valor de threshold a regra é considerada "Interessante"; caso contrário a regra é considerada "Não Interessante". O cálculo do threshold, assim como a simulação da classificação das regras por um usuário, podem ser vistos na Figura 3.11. Nessa figura, as regras que fazem parte do conjunto objetivo são as regras R1, R2 e R3. As regras selecionadas para serem classificadas pelo usuário são as regras Ra, Rb, Rc e Rd. São selecionadas as maiores similaridades de cada regra selecionada em relação as regras contidas no conjunto objetivo. No exemplo, a Ra possui maior similaridade com a R2 (0.7), a Rb maior similaridade com a R3 (0.8), a Rc com a R3 (0.3) e a Rd com a R1 (0.7). É calculada então a média dessas similaridades e esse valor é considerado como threshold; no exemplo o valor de threshold fica em 0.625. Desse modo, inicia-se a simulação da classificação, fazendo com que as regras que possuem um valor de similaridade maior que o threshold ( $\mathrm{Ra}, \mathrm{Rb}$ e $\mathrm{Rd}$ ) sejam classificadas como [I], enquanto as regras que possuem um valor menor que 0.625 de similaridade (Rc) sejam classificadas como [NI].

\section{Etapa 3 - Classificação}

Após capturar o interesse e/ou conhecimento do usuário, inicia-se a etapa de classificação. Como o tipo de rede [TR] influencia o algoritmo de classificação, foram escolhidos 2 algoritmos de classificação para cada tipo de rede. Para as redes homogêneas foram utilizados os algoritmos LLGC e GFHF. Esses algoritmos de classificação foram escolhidos por serem amplamente utilizados na literatura e obterem altos valores de acurácia. Para as redes bipartidas foram selecionados os algoritmos GNetMine e LPBHN. Ambos foram selecionados pelos mesmos critérios utilizados nos algoritmos de classificação de rede homogênea: amplo uso na literatura e alto valor de acurácia. As configurações utilizadas pelos algoritmos LLGC e GFHF são apresentadas na Tabela 3.2 e as configurações utilizadas pelos algoritmos GNetMine e LPBHN são apresentadas na Tabela 3.3.

\section{Etapa 4 - Critério de Parada}

Com todo o processo realizado, é necessário uma verificação com o objetivo de analisar se a abordagem deve continuar ou se o resultado obtido é satisfatório. Conforme discutido no item "Interação com o usuário", definiu-se uma simulação de classificação de regras por um usuário. Portanto, nos experimentos existem os conjuntos objetivo de regras de associação a serem encontrados. Para verificar se o processo 
deve ou não continuar, foi realizada uma varredura nas regras consideradas interessantes: se todas as regras do conjunto objetivo foram encontradas a abordagem finaliza; se não ela continua até encontrar todas as regras.

Tabela 3.2: Parâmetros associados as redes homogêneas.

\begin{tabular}{|c|c|}
\hline Parâmetro & Valor \\
\hline Tipo de Rede [TR] & $\begin{array}{c}\text { kNN Mútua }(\mathrm{K}=10,20,30,40 \text { e 50), } \\
\text { Gaussiana }(\sigma=0.25,0.50 \text { e 0.75), Convencional }\end{array}$ \\
\hline Similaridade [S] & $\begin{array}{c}\text { JaccardHomogênea(Eq. 3.1), } \\
\text { ConfiançaHomogênea (Eq. 3.2), Sahar(Eq. 3.3) }\end{array}$ \\
\hline Medida para Ranqueamento [MR] & Centralidade de Grau, PageRank \\
\hline Número de Regras Avaliadas [N] & 10 \\
\hline Algoritmos de Classificação & GFHF, LLGC $(\alpha=0.1,0.3,0.5,0.7$ e 0.9) \\
\hline
\end{tabular}

Tabela 3.3: Parâmetros associados as redes bipartidas.

\begin{tabular}{|c|c|}
\hline Parâmetro & Valor \\
\hline Tipo de Rede [TR] & Rede Heterogênea Bipartida \\
\hline Similaridade $[\mathrm{S}]$ & JaccardBipartida(Eq. 3.4), Confiança \\
\hline Medida para Ranqueamento $[\mathrm{MR}]$ & Centralidade de Grau, PageRank \\
\hline Número de Regras Avaliadas $[\mathrm{N}]$ & 10 \\
\hline Algoritmos de Classificação & LPBHN, GNetMine $(\alpha=0.1,0.3,0.5,0.7$ e 0.9) \\
\hline
\end{tabular}

Destaca-se que para cada base de dados foram geradas as regras de associação e, para cada conjunto de regras, foram realizadas 60 execuções por configuração (com um total de 348 configurações) descrita, sendo 30 com conjuntos gerados aleatoriamente e 30 com conjuntos gerados semialeatoriamente. As configurações utilizadas nos experimentos, tanto nas redes homogêneas (324 configurações) quanto nas redes bipartidas (24 configurações), podem ser vistas nas Tabelas 3.2 e 3.3 .

Os resultados obtidos com essas configurações experimentais (20880 para cada base de dados $(60 * 348))$ são discutidos na próxima seção.

\section{Análise dos Resultados}

Após a execução da $P A R_{L P}$, utilizando todas as configurações apresentadas nas Tabelas 3.2 e 3.3, para cada base de dados e conjunto objetivo, os resultados obtidos foram processados. Apenas o valor médio por configuração, para cada tipo de conjunto objetivo (aleatório e semi aleatório), foi considerado. Assim, cada uma das configurações tem como valor final a média de 30 execuções para cada tipo de conjunto objetivo. A análise dos resultados foi direcionada à redução do espaço de exploração, que é uma validação amplamente utilizada na literatura, em que analisa-se a quantidade de regras que o usuário deixa de explorar para encontrar todo o conhecimento que considera interessante. No caso desse experimento, o conhecimento considerado interessante encontra-se contido 
nos conjuntos objetivo e, portanto, o objetivo foi encontrar todas as regras contidas nos conjuntos objetivo, reduzindo ao máximo a quantidade de regras a serem exploradas.

Para analisar quais configurações se saíram melhor, considerando os resultados obtidos em todas as base de dados, configurações e tipos de conjunto objetivo, foi aplicado o teste de Friedman NxN com o pós teste de Nemenyi (Demšar, 2006). O teste estatístico foi realizado sobre os valores de ambas as estratégias de simulação, ou seja, tanto nos conjuntos objetivo totalmente aleatórios quanto nos conjuntos objetivo semi aleatório, considerando todas as bases de dados. O teste é realizado com o objetivo de encontrar as melhores configurações paramétricas, visando reduzir o número de configurações a serem analisadas. Devido ao grande número de configurações utilizadas, aplicar o teste estatístico em todas as configurações de uma única vez se tornou computacionalmente inviável. Para solucionar esse problema, os resultados foram particionados conforme apresentado na Tabela 3.4, em que cada linha possui um conjunto de configurações divididas de acordo com o tipo de rede [TR] e algoritmo de classificação. Nessa tabela, a Rede Knn com $K=10$ e algoritmo LLGC representa uma partição, a Rede Knn com $K=20$ e algoritmo LLGC outra partição, e assim por diante. Em cada particionamento foi aplicado o teste estatístico para obter as melhores configurações para cada [TR] e algoritmo de classificação.

Do resultado obtido, foram selecionadas as duas melhores configurações de cada particionamento (totalizando 40 configurações, abrangendo as melhores configurações de cada partição) para realizar um teste estatístico. As 20 melhores configurações obtidas dessas 40 configurações selecionadas, segundo o teste estatístico, podem ser vistas na Tabela 3.5.

Tabela 3.4: Particionamento dos resultados para análise estatística.

\begin{tabular}{|c|c|c|}
\hline Tipo de Rede & Parâmetro da Rede & Classificador \\
\hline $\mathrm{kNN}$ & $K=10$ & LLGC \\
\hline $\mathrm{kNN}$ & $K=20$ & LLGC \\
\hline $\mathrm{kNN}$ & $K=30$ & LLGC \\
\hline $\mathrm{kNN}$ & $K=40$ & LLGC \\
\hline $\mathrm{kNN}$ & $K=50$ & LLGC \\
\hline $\mathrm{kNN}$ & $K=10$ & GFHF \\
\hline $\mathrm{kNN}$ & $K=20$ & GFHF \\
\hline $\mathrm{kNN}$ & $K=30$ & GFHF \\
\hline $\mathrm{kNN}$ & $K=40$ & GFHF \\
\hline $\mathrm{kNN}$ & $K=50$ & GFHF \\
\hline Kernel RBF & $\sigma=0.25$ & LLGC \\
\hline Kernel RBF & $\sigma=0.50$ & LLGC \\
\hline Kernel RBF & $\sigma=0.75$ & LLGC \\
\hline Kernel RBF & $\sigma=0.25$ & GFHF \\
\hline Kernel RBF & $\sigma=0.50$ & GFHF \\
\hline Kernel RBF & $\sigma=0.75$ & GFHF \\
\hline Convencional & -- & LLGC \\
\hline Convencional & -- & GFHF \\
\hline Bipartida & -- & LPBHN \\
\hline Bipartida & -- & GNetMine \\
\hline
\end{tabular}


Tabela 3.5: As 20 melhores configurações obtidas nos experimentos realizados.

\begin{tabular}{|c|c|c|c|c|}
\hline Rede $[\mathrm{TR}]$ & Classificador & Sim. $[\mathrm{S}]$ & Ranqueamento [MR] & Sigla \\
\hline kNN $(K=10)$ & LLGC $(\alpha=0.5)$ & Confiança & PageRank & kNN-10-LLGC-0.5-CF-PR \\
\hline kNN $(K=10)$ & LLGC $(\alpha=0.7)$ & Confiança & PageRank & kNN-10-LLGC-0.7-CF-PR \\
\hline kNN $(K=20)$ & LLGC $(\alpha=0.1)$ & Confiança & Centralidade de Grau & kNN-20-LLGC-0.1-CF-OD \\
\hline kNN $(K=20)$ & LLGC $(\alpha=0.7)$ & Confiança & Centralidade de Grau & kNN-20-LLGC-0.7-CF-OD \\
\hline kNN $(K=30)$ & LLGC $(\alpha=0.7)$ & Confiança & PageRank & kNN-30-LLGC-0.7-CF-PR \\
\hline kNN $(K=30)$ & LLGC $(\alpha=0.7)$ & Confiança & Centralidade de Grau & kNN-30-LLGC-0.7-CF-OD \\
\hline kNN $(K=10)$ & GFHF & Jaccard & PageRank & kNN-10-GFHF-JC-PR \\
\hline kNN $(K=10)$ & GFHF & Jaccard & Centralidade de Grau & kNN-10-GFHF-JC-OD \\
\hline kNN $(K=20)$ & GFHF & Jaccard & PageRank & kNN-20-GFHF-JC-PR \\
\hline kNN $(K=20)$ & GFHF & Jaccard & Centralidade de Grau & kNN-20-GFHF-JC-OD \\
\hline kNN $(K=30)$ & GFHF & Jaccard & PageRank & kNN-30-GFHF-JC-PR \\
\hline kNN $(K=30)$ & GFHF & Jaccard & Centralidade de Grau & kNN-30-GFHF-JC-OD \\
\hline kNN $(K=40)$ & GFHF & Jaccard & Centralidade de Grau & kNN-40-GFHF-JC-PR \\
\hline kNN $(K=40)$ & GFHF & Jaccard & PageRank & kNN-40-GFHF-JC-OD \\
\hline kNN $(K=50)$ & GFHF & Jaccard & PageRank & kNN-50-GFHF-JC-PR \\
\hline kNN $(K=50)$ & GFHF & Jaccard & Centralidade de Grau & kNN-50-GFHF-JC-OD \\
\hline Convencional & GFHF & Jaccard & PageRank & Simi-GFHF-JC-PR \\
\hline Convencional & GFHF & Confiança & Centralidade de Grau & Simi-GFHF-CF-OD \\
\hline Bipartida & LPBHN & Jaccard & Centralidade de Grau & Bipartida-LPBHN-JC-OD \\
\hline Bipartida & LPBHN & Confiança & Centralidade de Grau & Bipartida-LPBHN-CF-OD \\
\hline
\end{tabular}

A análise que se segue foi realizada sobre as 20 melhores configurações anteriormente identificadas. Da Tabela 3.6 até a Tabela 3.13 são exibidas as médias de redução do espaço de exploração das 30 execuções de cada configuração (os resultados encontram-se divididos por tipo de conjunto objetivo), onde o resultado que obteve a maior redução do espaço de exploração, levando em consideração, segundo o teste estatístico, os conjuntos objetivo (aleatório e semi aleatório), estão em negrito. Na primeira coluna encontra-se a sigla de cada configuração, conforme definida na Tabela 3.5. Na segunda coluna é exibida a média de redução das 30 execuções com os conjuntos objetivo totalmente aleatório, ressaltando que esse percentual representa o porcentual de regras que não precisará ser explorada pelo usuário para encontrar as regras consideradas interessantes. Na terceira coluna é exibida a similaridade média das regras contidas nos conjuntos objetivo totalmente aleatório. Esse valor varia entre 0 e 1 , sendo 0 um conjunto que não possui similaridade alguma e 1 um conjunto totalmente similar. Na quarta coluna é exibida a média de redução das 30 execuções com os conjuntos objetivo semi aleatório. Na última coluna é exibido a similaridade média das regras contidas no conjunto objetivo semi aleatório.

Analisando os resultados pode-se notar que:

- Ao comparar a segunda coluna com a quarta coluna nas tabelas, é possível visualizar que, na maioria dos casos, as configurações obtiveram melhores resultados com o tipo de conjunto objetivo semi aleatório (os maiores valores encontram-se destacados em cinza), perdendo apenas em dois casos em redes bipartidas, quando o conjunto aleatório é melhor que o semi aleatório (base breast-cancer). Esses resultados demonstram que quando o conjunto objetivo é formado por regras mais similares, ou regras de um mesmo "tema", a redução tende a ser maior. 
- Houve uma variação na redução do espaço de exploração entre as bases de dados. Os maiores valores de redução foram encontrados nas bases balance-scale (Tabela 3.6), redução máxima de $63.69 \%$ em um conjunto objetivo com similaridade média de 0.6335 na configuração Simi-GFHF-CF-OD (valor em negrito), e Íris (Tabela 3.11), redução máxima de $66.49 \%$ em um conjunto objetivo com similaridade média de 0.1936 na configuração KNN-50-GFHF-JC-PR (valor em negrito). Já nas bases breast-cancer (Tabela 3.7) e zoo (Tabela 3.13) uma menor redução foi obtida, $42.45 \%$ e $46.38 \%$ respectivamente (valores em negrito), mesmo obtendo-se valores de similaridade média próximos, ou até maiores, aos obtidos as bases com melhor resultado (0.7645 e 0.1977 respectivamente). Essa variação ocorre devido às características das bases de dados: enquanto algumas podem ser muito bem representadas por algumas medidas, outras não conseguem uma representação tão satisfatória.

- É possível visualizar que as redes bipartidas possuem, tanto nos conjuntos aleatórios como nos semi aleatórios, uma similaridade média baixa (duas últimas linhas de cada tabela). Isso ocorre devido ao fato da medida utilizada nas redes bipartidas serem medidas objetivas em vez de medidas de similaridade. No caso, o valor médio calculado no conjunto objetivo denota o valor médio da medida objetiva. A exploração pela rede bipartida é realizada de acordo com a similaridade entre medidas objetivas e se mostrou menos efetiva em comparação com as redes homogêneas.

- Nas redes homogêneas é possível visualizar uma maior redução no espaço de exploração em relação as redes bipartidas (todas as linhas da tabela, com exceção das duas últimas). Isso ocorre por que as medidas selecionadas para construção da rede são medidas que calculam a similaridade entre as regras de associação. A medida Jaccard foi a que obteve melhores resultados, tanto nos conjuntos aleatórios quanto nos conjuntos semi aleatórios. Já a medida confiança conseguiu obter resultados razoáveis nos conjuntos semi aleatórios, superando em alguns casos a medida Jaccard. Já a medida Sahar não obteve resultados satisfatórios.

Após a obtenção dos resultados das 20 melhores configurações, foi aplicado novamente o teste estatístico de Friedman NxN com o pós teste de Nemenyi, visando encontrar as configurações que mais se destacaram. A escolha foi realizada de acordo com a discussão feita por Demšar (2006). O teste estatístico foi realizado sobre os valores de ambas as estratégias de simulação, ou seja, tanto nos conjuntos objetivo totalmente aleatórios quanto nos conjuntos objetivo semi aleatório, considerando todas as bases de dados. Na Figura 3.12 é possível visualizar o resultado do teste estatístico: quanto mais para a esquerda a configuração está, melhor o desempenho obtido. As linhas horizontais que passam por mais de uma configuração demonstram que a diferença entre os resultados obtidos por essas configurações não é estatisticamente significativa. Na figura é possível visualizar que várias configurações não possuem diferença estatística, o que significa que os resultados são bem parecidos. Observando o resultado do teste estatístico, nota-se que 
Tabela 3.6: Resultados obtidos após 30 execuções na base Balance-Scale.

\begin{tabular}{|c|c|c|c|c|}
\hline Sigla & Red. Aleatória & Sim. Média. & Red. Semialeatória & Sim. Média \\
\hline kNN-10-LLGC-0.5-CF-PR & $5.33 \%$ & 0.0304 & $33.68 \%$ & 0.3473 \\
\hline kNN-10-LLGC-0.7-CF-PR & $4.81 \%$ & 0.0304 & $33.79 \%$ & 0.3473 \\
\hline kNN-20-LLGC-0.1-CF-OD & $6.36 \%$ & 0.0304 & $31.56 \%$ & 0.6589 \\
\hline kNN-20-LLGC-0.7-CF-OD & $5.56 \%$ & 0.0304 & $31.44 \%$ & 0.6589 \\
\hline kNN-30-LLGC-0.7-CF-PR & $5.21 \%$ & 0.0304 & $29.50 \%$ & 0.6589 \\
\hline kNN-30-LLGC-0.7-CF-OD & $5.78 \%$ & 0.0304 & $30.53 \%$ & 0.6589 \\
\hline kNN-10-GFHF-JC-PR & $39.29 \%$ & 0.0411 & $58.82 \%$ & 0.1386 \\
\hline kNN-10-GFHF-JC-OD & $40.09 \%$ & 0.0411 & $58.30 \%$ & 0.1386 \\
\hline kNN-20-GFHF-JC-PR & $39.40 \%$ & 0.0436 & $58.71 \%$ & 0.1974 \\
\hline kNN-20-GFHF-JC-OD & $40.38 \%$ & 0.0436 & $58.30 \%$ & 0.1974 \\
\hline kNN-30-GFHF-JC-PR & $39.23 \%$ & 0.0436 & $60.82 \%$ & 0.1974 \\
\hline kNN-30-GFHF-JC-OD & $40.66 \%$ & 0.0436 & $59.97 \%$ & 0.1974 \\
\hline kNN-40-GFHF-JC-PR & $39.23 \%$ & 0.0436 & $59.79 \%$ & 0.1974 \\
\hline kNN-40-GFHF-JC-OD & $40.66 \%$ & 0.0436 & $60.94 \%$ & 0.1974 \\
\hline kNN-50-GFHF-JC-PR & $39.18 \%$ & 0.0436 & $60.88 \%$ & 0.1974 \\
\hline kNN-50-GFHF-JC-OD & $40.15 \%$ & 0.0436 & $60.14 \%$ & 0.1974 \\
\hline Simi-GFHF-JC-PR & $29.15 \%$ & 0.0889 & $58.65 \%$ & 0.3035 \\
\hline Simi-GFHF-CF-OD & $\mathbf{8 . 1 9 \%}$ & $\mathbf{0 . 0 4 2 8}$ & $\mathbf{6 3 . 6 9 \%}$ & $\mathbf{0 . 6 3 3 5}$ \\
\hline Bipartida-LPBHN-JC-OD & $5.50 \%$ & 0.0062 & $45.19 \%$ & 0.0041 \\
\hline Bipartida-LPBHN-CF-OD & $6.41 \%$ & 0.0062 & $47.54 \%$ & 0.0041 \\
\hline
\end{tabular}

Tabela 3.7: Resultados obtidos após 30 execuções na base Breast-Cancer.

\begin{tabular}{|c|c|c|c|c|}
\hline Sigla & Red. Aleatória & Sim. Média. & Red. Semialeatória & Sim. Média \\
\hline kNN-10-LLGC-0.5-CF-PR & $6.30 \%$ & 0.1111 & $31.84 \%$ & 0.3584 \\
\hline kNN-10-LLGC-0.7-CF-PR & $6.30 \%$ & 0.1111 & $31.84 \%$ & 0.3584 \\
\hline kNN-20-LLGC-0.1-CF-OD & $6.18 \%$ & 0.1480 & $31.59 \%$ & 0.7645 \\
\hline kNN-20-LLGC-0.7-CF-OD & $6.18 \%$ & 0.1480 & $31.59 \%$ & 0.7645 \\
\hline kNN-30-LLGC-0.7-CF-PR & $5.43 \%$ & 0.1480 & $31.84 \%$ & 0.7645 \\
\hline kNN-30-LLGC-0.7-CF-OD & $\mathbf{4 . 8 7 \%}$ & $\mathbf{0 . 1 4 8 0}$ & $\mathbf{4 2 . 4 5 \%}$ & $\mathbf{0 . 7 6 4 5}$ \\
\hline kNN-10-GFHF-JC-PR & $19.98 \%$ & 0.0793 & $35.77 \%$ & 0.1711 \\
\hline kNN-10-GFHF-JC-OD & $19.85 \%$ & 0.0793 & $31.02 \%$ & 0.1711 \\
\hline kNN-20-GFHF-JC-PR & $19.91 \%$ & 0.0880 & $30.59 \%$ & 0.2356 \\
\hline kNN-20-GFHF-JC-OD & $19.54 \%$ & 0.0880 & $38.51 \%$ & 0.2356 \\
\hline kNN-30-GFHF-JC-PR & $19.60 \%$ & 0.0880 & $38.33 \%$ & 0.2356 \\
\hline kNN-30-GFHF-JC-OD & $18.98 \%$ & 0.0880 & $35.83 \%$ & 0.2356 \\
\hline kNN-40-GFHF-JC-PR & $18.91 \%$ & 0.0880 & $40.64 \%$ & 0.2356 \\
\hline kNN-40-GFHF-JC-OD & $17.79 \%$ & 0.0880 & $36.39 \%$ & 0.2356 \\
\hline kNN-50-GFHF-JC-PR & $19.54 \%$ & 0.0880 & $37.89 \%$ & 0.2356 \\
\hline kNN-50-GFHF-JC-OD & $18.10 \%$ & 0.0880 & $39.83 \%$ & 0.2356 \\
\hline Simi-GFHF-JC-PR & $12.73 \%$ & 0.1451 & $24.97 \%$ & 0.3397 \\
\hline Simi-GFHF-CF-OD & $10.67 \%$ & 0.2451 & $28.15 \%$ & 0.7561 \\
\hline Bipartida-LPBHN-JC-OD & $5.37 \%$ & 0.0133 & $4.56 \%$ & 0.0144 \\
\hline Bipartida-LPBHN-CF-OD & $6.18 \%$ & 0.0133 & $4.68 \%$ & 0.0144 \\
\hline
\end{tabular}


Tabela 3.8: Resultados obtidos após 30 execuções na base Car.

\begin{tabular}{|c|c|c|c|c|}
\hline Sigla & Red. Aleatória & Sim. Média. & Red. Semialeatória & Sim. Média \\
\hline kNN-10-LLGC-0.5-CF-PR & $6.11 \%$ & 0.0153 & $35.37 \%$ & 0.2162 \\
\hline kNN-10-LLGC-0.7-CF-PR & $6.11 \%$ & 0.0153 & $35.37 \%$ & 0.2162 \\
\hline kNN-20-LLGC-0.1-CF-OD & $5.13 \%$ & 0.0153 & $26.77 \%$ & 0.4192 \\
\hline kNN-20-LLGC-0.7-CF-OD & $5.13 \%$ & 0.0153 & $30.47 \%$ & 0.4192 \\
\hline kNN-30-LLGC-0.7-CF-PR & $4.68 \%$ & 0.0153 & $30.09 \%$ & 0.4192 \\
\hline kNN-30-LLGC-0.7-CF-OD & $4.98 \%$ & 0.0153 & $35.37 \%$ & 0.4192 \\
\hline kNN-10-GFHF-JC-PR & $10.78 \%$ & 0.1368 & $32.73 \%$ & 0.1775 \\
\hline kNN-10-GFHF-JC-OD & $10.41 \%$ & 0.1368 & $32.13 \%$ & 0.1775 \\
\hline kNN-20-GFHF-JC-PR & $11.54 \%$ & 0.1547 & $26.85 \%$ & 0.2034 \\
\hline kNN-20-GFHF-JC-OD & $11.54 \%$ & 0.1547 & $23.53 \%$ & 0.2034 \\
\hline kNN-30-GFHF-JC-PR & $11.84 \%$ & 0.1547 & $25.79 \%$ & 0.2034 \\
\hline kNN-30-GFHF-JC-OD & $11.76 \%$ & 0.1547 & $24.36 \%$ & 0.2034 \\
\hline kNN-40-GFHF-JC-PR & $11.24 \%$ & 0.1547 & $22.17 \%$ & 0.2034 \\
\hline kNN-40-GFHF-JC-OD & $11.76 \%$ & 0.1547 & $22.47 \%$ & 0.2034 \\
\hline kNN-50-GFHF-JC-PR & $12.14 \%$ & 0.1547 & $22.85 \%$ & 0.2034 \\
\hline kNN-50-GFHF-JC-OD & $11.99 \%$ & 0.1547 & $24.59 \%$ & 0.2034 \\
\hline Simi-GFHF-JC-PR & $15.91 \%$ & 0.2231 & $30.17 \%$ & 0.4685 \\
\hline Simi-GFHF-CF-OD & $\mathbf{9 . 8 0 \%}$ & $\mathbf{0 . 0 2 9 7}$ & $\mathbf{5 2 . 6 4 \%}$ & $\mathbf{0 . 3 2 5 5}$ \\
\hline Bipartida-LPBHN-JC-OD & 12.59 & $0.0035 \%$ & $41.25 \%$ & 0.0049 \\
\hline Bipartida-LPBHN-CF-OD & 9.28 & $0.0035 \%$ & $39.29 \%$ & 0.0049 \\
\hline
\end{tabular}

Tabela 3.9: Resultados obtidos após 30 execuções na base Ecoli.

\begin{tabular}{|c|c|c|c|c|}
\hline Sigla & Red. Aleatória & Sim. Média. & Red. Semialeatória & Sim. Média \\
\hline kNN-10-LLGC-0.5-CF-PR & $6.35 \%$ & 0.1745 & $41.72 \%$ & 0.1517 \\
\hline kNN-10-LLGC-0.7-CF-PR & $6.35 \%$ & 0.1745 & $41.72 \%$ & 0.1517 \\
\hline kNN-20-LLGC-0.1-CF-OD & $6.05 \%$ & 0.1919 & $40.95 \%$ & 0.2141 \\
\hline kNN-20-LLGC-0.7-CF-OD & $6.05 \%$ & 0.1919 & $41.36 \%$ & 0.2141 \\
\hline kNN-30-LLGC-0.7-CF-PR & $5.46 \%$ & 0.1919 & $38.10 \%$ & 0.2141 \\
\hline kNN-30-LLGC-0.7-CF-OD & $4.87 \%$ & 0.1919 & $33.59 \%$ & 0.2141 \\
\hline kNN-10-GFHF-JC-PR & $20.47 \%$ & 0.0627 & $41.48 \%$ & 0.3522 \\
\hline kNN-10-GFHF-JC-OD & $20.36 \%$ & 0.0627 & $41.01 \%$ & 0.3522 \\
\hline kNN-20-GFHF-JC-PR & $21.13 \%$ & 0.0705 & $42.31 \%$ & 0.7711 \\
\hline kNN-20-GFHF-JC-OD & $20.95 \%$ & 0.0705 & $41.48 \%$ & 0.7711 \\
\hline kNN-30-GFHF-JC-PR & $20.95 \%$ & 0.0705 & $43.09 \%$ & 0.7711 \\
\hline kNN-30-GFHF-JC-OD & $22.61 \%$ & 0.0705 & $42.02 \%$ & 0.7711 \\
\hline kNN-40-GFHF-JC-PR & $26.29 \%$ & 0.0705 & $46.05 \%$ & 0.7711 \\
\hline kNN-40-GFHF-JC-OD & $22.97 \%$ & 0.0705 & $41.13 \%$ & 0.7711 \\
\hline kNN-50-GFHF-JC-PR & $28.66 \%$ & 0.0705 & $47.24 \%$ & 0.7711 \\
\hline kNN-50-GFHF-JC-OD & $23.56 \%$ & 0.0705 & $41.72 \%$ & 0.7711 \\
\hline Simi-GFHF-JC-PR & $22.26 \%$ & 0.1267 & $36.26 \%$ & 0.3268 \\
\hline Simi-GFHF-CF-OD & $\mathbf{1 0 . 1 5 \%}$ & $\mathbf{0 . 2 3 6 7}$ & $\mathbf{5 1 . 5 7 \%}$ & $\mathbf{0 . 7 9 2 9}$ \\
\hline Bipartida-LPBHN-JC-OD & $8.43 \%$ & 0.0181 & $27.77 \%$ & 0.0180 \\
\hline Bipartida-LPBHN-CF-OD & $5.88 \%$ & 0.0181 & $21.01 \%$ & 0.0180 \\
\hline
\end{tabular}


Tabela 3.10: Resultados obtidos após 30 execuções na base Habermann.

\begin{tabular}{|c|c|c|c|c|}
\hline Sigla & Red. Aleatória & Sim. Média. & Red. Semialeatória & Sim. Média \\
\hline kNN-10-LLGC-0.5-CF-PR & $11.23 \%$ & 0.0283 & $48.81 \%$ & 0.7802 \\
\hline kNN-10-LLGC-0.7-CF-PR & $11.23 \%$ & 0.0283 & $49.11 \%$ & 0.7802 \\
\hline kNN-20-LLGC-0.1-CF-OD & $12.33 \%$ & 0.0284 & $44.83 \%$ & 0.7802 \\
\hline kNN-20-LLGC-0.7-CF-OD & $11.43 \%$ & 0.0284 & $44.04 \%$ & 0.7802 \\
\hline kNN-30-LLGC-0.7-CF-PR & $9.15 \%$ & 0.0283 & $31.01 \%$ & 0.7802 \\
\hline kNN-30-LLGC-0.7-CF-OD & $12.23 \%$ & 0.0283 & $35.39 \%$ & 0.7802 \\
\hline kNN-10-GFHF-JC-PR & $32.70 \%$ & 0.0481 & $48.41 \%$ & 0.1950 \\
\hline kNN-10-GFHF-JC-OD & $27.93 \%$ & 0.0481 & $49.11 \%$ & 0.1950 \\
\hline kNN-20-GFHF-JC-PR & $36.98 \%$ & 0.0481 & $50.30 \%$ & 0.1950 \\
\hline kNN-20-GFHF-JC-OD & $32.21 \%$ & 0.0481 & $46.02 \%$ & 0.1950 \\
\hline kNN-30-GFHF-JC-PR & $46.12 \%$ & 0.0481 & $52.58 \%$ & 0.1950 \\
\hline kNN-30-GFHF-JC-OD & $44.73 \%$ & 0.0481 & $52.58 \%$ & 0.1950 \\
\hline kNN-40-GFHF-JC-PR & $45.83 \%$ & 0.0480 & $55.86 \%$ & 0.1950 \\
\hline kNN-40-GFHF-JC-OD & $43.94 \%$ & 0.0480 & $56.56 \%$ & 0.1950 \\
\hline kNN-50-GFHF-JC-PR & $44.04 \%$ & 0.0481 & $57.16 \%$ & 0.1950 \\
\hline kNN-50-GFHF-JC-OD & $\mathbf{4 0 . 5 6 \%}$ & $\mathbf{0 . 0 4 8 1}$ & $\mathbf{5 8 . 4 5 \%}$ & $\mathbf{0 . 1 9 5 0}$ \\
\hline Simi-GFHF-JC-PR & $34.59 \%$ & 0.0952 & $50.99 \%$ & 0.2941 \\
\hline Simi-GFHF-CF-OD & $16.90 \%$ & 0.0921 & $58.35 \%$ & 0.7920 \\
\hline Bipartida-LPBHN-JC-OD & $19.18 \%$ & 0.0065 & $29.72 \%$ & 0.0048 \\
\hline Bipartida-LPBHN-CF-OD & $23.56 \%$ & 0.0065 & $30.42 \%$ & 0.0048 \\
\hline
\end{tabular}

Tabela 3.11: Resultados obtidos após 30 execuções na base Iris.

\begin{tabular}{|c|c|c|c|c|}
\hline Sigla & Red. Aleatória & Sim. Média. & Red. Semialeatória & Sim. Média \\
\hline kNN-10-LLGC-0.5-CF-PR & $10.13 \%$ & 0.0593 & $51.50 \%$ & 0.8407 \\
\hline kNN-10-LLGC-0.7-CF-PR & $10.13 \%$ & 0.0593 & $51.60 \%$ & 0.8407 \\
\hline kNN-20-LLGC-0.1-CF-OD & $10.65 \%$ & 0.0592 & $53.15 \%$ & 0.8407 \\
\hline kNN-20-LLGC-0.7-CF-OD & $10.65 \%$ & 0.0592 & $53.05 \%$ & 0.8407 \\
\hline kNN-30-LLGC-0.7-CF-PR & $11.07 \%$ & 0.0592 & $50.05 \%$ & 0.8407 \\
\hline kNN-30-LLGC-0.7-CF-OD & $10.34 \%$ & 0.0592 & $51.09 \%$ & 0.8407 \\
\hline kNN-10-GFHF-JC-PR & $38.47 \%$ & 0.0476 & $55.43 \%$ & 0.1936 \\
\hline kNN-10-GFHF-JC-OD & $36.71 \%$ & 0.0476 & $53.36 \%$ & 0.1936 \\
\hline kNN-20-GFHF-JC-PR & $39.61 \%$ & 0.0476 & $54.91 \%$ & 0.1936 \\
\hline kNN-20-GFHF-JC-OD & $37.44 \%$ & 0.0476 & $54.29 \%$ & 0.1936 \\
\hline kNN-30-GFHF-JC-PR & $47.67 \%$ & 0.0477 & $63.81 \%$ & 0.1936 \\
\hline kNN-30-GFHF-JC-OD & $40.02 \%$ & 0.0477 & $57.39 \%$ & 0.1936 \\
\hline kNN-40-GFHF-JC-PR & $51.71 \%$ & 0.0477 & $66.18 \%$ & 0.1936 \\
\hline kNN-40-GFHF-JC-OD & $49.84 \%$ & 0.0477 & $65.05 \%$ & 0.1936 \\
\hline kNN-50-GFHF-JC-PR & $\mathbf{5 0 . 4 7 \%}$ & $\mathbf{0 . 0 4 7 7}$ & $\mathbf{6 6 . 4 9 \%}$ & $\mathbf{0 . 1 9 3 6}$ \\
\hline kNN-50-GFHF-JC-OD & $49.02 \%$ & 0.0477 & $62.67 \%$ & 0.1936 \\
\hline Simi-GFHF-JC-PR & $44.05 \%$ & 0.0914 & $49.33 \%$ & 0.3148 \\
\hline Simi-GFHF-CF-OD & $15.93 \%$ & 0.0679 & $65.56 \%$ & 0.8884 \\
\hline Bipartida-LPBHN-JC-OD & $19.03 \%$ & 0.0198 & $50.88 \%$ & 0.0194 \\
\hline Bipartida-LPBHN-CF-OD & $19.86 \%$ & 0.0198 & $39.50 \%$ & 0.0194 \\
\hline
\end{tabular}


Tabela 3.12: Resultados obtidos após 30 execuções na base Tic-Tac-Toe.

\begin{tabular}{|c|c|c|c|c|}
\hline Sigla & Red. Aleatória & Sim. Média. & Red. Semialeatória & Sim. Média \\
\hline kNN-10-LLGC-0.5-CF-PR & $6.68 \%$ & 0.0432 & $30.98 \%$ & 0.2016 \\
\hline kNN-10-LLGC-0.7-CF-PR & $6.68 \%$ & 0.0432 & $30.98 \%$ & 0.2016 \\
\hline kNN-20-LLGC-0.1-CF-OD & $7.67 \%$ & 0.0436 & $40.02 \%$ & 0.2869 \\
\hline kNN-20-LLGC-0.7-CF-OD & $9.57 \%$ & 0.0436 & $38.50 \%$ & 0.2869 \\
\hline kNN-30-LLGC-0.7-CF-PR & $4.02 \%$ & 0.0436 & $16.02 \%$ & 0.2869 \\
\hline kNN-30-LLGC-0.7-CF-OD & $5.01 \%$ & 0.0436 & $21.64 \%$ & 0.2869 \\
\hline kNN-10-GFHF-JC-PR & $24.07 \%$ & 0.0568 & $55.35 \%$ & 0.1949 \\
\hline kNN-10-GFHF-JC-OD & $29.84 \%$ & 0.0568 & $59.07 \%$ & 0.1949 \\
\hline kNN-20-GFHF-JC-PR & $34.09 \%$ & 0.0568 & $61.58 \%$ & 0.2794 \\
\hline kNN-20-GFHF-JC-OD & $\mathbf{3 4 . 8 5 \%}$ & $\mathbf{0 . 0 5 6 8}$ & $\mathbf{6 1 . 8 8 \%}$ & $\mathbf{0 . 2 7 9 4}$ \\
\hline kNN-30-GFHF-JC-PR & $36.60 \%$ & 0.0568 & $60.90 \%$ & 0.2794 \\
\hline kNN-30-GFHF-JC-OD & $35.91 \%$ & 0.0568 & $61.66 \%$ & 0.2794 \\
\hline kNN-40-GFHF-JC-PR & $36.14 \%$ & 0.0568 & $60.90 \%$ & 0.2794 \\
\hline kNN-40-GFHF-JC-OD & $37.05 \%$ & 0.0568 & $61.66 \%$ & 0.2794 \\
\hline kNN-50-GFHF-JC-PR & $36.37 \%$ & 0.0568 & $59.91 \%$ & 0.2794 \\
\hline kNN-50-GFHF-JC-OD & $36.83 \%$ & 0.0568 & $61.35 \%$ & 0.2794 \\
\hline Simi-GFHF-JC-PR & $34.09 \%$ & 0.0936 & $54.14 \%$ & 0.3602 \\
\hline Simi-GFHF-CF-OD & $9.79 \%$ & 0.0910 & $41.99 \%$ & 0.4205 \\
\hline Bipartida-LPBHN-JC-OD & $11.54 \%$ & 0.0108 & $46.32 \%$ & 0.0104 \\
\hline Bipartida-LPBHN-CF-OD & $10.63 \%$ & 0.0108 & $41.53 \%$ & 0.0104 \\
\hline
\end{tabular}

Tabela 3.13: Resultados obtidos após 30 execuções na base Zoo.

\begin{tabular}{|c|c|c|c|c|}
\hline Sigla & Red. Aleatória & Sim. Média. & Red. Semialeatória & Sim. Média \\
\hline kNN-10-LLGC-0.5-CF-PR & $4.40 \%$ & 0.1870 & $36.37 \%$ & 0.9575 \\
\hline kNN-10-LLGC-0.7-CF-PR & $4.52 \%$ & 0.1870 & $36.37 \%$ & 0.9575 \\
\hline kNN-20-LLGC-0.1-CF-OD & $5.07 \%$ & 0.5443 & $34.26 \%$ & 0.9575 \\
\hline kNN-20-LLGC-0.7-CF-OD & $5.19 \%$ & 0.5443 & $34.26 \%$ & 0.9575 \\
\hline kNN-30-LLGC-0.7-CF-PR & $7.06 \%$ & 0.5443 & $31.00 \%$ & 0.9575 \\
\hline kNN-30-LLGC-0.7-CF-OD & $4.83 \%$ & 0.5443 & $31.42 \%$ & 0.9575 \\
\hline kNN-10-GFHF-JC-PR & $28.17 \%$ & 0.0520 & $46.32 \%$ & 0.1367 \\
\hline kNN-10-GFHF-JC-OD & $23.28 \%$ & 0.0520 & $38.24 \%$ & 0.1367 \\
\hline kNN-20-GFHF-JC-PR & $24.00 \%$ & 0.0577 & $40.53 \%$ & 0.1977 \\
\hline kNN-20-GFHF-JC-OD & $23.88 \%$ & 0.0577 & $38.00 \%$ & 0.1977 \\
\hline kNN-30-GFHF-JC-PR & $23.94 \%$ & 0.0577 & $46.14 \%$ & 0.1977 \\
\hline kNN-30-GFHF-JC-OD & $23.82 \%$ & 0.0577 & $45.05 \%$ & 0.1977 \\
\hline kNN-40-GFHF-JC-PR & $24.73 \%$ & 0.0577 & $45.90 \%$ & 0.1977 \\
\hline kNN-40-GFHF-JC-OD & $25.75 \%$ & 0.0577 & $45.84 \%$ & 0.1977 \\
\hline kNN-50-GFHF-JC-PR & $\mathbf{2 7 . 0 8 \%}$ & $\mathbf{0 . 0 5 7 7}$ & $\mathbf{4 6 . 3 8 \%}$ & $\mathbf{0 . 1 9 7 7}$ \\
\hline kNN-50-GFHF-JC-OD & $26.48 \%$ & 0.0577 & $44.15 \%$ & 0.1977 \\
\hline Simi-GFHF-JC-PR & $30.88 \%$ & 0.1116 & $41.13 \%$ & 0.3134 \\
\hline Simi-GFHF-CF-OD & $7.66 \%$ & 0.6115 & $21.59 \%$ & 0.9441 \\
\hline Bipartida-LPBHN-JC-OD & $9.59 \%$ & 0.0383 & $17.31 \%$ & 0.0385 \\
\hline Bipartida-LPBHN-CF-OD & $6.45 \%$ & 0.0383 & $17.13 \%$ & 0.0385 \\
\hline
\end{tabular}




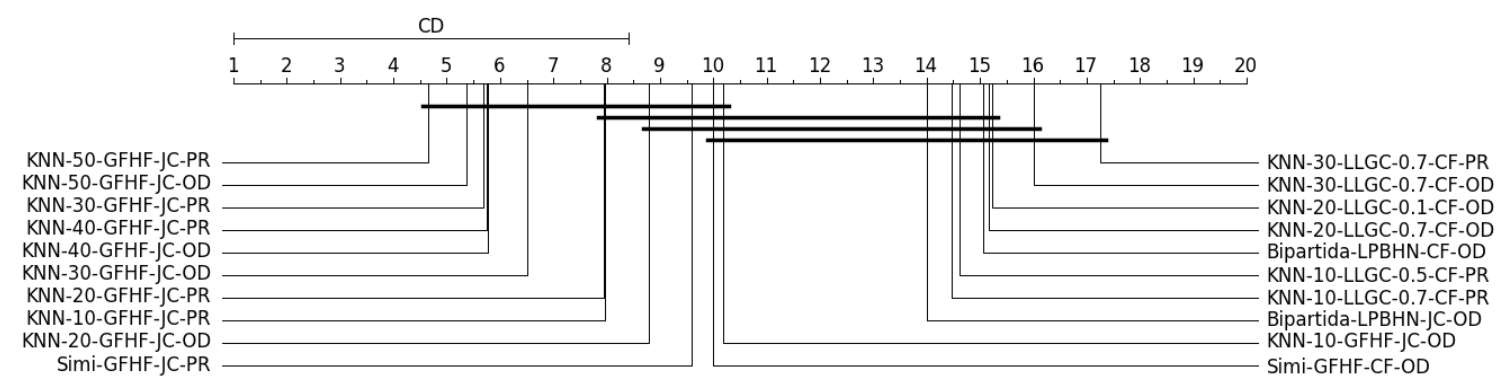

Figura 3.12: Teste estatístico realizado nas 20 melhores configurações obtidas.

a melhor configuração obtida foi a rede $k N N \operatorname{com} k=50$, utilizando o algoritmo GFHF com a medida de similaridade Jaccard e o ranqueamento realizado utilizando PageRank. O teste demonstra uma grande superioridade da rede $k N N$ e do algoritmo GFHF em comparação com os outros utilizados. Tem-se, portanto, como melhores configurações, um conjunto de parâmetros que não mostraram ser estatisticamente diferentes. Contudo, a maior parte dessas configurações paramétricas utilizam rede $k N N$ em conjunto com a medida de similaridade Jaccard, mostrando que essas configurações tendem a obter melhores resultados. No melhor caso, a configuração $k N N$ com $k=50$ e medida de similaridade Jaccard conseguiu uma redução média de $66.49 \%$, na base Iris, deixando apenas $32.51 \%$ das regras para serem exploradas pelo usuário (aproximadamente um terço). Parte dos resultados obtidos nessa seção foram publicados em Padua et al. (2014).

\subsubsection{Avaliação Com a Participação de Usuário Especialista em Segurança Pú- blica}

Neste tipo de experimento, com a participação de usuário especialista em segurança pública, o objetivo foi encontrar as regras de associação consideradas interessantes pelo mesmo.

A base de dados utilizada foi fornecida pela Defesa Civil da cidade de Rio Claro, a qual contém as ocorrências atendidas pelo órgão de 2008 a 2012. Antes do pré-processamento a base continha 2323 transações e 16 atributos. Após o pré-processamento restaram 1043 transações e 9 atributos. O pré-processamento foi realizado com o apoio do especialista. Na Tabela 3.14 encontra-se a descrição dos atributos originais e do pré-processamento realizado. As regras de associação foram obtidas a partir da base pré-processada, utilizando $5 \%$ de suporte mínimo, $0 \%$ de confiança mínima (para não limitar à regras muito óbvias), regras com no mínimo 2 itens e máximo de 5 itens. 2215 regras foram geradas inicialmente. Após uma análise inicial do especialista, o qual retirou da análise algumas regras com determinados itens no consequente, 1463 regras foram por ele avaliadas, sendo 181 dessas regras consideradas como interessantes.

Assim, para a realização desse tipo de experimento, a Etapa 2 da Figura 3.1, referente a classificação, foi realizada pelo usuário. Esse experimento também foi direcionado a analisar diferentes configurações em um cenário real, no qual o conhecimento (classificação 
Tabela 3.14: Descrição da base de dados incluindo o pré-processamento.

\begin{tabular}{|c|c|c|}
\hline Atributo & Descrição & Pré-processamento \\
\hline BO & Número do Boletim de Ocorrência & Excluído \\
\hline Natureza & $\begin{array}{l}\text { Natureza da ocorrência, sendo: } 1] \text { Ave- } \\
\text { riguação; [2] Não criminal; [3] Ato in- } \\
\text { fracional; [4] Criminal; [5] Acidente de } \\
\text { Trânsito; [6] Outros; [9] Sem identifica- } \\
\text { ção }\end{array}$ & $\begin{array}{l}\text { Excluído, pois consideram apenas as transa- } \\
\text { ções relacionadas aos códigos [2] e [6] }\end{array}$ \\
\hline Data do Fato & Dia, mês e ano da ocorrência & $\begin{array}{l}\text { Foi processado e mantido apenas o mês em } \\
\text { valores categóricos (JAN, FEV, ..., DEZ) }\end{array}$ \\
\hline $\begin{array}{l}\text { Dia da Se- } \\
\text { mana }\end{array}$ & Dia da semana da ocorrência & $\begin{array}{l}\text { Foi processado e mantido em valores categóri- } \\
\text { cos (SEG, TER, ..., DOM) }\end{array}$ \\
\hline Hora do Fato & $\begin{array}{l}\text { Hora (somente parte inteira; por exem- } \\
\text { plo, } 1 \mathrm{~h}, 3 \mathrm{~h}, 20 \mathrm{~h} \text { ) da ocorrência }\end{array}$ & $\begin{array}{l}\text { Foi processado e agrupado em períodos, a sa- } \\
\text { ber: Manhã }(7, \ldots, 12) \text {, Tarde }(13, \ldots, 18) \text {, } \\
\text { Noite }(19, \ldots, 24) \text { e Madrugada }(1, \ldots, 6)\end{array}$ \\
\hline Local & $\begin{array}{l}\text { Nome da rua ou da avenida que gerou } \\
\text { a ocorrência, incluindo número }\end{array}$ & Excluído \\
\hline Bairro & Bairro que gerou a ocorrência & $\begin{array}{l}\text { Foi processado, trocando-se os bairros pela re- } \\
\text { gião da cidade em que os mesmos se encontram } \\
\text { (de acordo com a divisão fornecida pela pre- } \\
\text { feitura) }\end{array}$ \\
\hline Condição & $\begin{array}{l}\text { Indica se a ocorrência teve vítima e in- } \\
\text { frator, se for acidente de trânsito, etc }\end{array}$ & $\begin{array}{l}\text { Excluído, devido as naturezas consideradas } \\
([2] \text { e }[6])\end{array}$ \\
\hline Naturalidade & $\begin{array}{l}\text { Naturalidade da pessoa que gerou a } \\
\text { ocorrência, sendo: [1] Rio Claro; [2] Ou- } \\
\text { tras cidades de SP; [3] Outros estados; } \\
\text { [4] Outros países; [9] Sem definição }\end{array}$ & $\begin{array}{l}\text { Foi processado para valores categóricos asso- } \\
\text { ciados apenas aos códigos [1], [2], [3] e [4]. } \\
\text { Transaçôes relacionadas ao código [9] foram } \\
\text { excluídas. }\end{array}$ \\
\hline Sexo & $\begin{array}{l}\text { Sexo da pessoa que gerou a ocorrência, } \\
\text { sendo: [1] Masculino; [2] Feminino; [9] } \\
\text { Sem definição }\end{array}$ & $\begin{array}{l}\text { Foi processado para valores categóricos asso- } \\
\text { ciados apenas aos códigos [1] e [2]. Transações } \\
\text { relacionadas ao código [9] foram excluídas. }\end{array}$ \\
\hline $\begin{array}{l}\text { Ano de Nas- } \\
\text { cimento }\end{array}$ & $\begin{array}{l}\text { Ano de nascimento da pessoa que gerou } \\
\text { a ocorrência (quatro dígitos) }\end{array}$ & $\begin{array}{l}\text { Foi processado, trocando pela idade da pes- } \\
\text { soa, a qual foi substituída por valores categóri- } \\
\text { cos associados as seguintes faixas etárias: Cri- } \\
\text { ança (idade }<=11 \text { ); Adolescente (idade }>=12 \\
\text { e idade }<=18 \text { ); Adulto (Idade }>=19 \text { e idade } \\
<=59 \text { ); Idoso (idade }>=60 \text { ) }\end{array}$ \\
\hline Cor & $\begin{array}{l}\text { Cor da pessoa que gerou a ocorrência, } \\
\text { sendo: [1] Branca; [2] Negra; [3] Mu- } \\
\text { lato, pardo ou sinônimos; [4] Outros; [9] } \\
\text { Sem definição }\end{array}$ & $\begin{array}{l}\text { Foi processado para valores categóricos asso- } \\
\text { ciados apenas aos códigos [1], [2], [3], [4] e [5]. } \\
\text { Transaçôes relacionadas ao código [9] foram } \\
\text { excluídas. }\end{array}$ \\
\hline Estado Civil & $\begin{array}{l}\text { Estado civil da pessoa que gerou a ocor- } \\
\text { rência, sendo: [1] Casado; [2] Solteiro; } \\
\text { [3] Viúvo, desquitado, divorciado; [4] } \\
\text { Amasiado; [5] Outros; [9] Sem definição }\end{array}$ & $\begin{array}{l}\text { Foi processado para valores categóricos asso- } \\
\text { ciados apenas aos códigos [1], [2], [3], [4] e [5]. } \\
\text { Transaçôes relacionadas ao código [9] foram } \\
\text { excluídas. }\end{array}$ \\
\hline Endereço & $\begin{array}{l}\text { Nome da rua ou da avenida em que } \\
\text { mora a pessoa que acionou a defesa ci- } \\
\text { vil, incluindo número }\end{array}$ & Excluído \\
\hline Bairro & $\begin{array}{l}\text { Bairro em que mora a pessoa que acio- } \\
\text { nou a defesa civil }\end{array}$ & $\begin{array}{l}\text { Excluído, devido as naturezas consideradas } \\
\text { ([2] e [6]) }\end{array}$ \\
\hline
\end{tabular}

sobre as regras) foi informado pelo usuário e não gerado por meios automáticos. Nesse experimento foram variados os tipos de rede, medidas de similaridade e ranqueamento, assim como algoritmos de classificação. As configurações utilizadas foram as mesmas da Seção 3.3.1 (Tabelas 3.2 e 3.3). Portanto, a diferença entre as avaliações encontra-se na interação com o usuário, em que utilizou-se o conjunto de regras totalmente classificado pelo usuário, chamada de base gold, como conjunto objetivo, tendo assim uma classificação real do conjunto de regras. Nessa base, as regras foram previamente classificadas pelo usuário em "Interessantes" e "Não Interessantes". As regras classificadas como [I] foram definidas como conjunto objetivo para serem encontradas. Desse modo, para realizar a rotulação das regras selecionadas pela abordagem foi realizada uma comparação com o conjunto objetivo. Apenas foram consideradas interessantes as regras que faziam parte do 
conjunto objetivo, eliminando o threshold. Assim, na interação não se classificou regras próximas ao conjunto objetivo como interessantes, focando apenas nas regras que o usuário realmente classificaria como [I].

Diante do apresentado, a abordagem foi executada, para todas as configuraçõos apresentadas nas Tabelas 3.2 e 3.3, levando em consideração apenas a base gold como conjunto objetivo. As reduções do espaço de exploração obtidas podem ser vistas na Tabela 3.15. Com exceção de duas configurações, todas as outras obtiveram o mesmo resultado e, portanto, todas elas foram agrupadas na linha "Todas as outras configurações", enquanto que as configurações que obtiveram resultados diferentes são descritas separadamente.

Tabela 3.15: Tabela contendo os resultados obtidos na base gold.

\begin{tabular}{|c|c|c|c|c|}
\hline Rede [TR] & Classificador & Sim. [S] & Ranqueamento [MR] & Redução \\
\hline Bipartida & LPBHN & Confiança & PageRank & $0.89 \%$ \\
\hline kNN $(K=20)$ & GFHF & Jaccard & PageRank & $0.55 \%$ \\
\hline \multicolumn{6}{|c|}{ Todas as outras configurações } & $0.21 \%$ \\
\hline
\end{tabular}

Como nota-se na Tabela 3.15, uma baixa redução em relação ao espaço de exploração foi obtida. Esses resultados ocorreram devido a baixa similaridade existente entre as regras no conjunto objetivo, conforme pode ser visualizado na Tabela 3.16. Os valores de similaridade variam entre 0 e 1 (a medida Sahar (que possui variação entre 0 e 3 ) foi normalizada). Em todos os casos a similaridade média do conjunto objetivo é menor que a similaridade média da própria rede, o que demonstra que o conjunto objetivo está fracamente relacionado e, por consequência, distribuído por toda a rede. Observou-se também que essa baixa similaridade é resultante da avaliação do usuário em todo o conjunto de regras, o que o levou a classificar regras muito dissimilares como pertencentes a classe interessante, fazendo com que a abordagem classificasse praticamente toda a base para conseguir contemplar todas as regras. Essa é uma limitação existente na abordagem que é discutida no Capítulo 4, em conjunto com alguns trabalhos futuros. Isso significa que a abordagem foca em uma parte da rede e, caso existam regras a serem encontradas que não fazem parte desse "tema" específico, a abordagem precisa explorar todo o conjunto de regras pertencente àquela parte da rede para, só então, explorar outros conjuntos em busca dessas regras faltantes, o que acaba gerando várias separações na rede, aumentando a quantidade de regras interessantes.

Por fim, nota-se que, no segundo melhor caso, encontra-se a rede $k N N$, o algoritmo GFHF, a medida de similaridade Jaccard e a medida PageRank, configuração que se destaca também nos experimentos realizados na Seção 3.3.1, reforçando (i) a tendência de ser uma boa configuração a ser utilizada pela abordagem; (ii) que os experimentos realizados na Seção 3.3.1 foram abrangentes o suficiente para validar a abordagem proposta. 
Tabela 3.16: Tabela contendo a média de similaridade por medida.

\begin{tabular}{|c|c|c|}
\hline Medida de Similaridade [S] & Sim. Média Rede & Sim. Média Cjto. Objetivo \\
\hline Jaccard (Rede Homogênea) & 0.1239 & 0.1049 \\
\hline Confiança (Rede Homogênea) & 0.1212 & 0.1078 \\
\hline Sahar (Rede Homogênea) & 0.6755 & 0.6634 \\
\hline Jaccard (Rede Bipartida) & 0.1015 & 0.0001 \\
\hline Confiança (Rede Bipartida) & 0.4084 & 0.0001 \\
\hline
\end{tabular}

\subsubsection{Discussão sobre as Avaliações Experimentais}

Conforme pôde-se observar nas seções anteriores, a redução na quantidade de regras a serem exploradas depende da similaridade média do conjunto objetivo. Essa dependência existe devido a dois fatores: abordagens de propagação de rótulos e problema de classificação binária. As abordagens de propagação de rótulos colocam os elementos similares em uma mesma classe. Dessa maneira, um conjunto objetivo com regras mais similares tendem a serem encontradas mais facilmente do que conjuntos objetivos com regras menos similares, devido a força da conexão ser muito menor. Já a classificação binária particiona o domínio em classes, fazendo com que conjuntos objetivos contendo regras distantes aumentem a quantidade de regras que são classificadas como "Interessante". Conjuntos objetivos mais similares tendem a concentrar todas as regras objetivos em uma área densa, reduzindo o chance de regras "Interessantes" estarem em pontos distintos da rede.

Ao realizar uma comparação com os 3 tipos de interação (conjunto aleatório, conjunto semi aleatórios e base gold), é possível observar a variação de resultados de acordo com a variação da similaridade média. Nos experimentos realizados com os conjuntos objetivos semi aleatórios, em comparação com os experimentos realizados com conjuntos objetivos aleatórios, foi possível verificar o aumento na redução do espaço de exploração. Esse resultado se mantém ao comparar o resultado da base gold com os conjuntos aleatórios. A base gold possui um valor de similaridade média inferior ao conjunto aleatório, obtendo também uma redução no espaço de exploração inferior ao obtido nos experimentos anteriores. Isso ocorre também devido ao direcionamento dado pela abordagem, que considera as regras já classificadas como interessante para sugerir outras regras a serem classificadas pelo usuário. Dessa maneira, a abordagem foca em uma parte da rede e, caso existam regras a serem encontradas que não fazem parte desse "tema" específico, a abordagem precisa explorar todo o conjunto de regras pertencente àquela parte da rede para, só então, explorar outros conjuntos em busca dessas regras faltantes, o que acaba gerando várias separações na rede, aumentando a quantidade de regras interessantes. Contudo, nota-se que por meio da abordagem, o usuário é capaz de, baseado nas sugestões dadas pela abordagem, explorar um "tema" de interesse que não era conhecido antes. 


\subsection{Considerações Finais}

Neste capítulo a abordagem proposta, $P A R_{L P}$, foi descrita em detalhes, demonstrando seu funcionamento e o objetivo da exploração. Foram realizados 348 experimentos em cada uma das 8 bases, utilizando 2 tipos de conjunto objetivo, cada qual contendo 30 variações, em conjunto com uma base previamente classificada, a qual foi também explorada usando todas as 348 configurações anteriores.

Os resultados obtidos foram avaliados por um método bastante utilizado, contabilizando a redução no espaço de exploração após encontrar todas as regras do conjunto objetivo. Houve uma grande variação na redução obtida nos experimentos realizados. Essa variação depende principalmente da similaridade média do conjunto objetivo, conforme apresentado nas tabelas de resultado.

Nota-se, portanto, que os resultados obtidos reforçam a hipótese inicial, que consiste em direcionar a exploração do usuário para o conhecimento útil. Caso o usuário realize a exploração das regras de acordo com "temas", selecionando regras que representem conhecimento semelhante, a $P A R_{L P}$ é capaz de direcionar a exploração para o conhecimento útil, conseguindo reduzir a quantidade de regras a serem exploradas. Porém, caso o usuário realize a busca por conhecimentos não semelhantes em uma mesma execução, a $P A R_{L P}$ encontrará dificuldade em reduzir o espaço de exploração devido às características dos algoritmos de propagação de rótulo aplicados em um problema de classificação binária. Contudo, nota-se que por meio da abordagem, o usuário é capaz de, baseado nas sugestões dadas pela abordagem, explorar um "tema" de interesse que não era conhecido antes.

Diante do apresentado, ressalta-se que as contribuições deste trabalho estão na capacidade de se extrair o conhecimento e/ou interesse do usuário de acordo com as características da base de dados e direcionar sua exploração sem a necessidade de se definir previamente o que será explorado. Além disso, os resultados obtidos demonstram a capacidade da $P A R_{L P}$ em direcionar o usuário para o conhecimento considerado interessante, reduzindo, para tanto, a quantidade de regras a serem exploradas. Por fim, este trabalho contribui também para demonstrar que é possível tratar o pós-processamento de regras de associação como um problema de propagação de rótulos. 


\section{Conclusões e Trabalhos Futuros}

Neste mestrado foi proposta uma abordagem de pós-processamento de regras de associação, denominada $P A R_{L P}$, interativa e iterativa, em que o usuário é direcionado para o conhecimento que considera interessante de acordo com suas interações com a abordagem. As diferenças da $P A R_{L P}$ em comparação com as abordagens existentes na literatura são: (i) a capacidade de extrair o conhecimento do usuário durante o pós-processamento das regras de associação, retirando a necessidade do usuário saber, apriori, o que deseja explorar, sem a necessidade de utilizar linguagens para descrever o conhecimento; (ii) tratar o problema como um problema de classificação.

A interação com o usuário é realizada por meio de um ranqueamento realizado nas regras, considerando o conhecimento já obtido em iterações anteriores quando possível, direcionando o usuário para as regras que são potencialmente mais interessantes de acordo com a medida de similaridade selecionada. O usuário classifica, então, as regras e o seu conhecimento é disseminado para as outras regras utilizando algoritmos de propagação de rótulos. Esses algoritmos de aprendizado transdutivo semissupervisionado propaga os rótulos para toda a base utilizando a similaridade entre as regras do domínio. Para facilitar a propagação de rótulos e também auxiliar na seleção das regras para realizar a interação, foram utilizadas redes para modelar as regras de associação, devido à sua alta capacidade de modelagem, conectando as regras de acordo com medidas de similaridade.

Os experimentos foram executados em bases de domínio público, nas quais a classificação das regras por um usuário foi simulada, e em uma base real pré-classificada por um especialista da área. Nas bases de domínio público foi realizada a simulação da classificação do usuário utilizando conjuntos de regras objetivo a serem encontradas na base de regras. Esses conjuntos foram definidos de duas maneiras: selecionando aleatoriamente as regras e selecionando uma regra aleatória para ser utilizada como base, completando o conjunto com as regras mais similares a regra base. Os resultados obtidos nas bases 
de domínio público demonstraram que conjuntos objetivo que possuem uma maior similaridade entre as regras selecionadas tendem a obter melhores resultados. Os conjuntos de regras selecionadas aleatoriamente obtiveram resultados inferiores aos conjuntos de regras criado de maneira semi aleatória. Além disso, também foi possível visualizar que as redes $k N N$, em conjunto com o algoritmo de classificação $G F H F$, geraram, em geral, os melhores resultados. Já na base classificada pelo especialista, os resultados obtidos foram baixos, inferiores a $1 \%$, devido ao fato da similaridade média do conjunto objetivo ser muito baixa.

Os resultados obtidos indicam que: (i) a $P A R_{L P}$ é sensível a interação do usuário e (ii) caso a exploração seja realizada considerando a busca por itens similares (ou "temas"), a $P A R_{L P}$ é capaz de direcionar o usuário para um conjunto de regras potencialmente interessantes. A sensibilidade da $P A R_{L P}$ pode ser vista na variação de resultados obtida a partir da variação da similaridade média do conjunto objetivo. Isso se deve às características dos algoritmos de propagação de rótulo, que tendem a classificar regras similares em classes iguais. Ao gerar um conjunto objetivo pouco similar, as regras que necessitam ser encontradas estão espalhadas pela rede, fazendo com que a abordagem tenha de encontrar vários pontos que contenham regras similares. Os conjuntos mais similares são encontrados com mais facilidade, e com uma maior redução de espaço de exploração, devido ao fato das regras estarem todas próximas a um ponto em comum. Sendo assim, é possível reforçar a hipótese inicial de que a $P A R_{L P}$ é capaz de direcionar a exploração para o conhecimento interessante. Por realizar o direcionamento da exploração em um problema de classificação binária, a abordagem faz com que o usuário realize a exploração guiado por "temas", ou seja, caso o usuário altere o "tema" de sua exploração, durante a execução da abordagem, isso poderá aumentar a quantidade de regras que deverão ser exploradas. Apesar da limitação, i.e., da abordagem obter resultados menos satisfatórios caso a exploração não seja direcionada a um determinado conceito ou "tema", diminuindo a redução do espaço de exploração, os resultados mostram que a abordagem é eficiente nos casos de busca por regras similares.

Como trabalho futuro, tem-se como objetivo trabalhar nas limitações da abordagem, preparando a abordagem para tratar os casos em que o usuário deseja explorar diferentes "temas" de seu interesse em uma única exploração. Para que seja possível explorar diversos "temas", propõe-se o uso de classificação com $N$ classes. Dessa maneira, quando o usuário rotular uma regra como interessante e essa regra estiver distante das regras já classificadas como interessante, a abordagem a colocaria em uma outra classe, mantendo a regra com a classificação de interessante, porém, um "tema" diferente. A principal vantagem de utilizar mais de uma classe está em particionar o resultado final em diferentes grupos de interesse, exibindo para o usuário não apenas o conceito de interessante mas sim o conceito de interessante de acordo com as classificações que ele realizou.

Além de considerar mais classes, tem-se também como trabalho a aplicação da abordagem proposta na área de sistemas de recomendação. Sistemas de recomendação utilizam 
regras de associação para sugerir um produto (acesso, atividade, etc.) baseado nos produtos que ele já consumiu. Para que seja possível realizar a sugestão, essas regras são geradas de acordo com a base de dados de consumo e, tendo o consumo de um usuário específico, são exploradas as regras em busca de produtos que possam ser sugeridos. A abordagem proposta pode contribuir bastante para a área, uma vez que ela considera o conhecimento (ou consumo no caso) do usuário para explorar as regras de associação existentes.

Por fim, o desenvolvimento e os resultados obtidos neste mestrado geraram, até o momento, 4 artigos, sendo 2 deles diretamente ligado ao desenvolvimento do mestrado e 2 de trabalhos relacionados ao tema do mestrado. A seguir estão os artigos publicados em ordem cronológica.

1. Domingues et al. (2013): Trabalho desenvolvido em parceria com outros alunos do laboratório. Este trabalho consiste em um sistema de recomendação de nomes baseado em regras de associação que, dado um nome digitado pelo usuário, o sistema deve recomendar um conjunto de possíveis nomes. A contribuição neste artigo referese a geração e processamento das regras de associação.

2. Padua et al. (2013): Trabalho desenvolvido em parceria com outros alunos do laboratório. Este trabalho consiste em uma análise subjetiva de técnicas de rotulação de grupos de regras de associação. A contribuição neste artigo refere-se ao desenvolvimento de uma técnica de rotulação de regras de associação, assim como acompanhamento na validação das regras sugeridas como rótulos pelas abordagens comparadas.

3. Carvalho et al. (2014): Trabalho desenvolvido em parceria com a Profa. Dra. Veronica Oliveira de Carvalho, docente da UNESP. Este trabalho consiste na publicação da ideia geral de se tratar o problema de pós-processamento de regras de associação como um problema de classificação, contendo toda a motivação para tal e alguns experimentos que demonstram que tratar o pós-processamento como classificação é uma área promissora. A contribuição neste artigo refere-se a toda a discussão das possibilidades envolvidas no uso de classificação para pós-processar as regras de associação, assim como auxílio na realização dos experimentos.

4. Padua et al. (2014): Trabalho desenvolvido em parceria com a Profa. Dra. Veronica Oliveira de Carvalho, docente da UNESP. Este é o principal artigo desenvolvido neste mestrado, que publica parte dos experimentos descritos no capítulo anterior e discute o uso de propagação de rótulos e redes como meio viável para pós-processamento de regras de associação. Neste artigo o objetivo principal foi demonstrar que algoritmos de propagação de rótulos são promissores na aplicação para pós-processar regras de associação, gerando uma discussão em torno das possibilidades e da limitação existente. 



\section{Referências Bibliográficas}

Agrawal, R., Imielinski, T., e Swami, A. (1993). Mining association rules between sets of items in large databases. Special Interest Group on Management of Data, 22(2):207-216. Citado nas páginas 8 e 9.

Alpar, P. e Winkelstrater, S. (2014). Assessment of data quality in accounting data with association rules. Expert Systems and Applications, 41(5):2259-2268. Citado na página 2.

Benzi, M. e Klymko, C. (2013). Total communicability as a centrality measure. Journal of Complex Networks, 1(2):124-149. Citado na página 29.

Berrado, A. e Runger, G. C. (2007). Using metarules to organize and group discovered association rules. Data Mining and Knowledge Discovery, 14(3):409-431. Citado nas páginas 12 e 21.

Bie, T. D. (2013). Subjective interestingness in exploratory data mining. In Advances in Intelligent Data Analysis, volume 8207 of Lecture Notes in Computer Science, páginas 19-31. Springer. Citado nas páginas 2, 41, e 54.

Blanchard, J., Guillet, F., Gras, R., e Briand, H. (2005). Using information-theoretic measures to assess association rule interestingness. International Conference on Data Mining, 0:66-73. Citado na página 12.

Blum, A. e Chawla, S. (2001). Learning from labeled and unlabeled data using graph mincuts. In International Conference on Data Mining, páginas 19-26. Morgan Kaufmann. Citado na página 34.

Carvalho, V. O., Padua, R., e O., R. S. (2014). Semi-supervised learning to support the exploration of association rules. In International Conference on Big Data Analytics and Knowledge Discovery, páginas 452-464. Citado nas páginas 6 e 71.

Carvalho, V. O., Rezende, S. O., e Castro, M. (2007). Obtaining and evaluating generalized association rules. In International Conference on Enterprise Information Systems, volume 2, páginas 310-315. Citado nas páginas 14 e 21. 
Carvalho, V. O., Santos, F. F., Rezende, S. O., e Padua, R. (2011). Par-com: A new methodology for post-processing association rules. In International Conference on Enterprise Information System, volume 102 of Lecture Notes in Business Information Processing, páginas 66-80. Springer. Citado na página 13.

Cavique, L. (2007). A scalable algorithm for the market basket analysis. Journal of Retailing and Consumer Services, 14(6):400-407. Citado na página 36.

Changguo, Y., Nianzhong, W., Tailei, W., Qin, Z., e Xiaorong, Z. (2009). The research on the application of association rules mining algorithm in network intrusion detection. In $\mathrm{Hu}$, Z. e Liu, Q., editors, International Workshop on Education Technology and Computer Science, volume 2, páginas 849-852. Citado nas páginas 2 e 8.

Choi, Y. K. e Kim, S. K. (2014). An auxiliary recommendation system for repetitively purchasing items in e-commerce. In Big Data and Smart Computing, páginas 96-98. Citado nas páginas 2 e 8 .

Dadaser-Celik, F., Celik, M., e Dokuz, A. S. (2012). In International Conference on Environmental Science and Technology, volume 14, páginas 354-361. Citado nas páginas 2 e 8.

de Sousa, C. A. R., Rezende, S. O., e Batista, G. E. A. P. A. (2013). Influence of graph construction on semi-supervised learning. In European Conference on Machine Learning and Principles and Practice of Knowledge Discovery in Databases, volume 8190 of Lecture Notes in Computer Science, páginas 160-175. Springer. Citado nas páginas 28 e 29.

Demšar, J. (2006). Statistical comparisons of classifiers over multiple data sets. Journal of Machine Learning Research, 7:1-30. Citado nas páginas 57 e 59.

Domingues, M. A., Cherman, E. A., Nogueira, B., Conrado, M., Rossi, R., Padua, R., Marcacini, R. M., Souza, V., Batista, G. E., e Rezende, S. O. (2013). A comparative study of algorithms for recommending given names. In International Conference on Informatics and Applications, páginas 66-71. Citado na página 71.

Estrada, E. e Rodriguez-Velazquez, J. A. (2005). Subgraph centrality in complex networks. Physical Review E, 71:056103. Citado na página 29.

Fritscher, E., Hoppen, C., e Trevisan, V. (2011). Propriedades espectrais de um grafo. Dissertação de Mestrado, Universidade Federal Do Rio Grande Do Sul. Citado na página 26.

Geng, L. e Hamilton, H. J. (2007). Choosing the right lens: Finding what is interesting in data mining. In Guillet, F. e Hamilton, H. J., editors, Quality Measures in Data Mining, volume 43 of Studies in Computational Intelligence, páginas 3-24. Springer. Citado nas páginas xi, 10, e 11. 
Gionis, A., Mannila, H., Mielikäinen, T., e Tsaparas, P. (2007). Assessing data mining results via swap randomization. ACM Transactions on Knowledge Discovery from Data, 1(3). Citado na página 54.

Gupta, G., Strehl, A., e Ghosh, J. (1999). Distance based clustering of association rules. In Intelligent Engineering Systems Through Artificial Neural Networks, páginas 759-764. ASME Press. Citado na página 18.

Hanhijärvi, S., Ojala, M., Vuokko, N., Puolamäki, K., Tatti, N., e Mannila, H. (2009). Tell me something i don't know: randomization strategies for iterative data mining. In International Conference on Knowledge Discovery and Data Mining, páginas 379-388. ACM. Citado na página 54.

Hein, M. e Maier, M. (2007). Manifold Denoising. páginas 561-568. MIT Press. Citado na página 29 .

Hines, P. e Blumsack, S. (2008). A centrality measure for electrical networks. In Hawaii International Conference on System Sciences, página 185. IEEE Computer Society. Citado na página 29.

Ji, M., Sun, Y., Danilevsky, M., Han, J., e Gao, J. (2010). Graph regularized transductive classification on heterogeneous information networks. In European Conference on Machine Learning and Knowledge Discovery in Databases, páginas 570-586. SpringerVerlag. Citado na página 35.

Jorge, A. (2004). Hierarchical clustering for thematic browsing and summarization of large sets of association rules. In Berry, M. W., Dayal, U., Kamath, C., e Skillicorn, D. B., editors, SIAM International Conference on Data Mining. Society for Industrial and Applied Mathematics. Citado na página 19.

Liu, B., Hsu, W., e Ma, Y. (1999). Pruning and summarizing the discovered associations. In International Conference on Knowledge Discovery and Data Mining, páginas 125134. Citado nas páginas 11 e 21.

Liu, H., Sun, J., e Zhang, H. (2009). Post-Mining of Association Rules: Techniques for Effective Knowledge Extraction, capítulo Post-Processing for Rule Reduction Using Closed Set, páginas 81-99. IGI Global. Citado nas páginas 13 e 21.

Liu, W. e Chang, S. (2009). Robust multi-class transductive learning with graphs. In International Conference on Computer Vision and Pattern Recognition, páginas 381388. IEEE. Citado na página 28.

Maier, M., Hein, M., e von Luxburg, U. (2007). Cluster identification in nearest-neighbor graphs. In Hutter, M., Servedio, R. A., e Takimoto, E., editors, Conference on Learning Theory, volume 4754 of Lecture Notes in Computer Science, páginas 196-210. Springer. Citado na página 28. 
Maier, M., Hein, M., e von Luxburg, U. (2009a). Optimal construction of knearest-neighbor graphs for identifying noisy clusters. Theoretical Computer Science, 410(19):1749-1764. Citado na página 28.

Maier, M., von Luxburg, U., e Hein, M. (2009b). Influence of graph construction on graph-based clustering measures. In Koller, D., Schuurmans, D., Bengio, Y., e Bottou, L., editors, Advances in Neural Information Process Systems, volume 21, páginas 10251032. Citado na página 28.

Mansingh, G., Osei-Bryson, K., e Reichgelt, H. (2011). Using ontologies to facilitate postprocessing of association rules by domain experts. Information Sciences, 181(3):419434. Citado nas páginas 15 e 21.

Martinez-Ballesteros, M., Martinez-Alvarez, F., Lora, A. T., e Riquelme, J. C. (2011). An evolutionary algorithm to discover quantitative association rules in multidimensional time series. Soft Computing, 15(10):2065-2084. Citado na página 13.

Martinez-Ballesteros, M., Martinez-Alvarez, F., Lora, A. T., e Riquelme, J. C. (2013). Selecting the best measures to discover quantitative association rules. Neurocomputing, 126:3-14. Citado nas páginas xi, 10, 11, 13, e 21.

Munkova, D., Munk, M., e Fraterova, Z. (2013). Identifying social and expressive factors in request texts using transaction/sequence model. In Recent Advances in Natural Language Processing, páginas 496-503. Citado na página 2.

Newman, M. E. J. (2010). Networks: An Introduction. Oxford University Press. Citado nas páginas 23, 29, e 30 .

Newman, M. E. J. e Girvan, M. (2004). Finding and evaluating community structure in networks. Physical Review, E 69. Citado nas páginas 26 e 27.

Nuwangi, S. M., Oruthotaarachchi, C. R., Tilakaratna, J. M. P. P., e Caldera, H. A. (2010). Usage of association rules and classification techniques in knowledge extraction of diabetes. In International Conference on Advanced Information Management and Service, páginas 372-377. Citado nas páginas 2 e 8.

Oellrich, A., Jacobsen, J., Papatheodorou, I., Project, T. S. M. G., e Smedley, D. (2014). Using association rule mining to determine promising secondary phenotyping hypotheses. Bioinformatics, 30(12):i52-i59. Citado na página 8.

Padua, R., Carvalho, V. O., e Rezende, S. O. (2014). Post-processing association rules using networks and transductive learning. In 13th International Conference on Machine Learning and Applications, páginas 318-323. Citado nas páginas 6, 64, e 71.

Padua, R., Santos, F. F., Conrado, M. S., Carvalho, V. O., e Rezende, S. O. (2013). Subjective evaluation of labeling methods for association rule clustering. In Mexican 
International Conference on Artificial Intelligence, páginas 289-300. Citado na página 71 .

Pandey, G., Chawla, S., Poon, S., Arunasalam, B., e Davis, J. G. (2009). Association rules network: Definition and applications. Statistical Analysis and Data Mining, 1(4):260279. Citado nas páginas ix, 37, e 38.

Raeder, T. e Chawla, N. V. (2011). Market basket analysis with networks. Social Network Analysis and Mining, 1(2):97-113. Citado na página 37.

Rajasekar, U. e Weng, Q. (2009). Application of association rule mining for exploring the relationship between urban land surface temperature and biophysical/social parameters. Photogrammetric Engineering \& Remote Sensing, 75(3):385-396. Citado na página 2.

Reynolds, A. P., Richards, G., de la Iglesia, B., e Rayward-Smith, V. J. (2006). Clustering rules: A comparison of partitioning and hierarchical clustering algorithms. Journal of Mathematical Modeling and Algorithms, 5(4):475-504. Citado na página 18.

Rezende, S. O., Melanda, E. A., Fujimoto, M. L., Sinoara, R. A., e Carvalho, V. O. (2009). Combining data-driven and user-driven evaluation measures to identify interesting rules. In Zhao, Y., Zhang, C., e Cao, L., editors, Post-Mining of Association Rules: Techniques for Effective Knowledge Extraction, capítulo 3. IGI Global. Citado nas páginas 15 e 21.

Rezende, S. O., Pugliesi, J. B., Melanda, E. A., e Paula, M. F. (2003). Mineração de dados. In Rezende, S. O., editor, Sistemas inteligentes: Fundamentos e aplicações, capítulo 12, páginas 307-335. Manole. Citado na página 1.

Rossi, R. G., Lopes, A. A., e Rezende, S. O. (2014). A parameter-free label propagation algorithm using bipartite heterogeneous networks for text classification. In $A C M$ Symposium on Applied Computing, SAC '14, páginas 79-84. Citado nas páginas 35 e 36 .

Sahar, S. (2002). Exploring interestingness through clustering: A framework. In Internacional Conference on Data Mining., páginas 677-680. IEEE Computer Society. Citado na página 19.

Singh, B. e Mustafi, A. (2014). A novel approach to rank association rules using genetic algorithm. International Journal of Current Engineering and Technology, páginas 850859. Citado nas páginas 13 e 21.

Sulthana, A. e Murugeswari, B. (2011). Aripso: Association rule interactive postmining using schemas and ontologies. In International Conference on Emerging Trends in Electrical and Computer Technology, páginas 941-946. Citado nas páginas 16, 17, e 21 . 
Sweetlin, C. e Kalaivani, V. (2012). User interactive post-processing of association rules and correlation based redundancy removal. International Journal of Computer Applications, ICON3C(3):31-35. Citado nas páginas 16, 17, e 21.

Toivonen, H., Klemettinen, M., Ronkainen, P., Hatonen, K., e Mannila, H. (1995). Pruning and grouping discovered association rules. In Workshop on Statistics, Machine Learning, and Knowledge Discovery in Databases, páginas 47-52. Citado na página 18.

Tsai, C. e Huang, S. (2014). A data mining approach to optimise shelf space allocation in consideration of customer purchase and moving behaviours. International Journal of Production Research, páginas 1-17. Citado na página 9.

Videla-Cavieress, I. F. e Rios, S. A. (2014). Extending market basket analysis with graph mining techniques: A real case. Expert Systems with Applications, 41(4, Part 2):1928 1936. Citado na página 38.

Wu, X. e Kumar, V. (2009). The Top Ten Algorithms in Data Mining. Chapman \& Hall/CRC, 1st ${ }^{\mathrm{a}}$ edição. Citado na página 1.

Xiao, G. (2011). Association rules algorithm in bank risk assessment. Advanced Electrical and Electronics Engineering, 87:675-681. Citado nas páginas 2 e 8.

Yan, X., Zhai, L., e Fan, W. (2013). C-index: A weighted network node centrality measure for collaboration competence. Journal of Informetrics, 7(1):223-239. Citado na página 29.

Yu, J., Ho, C., Hsu, Y., Wang, J., e Hsieh, C. (2014). Traditional chinese medicine treatments for upper respiratory tract infections/common colds in taiwan. European Journal of Integrative Medicine, páginas 538-544. Citado nas páginas 8 e 10.

Zaki, M. J. (2004). Mining non-redundant association rules. Data Mining and Knowledge Discovery, 9(3):223-248. Citado na página 21.

Zhou, D., Bousquet, O., Navin Lal, T., Weston, J., e Scholkopf, B. (2004). Learning with local and global consistency. In Advances in Neural Information Processing Systems, páginas 321-328. MIT Press. Citado na página 34.

Zhu, X. (2005). Semi-supervised Learning with Graphs. Tese de Doutorado, Pittsburgh, PA, USA. Citado nas páginas 3, 32, e 33.

Zhu, X., Ghahramani, Z., e Lafferty, J. (2003). Semi-supervised learning using gaussian fields and harmonic functions. In International Conference on Machine Learning, páginas 912-919. Citado na página 34. 